UNIVERSIDADE DE SÃO PAULO

ESCOLA DE EDUCAÇÃO FÍSICA E ESPORTE

\title{
LIBERDADE NA ESCOLHA DA RESPOSTA \\ E MOMENTO DA ESTABILIZAÇÃO \\ EM APRENDIZAGEM MOTORA
}

Ulysses Okada de Araujo

SÃO PAULO

2009 
LIBERDADE NA ESCOLHA DA RESPOSTA

E MOMENTO DA ESTABILIZAÇÃO

EM APRENDIZAGEM MOTORA

ULYSSES OKADA DE ARAUJO

Dissertação apresentada à Escola de Educação Física e Esporte da Universidade de São Paulo, como requisito parcial para a obtenção do grau de Mestre em Educação Física. 


\section{AGRADECIMENTOS}

À orientadora, a Profa. Dra Andrea Michele Freudenheim, pela orientação e pela confiança depositada para a realização do presente trabalho, e pelo estímulo e atenção dedicados ao longo do processo.

Aos membros da banca, Prof. Dr. Umberto César Corrêa e Prof. Dr. Herbert Ugrinowitsch, pelas contribuições indispensáveis à elaboração do trabalho.

Ao Conselho Nacional de Desenvolvimento Científico e Tecnológico pelo apoio para a realização do curso de pós-graduação.

A Flavio Henrique Bastos e Cinthya Walter, pelas discussões e considerações no desenvolvimento do estudo, e pela amizade fomentada ao longo da convivência.

À Jane Aparecida de Oliveira Silva, pela colaboração na coleta de dados e pela hospitalidade na minha permanência em sua casa.

Aos amigos do LACOM, pelas contribuições e pela estima nas reuniões e nos momentos de confraternização.

À Karina Harume Okano, pela compreensão e pelo apoio em todas as horas.

Aos meus pais, pelo amor incondicional. 


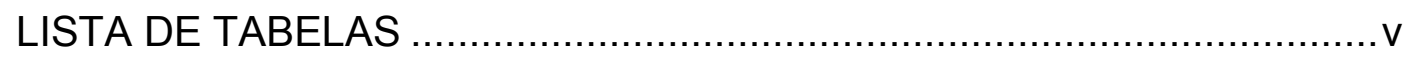

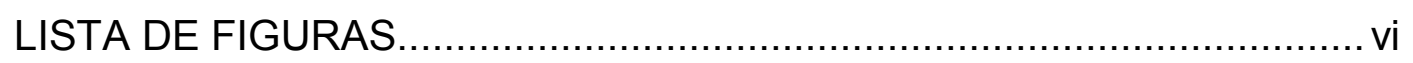

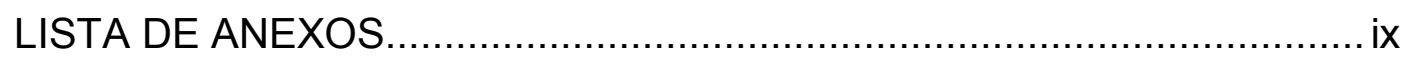

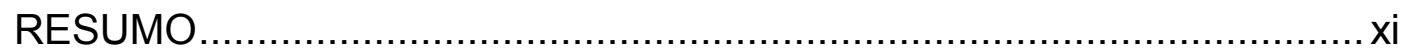

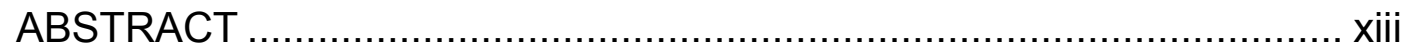

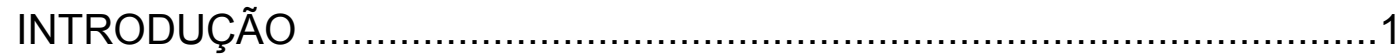

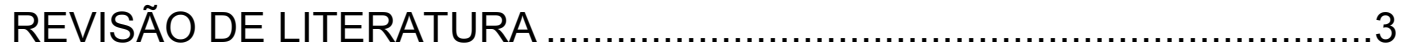

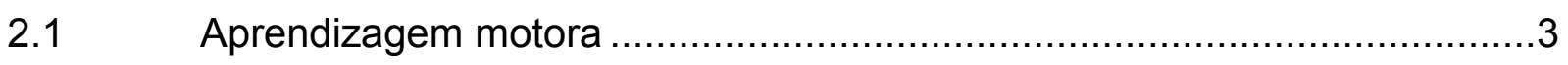

2.2 Processo adaptativo em aprendizagem motora .................................

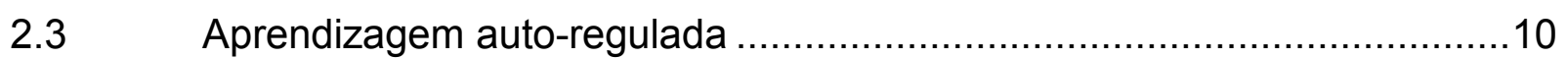

$2.4 \quad$ Auto-controle em aprendizagem motora ..........................................12

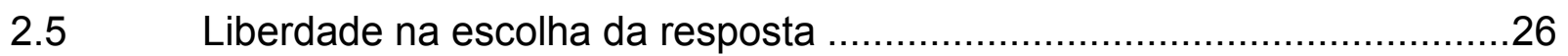

3 OBJETIVO

$4 \quad$ MÉTODO

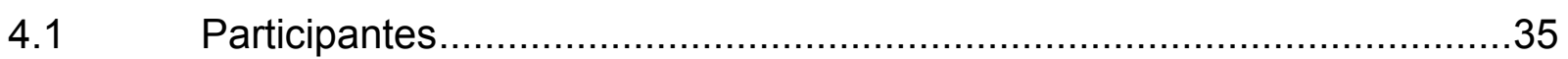

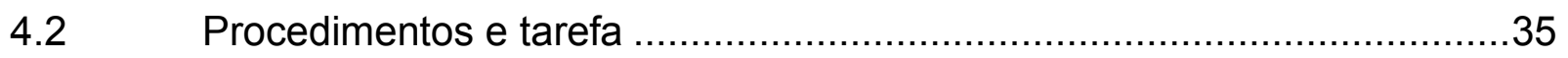

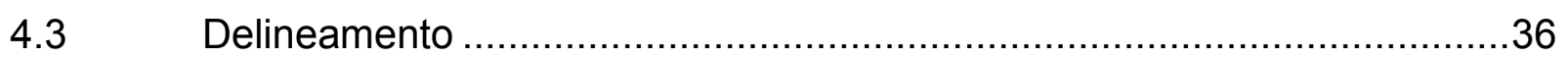

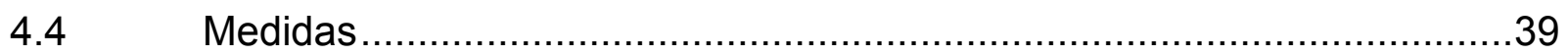

$4.5 \quad$ Análise

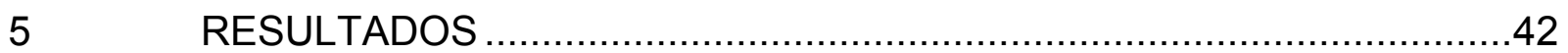

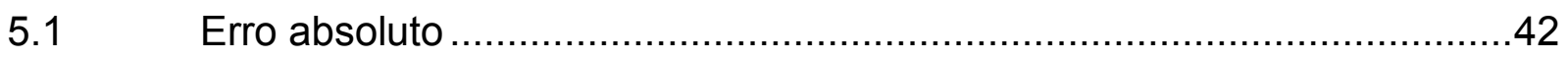

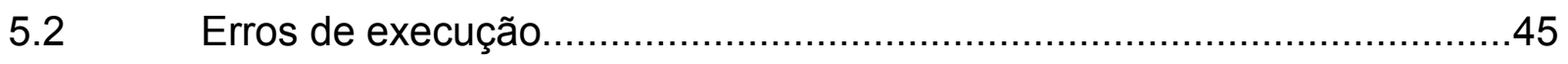

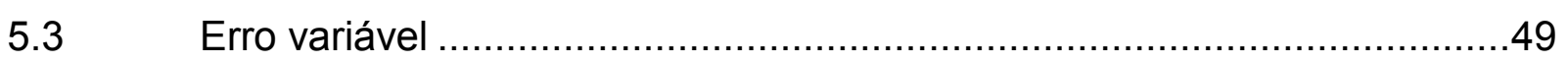

5.4 Número de tentativas até desempenho critério ....................................53 


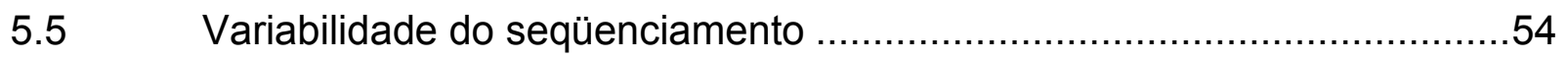

5.6 Variabilidade da macroestrutura................................................. 60

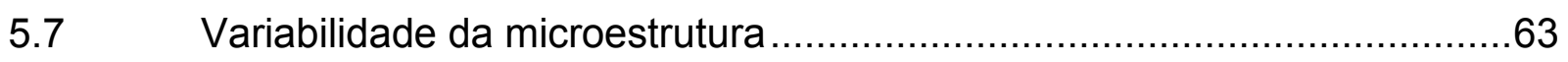

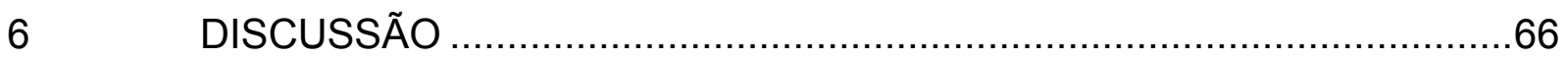

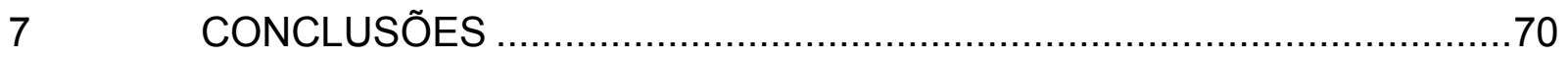

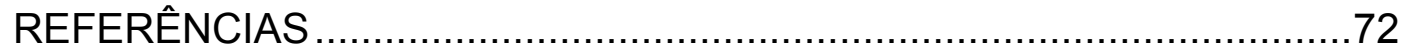




\section{LISTA DE TABELAS}

Página

TABELA 1 - Informação X entropia (adaptado de Miller, 1978)....................... 6

TABELA 2 - Análise conceitual das dimensões da auto-regulação acadêmica (adaptado de Zimmerman, 1989).

TABELA 3 - Síntese dos estudos sobre auto-controle em aprendizagem motora em uma perspectiva orientada ao equilíbrio.

TABELA 4 - Síntese dos estudos sobre liberdade na escolha da resposta no processo adaptativo em aprendizagem motora....................... 32

TABELA 5 - Delineamento e condições experimentais............................... 38

TABELA 6 - Resultados significativos do teste $U$ de Mann-Whitney para variações do seqüenciamento entre grupos no primeiro bloco da fase de estabilização.

TABELA 7 - Resultados significativos do teste $U$ de Mann-Whitney para variações do seqüenciamento entre grupos no segundo bloco da fase de estabilização.

TABELA 8 - Resultados significativos do teste $U$ de Mann-Whitney para variações do seqüenciamento entre grupos no terceiro bloco da fase de estabilização. 


\section{LISTA DE FIGURAS}

Página

FIGURA 1 - Representação esquemática das condições de realização da 37 tarefa (adaptado de Bastos, 2007).

FIGURA 2 - Média do erro absoluto dos grupos ALT-ALT, ALT-MED, ALTSEM, MED-ALT, MED-MED, MED-SEM, SEM-ALT, SEM-MED e SEM-SEM na fase de estabilização (E1, E2 e E3) e na fase de adaptação (A1, A2 e A3) por blocos de dez tentativas

FIGURA 3 - Média do erro absoluto na fase de adaptação (A1, A2 e A3) por condição do início da fase de estabilização (ALT, MED e SEM) por blocos de dez tentativas.

FIGURA 4 - Média do erro absoluto na fase de adaptação (A1, A2 e A3) por condição do final da fase de estabilização (ALT, MED e SEM) por blocos de dez tentativas

FIGURA 5 - Média dos erros de execução dos grupos ALT-ALT, ALT-MED, ALT-SEM, MED-ALT, MED-MED, MED-SEM, SEM-ALT, SEMMED e SEM-SEM na fase de estabilização (E1, E2 e E3) e na fase de adaptação (A1, A2 e A3) por blocos de dez tentativas....

FIGURA 6 - Média dos erros de execução na fase de adaptação (A1, A2 e A3) por condição do início da fase de estabilização (ALT, MED e SEM) por blocos de dez tentativas.

FIGURA 7 - Média dos erros de execução na fase de adaptação (A1, A2 e A3) por condição do final da fase de estabilização (ALT, MED e SEM) por blocos de dez tentativas. 
FIGURA 8 - Média do erro variável dos grupos ALT-ALT, ALT-MED, ALTSEM, MED-ALT, MED-MED, MED-SEM, SEM-ALT, SEM-MED e SEM-SEM na fase de estabilização (E1, E2 e E3) e na fase de adaptação (A1, A2 e A3) por blocos de dez tentativas.................

FIGURA 9 - Média do erro variável na fase de adaptação (A1, A2 e A3) por condição do início da fase de estabilização (ALT, MED e SEM) por blocos de dez tentativas

FIGURA 10 - Média do erro variável na fase de adaptação (A1, A2 e A3) por condição do final da fase de estabilização (ALT, MED e SEM) por blocos de dez tentativas

FIGURA 11 - Média e desvio-padrão do número de tentativas necessário ao alcance do critério de desempenho nos grupos ALT-ALT, ALTMED, ALT-SEM, MED-ALT, MED-MED, MED-SEM, SEM-ALT, SEM-MED e SEM-SEM.

FIGURA 12 - Boxplot (mediana, percentis 25 e 75 e valores máximos e mínimos) da proporção de variações de seqüenciamento realizadas pelos grupos ALT-ALT, ALT-MED, ALT-SEM, MEDALT, MED-MED, MED-SEM, SEM-ALT, SEM-MED e SEM-SEM no primeiro bloco da fase de estabilização.

FIGURA 13 - Boxplot (mediana, percentis 25 e 75 e valores máximos e mínimos) da proporção de variações de seqüenciamento realizadas pelos grupos ALT-ALT, ALT-MED, ALT-SEM, MEDALT, MED-MED, MED-SEM, SEM-ALT, SEM-MED e SEM-SEM no segundo bloco da fase de estabilização.

FIGURA 14 - Boxplot (mediana, percentis 25 e 75 e valores máximos e mínimos) da proporção de variações de seqüenciamento realizadas pelos grupos ALT-ALT, ALT-MED, ALT-SEM, MEDALT, MED-MED, MED-SEM, SEM-ALT, SEM-MED e SEM-SEM no terceiro bloco da fase de estabilização. 
FIGURA 15 - Média da média do desvio padrão dos tempos de toques relativos dos grupos ALT-ALT, ALT-MED, ALT-SEM, MED-ALT, MED-MED, MED-SEM, SEM-ALT, SEM-MED e SEM-SEM na fase de estabilização (E1, E2 e E3) e na fase de adaptação (A1, A2 e A3) por blocos de dez tentativas.

FIGURA 16 - Média da média do desvio padrão dos tempos de toques relativos na fase de adaptação (A1, A2 e A3) por condição do início da fase de estabilização (ALT, MED e SEM) por blocos de dez tentativas.

FIGURA 17 - Média da média do desvio padrão dos tempos de toques relativos na fase de adaptação (A1, A2 e A3) por condição do final da fase de estabilização (ALT, MED e SEM) por blocos de dez tentativas.

FIGURA 18 - Média da média do desvio padrão dos tempos de toques absolutos dos grupos ALT-ALT, ALT-MED, ALT-SEM, MED-ALT, MED-MED, MED-SEM, SEM-ALT, SEM-MED e SEM-SEM na fase de estabilização (E1, E2 e E3) e na fase de adaptação (A1, A2 e A3) por blocos de dez tentativas.

FIGURA 19 - Média da média do desvio padrão dos tempos de toques absolutos na fase de adaptação (A1, A2 e A3) por condição do início da fase de estabilização (ALT, MED e SEM) por blocos de dez tentativas.

FIGURA 20 - Média da média do desvio padrão dos tempos de toques absolutos na fase de adaptação (A1, A2 e A3) por condição do final da fase de estabilização (ALT, MED e SEM) por blocos de dez tentativas. 
LISTA DE ANEXOS

Página

ANEXO I - Termo de consentimento livre e esclarecido

ANEXO II - Dados individuais médios do erro absoluto nos grupos ALT-ALT, ALT-MED, ALT-SEM, MED-ALT, MED-MED, MED-SEM, SEMALT, SEM-MED e SEM-SEM na fase de estabilização (E1, E2 e E3) e na fase de adaptação (A1, A2 e A3).

ANEXO III - Dados individuais do erro de execução nos grupos ALT-ALT, ALT-MED, ALT-SEM, MED-ALT, MED-MED, MED-SEM, SEMALT, SEM-MED e SEM-SEM na fase de estabilização (E1, E2 e E3) e na fase de adaptação (A1, A2 e A3).

ANEXO IV - Dados individuais médios do erro variável nos grupos ALT-ALT, ALT-MED, ALT-SEM, MED-ALT, MED-MED, MED-SEM, SEMALT, SEM-MED e SEM-SEM na fase de estabilização (E1, E2 e E3) e na fase de adaptação (A1, A2 e A3).

ANEXO V - Número de tentativas utilizadas pelos participantes nos grupos ALT-ALT, ALT-MED, ALT-SEM, MED-ALT, MED-MED, MEDSEM, SEM-ALT, SEM-MED e SEM-SEM para alcançar o critério de desempenho.

ANEXO VI - Dados individuais da proporção de variações do seqüenciamento nos grupos ALT-ALT, ALT-MED, ALT-SEM, MED-ALT, MED-MED, MED-SEM, SEM-ALT, SEM-MED e SEMSEM na fase de estabilização (E1, E2 e E3). 
ANEXO VII - Dados individuais médios do desvio padrão dos tempos de movimento relativos nos grupos ALT-ALT, ALT-MED, ALT-SEM, MED-ALT, MED-MED, MED-SEM, SEM-ALT, SEM-MED e SEMSEM nas fases de estabilização (E1, E2 e E3) e adaptação (A1, A2 e A3)

ANEXO VIII - Dados individuais médios do desvio padrão dos tempos de movimento absolutos nos grupos ALT-ALT, ALT-MED, ALTSEM, MED-ALT, MED-MED, MED-SEM, SEM-ALT, SEM-MED e SEM-SEM nas fases de estabilização (E1, E2 e E3) e adaptação (A1, A2 e A3).

ANEXO IX - Dados ausentes (missing values) substituídos pela média dos participantes nas variáveis erro absoluto (EA), erro variável (EV), erros de execução (EE), variabilidade do seqüenciamento (SEQ), variabilidade do tempo relativo (VTR) e variabilidade do tempo absoluto (VTA) por bloco das fases de estabilização (E1, E2 e E3) e adaptação (A1, A2 e A3).

ANEXO X - Outliers extremos substituídos pela média dos participantes nas variáveis erro absoluto (EA), erro variável (EV), erros de execução (EE), variabilidade do seqüenciamento (SEQ), variabilidade do tempo relativo (VTR) e variabilidade do tempo absoluto (VTA) por bloco das fases de estabilização (E1, E2 e E3) e adaptação (A1, A2 e A3). 


\title{
RESUMO
}

\section{LIBERDADE NA ESCOLHA DA RESPOSTA \\ E MOMENTO DA ESTABILIZAÇÃO \\ EM APRENDIZAGEM MOTORA}

\author{
Autor: ULYSSES OKADA DE ARAUJO \\ Orientadora: PROFA. DRA. ANDREA MICHELE FREUDENHEIM
}

O estudo teve como objetivo investigar, a partir de uma perspectiva de processo adaptativo em aprendizagem motora, o efeito da liberdade na escolha da resposta em diferentes momentos do processo de estabilização. A possibilidade de escolher a ordem dos componentes que compõem uma seqüência de movimentos (liberdade na escolha da resposta) tem se mostrado benéfica à aquisição de habilidades motoras. Contudo, o efeito da liberdade na escolha da resposta pode ser mediado pelo processo de estabilização funcional. Para investigar esta hipótese, 135 voluntários com média de idade de $22( \pm 4,1)$ anos, de ambos os sexos, foram alocados a nove grupos experimentais, derivados da combinação de três condições experimentais (SEM, MED e ALT) e dois momentos da estabilização (antes e após a estabilização inicial do desempenho). A liberdade na escolha da resposta foi operacionalizada neste estudo como a possibilidade de escolher a ordem de uma seqüência de toques em sensores, em uma tarefa complexa de timing coincidente. Os resultados mostraram que não houve efeito da condição experimental do início da prática no desempenho na fase de adaptação, porém condições intermediárias de liberdade de escolha no final da prática não apresentaram queda na consistência 
frente à modificação da tarefa. Nesse sentido, a liberdade na escolha da resposta não trouxe prejuízos à adaptação.

Palavras-chave: liberdade na escolha da resposta; aprendizagem auto-regulada; aprendizagem motora; processo adaptativo. 


\title{
ABSTRACT
}

\section{FREEDOM IN RESPONSE CHOICE AND MOMENT OF STABILIZATION \\ IN MOTOR LEARNING}

\author{
Author: ULYSSES OKADA DE ARAUJO \\ Adviser: PROF. DR. ANDREA MICHELE FREUDENHEIM
}

The objective of the study was to investigate, from an adaptive process perspective on motor learning, the effect of freedom in response choice in different moments of the stabilization process. The possibility of choosing the order of the components which generate a movement sequence (freedom in response choice) has been shown as beneficial to motor skills' acquisition. However, the effect of freedom in response choice could be mediated by the process of functional stabilization. To investigate the hypothesis, a hundred thirty-five volunteers with mean age of 22 ( \pm 4,1 ) years were assigned to nine experimental groups, derived from the combination of three experimental conditions (SEM, MED and ALT) and two moments of stabilization (before and after initial performance stabilization). Freedom in response choice was manipulated in this study as the possibility of choosing the order of tapping a sequence of sensors, in a complex anticipation timing task. Results showed there was no effect of experimental condition in the beginning of practice in performance in adaptation phase, although intermediate conditions of freddom of choice didn't show decrease in consistency following task modification. In this sense, freedom in response choice wasn't detrimental to adaptation. 
Keywords: freedom in response choice; self-regulated learning; motor learning; adaptive process. 
O movimento é o meio pelo qual nós, seres humanos, interagimos com o ambiente. Nossa alimentação, comunicação e deslocamento, por exemplo, dependem em grande parte da nossa capacidade de realizar movimentos. Conseqüentemente, modificações na forma como os movimentos são realizados podem comprometer a interação com o meio, ou, por outro lado, possibilitar a melhora nessa interação. $O$ foco do presente trabalho são as modificações no movimento dos indivíduos num período relativamente breve: o fenômeno definido como aprendizagem motora.

A aprendizagem motora pode ser definida como um conjunto de processos associados à prática ou experiência que levam a mudanças relativamente permanentes na capacidade de executar um movimento (SCHMIDT; LEE, 1999). A partir da definição percebe-se que a prática é um aspecto que pode influenciar a aquisição de habilidades motoras. Os estudos realizados na área evidenciam outros fatores que também podem influenciar a aprendizagem motora, como os associados à instrução e ao feedback (informação sobre o movimento em andamento ou já realizado). Um dos fatores que parece favorecer a aquisição de habilidades motoras é deixar parte das decisões relacionadas a fatores que afetam a aprendizagem, por exemplo, relativas à prática, conhecimento de resultados ou resposta motora, sob responsabilidade do aprendiz (WULF, 2007).

Todavia, embora a aprendizagem, como fenômeno, possa ser circunscrita a períodos breves, não necessariamente finda em determinado momento. Um indivíduo que pratica uma habilidade motora específica, além da capacidade relativamente estável de desempenhar a habilidade, pode apresentar outra característica. Seu desempenho pode modificar-se com a experiência, assim como suas metas ao realizar a tarefa. Por exemplo, um aprendiz que realizava malabarismos mantendo, com dificuldade, três bolas de tênis no ar simultaneamente, pode passar a realizar os mesmos movimentos com mais bolas ao mesmo tempo, com diferentes objetos ou realizar ações diferentes com os mesmos. As características do desempenho da habilidade podem modificar-se sucessivamente ao longo do processo, sendo possível identificar algumas destas mudanças, como 
diferentes níveis de desempenho ao longo da prática em determinadas habilidades (FREUDENHEIM; MANOEL, 1999). A reorganização de habilidades já adquiridas em habilidades crescentemente complexas (adaptação) é, portanto, um aspecto fundamental da aprendizagem motora (TANI, 1982, 1995). A partir da consideração da natureza contínua do processo de aquisição de habilidades motoras, surgem questões relacionadas às condições de aprendizagem que promovem uma melhor adaptação da habilidade adquirida. Nesse sentido têm sido desenvolvidos estudos investigando diversos fatores que afetam a aquisição de habilidades motoras como a estrutura de prática (p.ex. CORRÊA, 2001) e o conhecimento de resultados (p. ex. MEIRA JR, 2005).

Nesta perspectiva de processo adaptativo em aprendizagem motora a preocupação com condições em que o aprendiz pode tomar parte das decisões relacionadas à prática também se faz presente. Os resultados, semelhantes aos obtidos nos estudos realizados em uma perspectiva clássica de aprendizagem motora (WULF, 2007), também apontam para vantagens da possibilidade de escolher em relação a condições em que o aprendiz não pode realizar as escolhas. Em especial, a possibilidade de escolher entre elementos de uma seqüência é uma variável investigada por diversos estudos anteriores (TANI, 1982; BASTOS, 2007; WALTER, 2007; BASTOS; ARAUJO; WALTER; FREUDENHEIM, 2008; WALTER; BASTOS; ARAUJO; SILVA; CORREAA, 2008) tendo sido denominada liberdade na escolha da resposta. Os resultados apontam benefícios, mas também limitações da introdução da liberdade na escolha da resposta: há evidências que graus excessivos desta variável podem dificultar a estabilização funcional. Entretanto, uma característica importante da prática não foi anteriormente abordada nas investigações sobre liberdade na escolha da resposta: sua interação com a estabilização do desempenho.

Como mencionado, em virtude do processo de estabilização são observáveis alterações nas características do desempenho, como diferentes níveis de erro na fase de estabilização, e diferenças com relação à manutenção do desempenho frente a modificações da tarefa (FREUDENHEIM; MANOEL, 1999; UGRINOWITSCH, 2003). Nesse sentido, no presente estudo investigou-se o efeito 
da liberdade na escolha da resposta em diferentes momentos do processo de estabilização.

Os seres vivos são capazes, ao longo do tempo, de modificar as ações que utilizam ao interagir com o ambiente. A aprendizagem de novas habilidades e a modificação das já adquiridas são aspectos essenciais na interação dos organismos vivos com o meio. A capacidade de aprender do ser humano é, inclusive, reconhecida como uma das responsáveis pelo seu sucesso em termos evolutivos (PINKER, 1998). A aprendizagem motora, definida como um conjunto de processos associados à prática ou experiência que levam a mudanças relativamente permanentes na capacidade de executar um movimento (SCHMIDT; LEE, 1999) não é observável diretamente, mas é possível discernir claramente mudanças na interação com objetos ou com outros seres vivos.

$\mathrm{Na}$ investigação sobre a aprendizagem motora, os anos 60 e 70 do século XX podem ser considerados um período de transição na investigação sobre a aquisição de habilidades motoras (TANI; FREUDENHEIM; MEIRA JR.; CORRÊA, 2004). Até então, se focava prioritariamente o efeito de variáveis na aprendizagem de tarefas específicas. A partir da adoção de um paradigma de processamento de informações (MARTENIUK, 1976), o campo de comportamento motor transitou de uma orientação à tarefa (AOT) para uma abordagem orientada ao processo (AOP) (PEW, 1974; SCHMIDT, 1975). Passou-se a considerar que o ser humano codifica, representa e armazena informação relacionada ao movimento, e que esses eventos mentais ou neurais, assim como os processos de seleção de resposta e programação motora, podem ser inferidos a partir do comportamento do indivíduo.

Dois trabalhos tiveram influência importante, de acordo com Schmidt e Lee (1999), no estabelecimento de bases para o estudo do comportamento humano a partir de suas capacidades de processamento de informação: a Cibernética 
(WIENER, $1948^{1}$ ) e a Teoria matemática da comunicação (SHANNON; WEAVER, $1949^{2}$, citado por SCHMIDT; LEE, 1999). O trabalho de Claude Shannon e Warren Weaver estabeleceu importantes princípios para o estudo do sistema motor em termos de suas capacidades e limitações no processamento de informações. Por sua vez, Norbert Wiener é responsável por delinear as bases do estudo do processamento de informação no comportamento humano.

Wiener $\left(1954^{3}\right)$ lida, por exemplo, com o conceito de feedback e sua relevância no comportamento motor humano. O autor sugere que o feedback, definido como a reintrodução no sistema dos resultados do desempenho anterior, poderia ser utilizado tanto para a regulação do desempenho de um sistema quanto para a modificação do padrão ou método a partir da qual o desempenho foi alcançado. Outro conceito abordado por Wiener (1954) é o de informação. De acordo com o autor, informação pode ser considerada o negativo de sua entropia. Entropia, em termodinâmica, é a medida de desorganização de um sistema. Desse modo, para Wiener (1954), da mesma forma que a entropia é uma medida de desorganização, a informação transmitida pode ser considerada uma medida de organização. A informação, portanto, pode ser utilizada em sistemas abertos (que realizam trocas com o meio) para a modificação de seus estados de organização.

A influência dos conceitos da cibernética e da teoria da comunicação no estudo do comportamento motor é observável, por exemplo, nos mecanismos propostos pelas teorias e descrições correntes do processo de aquisição de habilidades motoras (ADAMS, 1971; FITTS; POSNER, 1967; SCHMIDT, 1975). Os modelos clássicos descrevem o processo de aquisição de habilidades motoras como compreendendo duas (ADAMS, 1971) ou três fases (FITTS; POSNER, 1967). Apesar da divergência quanto ao número de fases e suas denominações, há consenso desses modelos em relação a suas características. Neles a progressão é vista como finita: o início corresponde a um comportamento com forte componente cognitivo, com inconsistência nos movimentos e pequena capacidade de detecção e correção

\footnotetext{
${ }^{1}$ WIENER, N. (1948). Cibernética. São Paulo: Pioneira, 1970.

2 SHANNON, C.; WEAVER, W. The mathematical theory of communication. Urbana: University of Illinois, 1949. (1954). Cibernética e sociedade: o uso humano de seres humanos. São Paulo: Cultrix, 1984.
} 
de erros. O término do processo tem como características consistência e precisão na execução do movimento, capacidade de detecção e correção dos erros, relativa independência em relação às demandas de atenção e do conhecimento de resultados. Neles a estabilização funcional, ou seja, a execução de movimentos precisos e padronizados em virtude da formação de uma estrutura, associada em alguns modelos à automatização, representa o fim do processo de aquisição.

Entretanto, a evolução da pesquisa nos campos da cibernética e da teoria da informação continuou a influenciar o estudo do comportamento motor. Heylighen e Joslyn (2001) descrevem a colaboração de pesquisadores da cibernética com o campo da Teoria Geral dos Sistemas, fundado nos anos 1950 por Ludwig von Bertalanffy (BERTALANFFY, 1968) na tentativa de descobrir princípios comuns que governam sistemas abertos e em evolução. Para os autores, apesar da existência de distinções entre a cibernética (que foca sistemas funcionais direcionados a uma meta e que envolvem relações de controle) e a teoria geral de sistemas (que abarca sistemas de todos os níveis de generalidade), ambos podem ser vistos como a tentativa de revelar princípios de organização de sistemas válidos em diversos campos.

Os avanços nos campos acima relacionados trouxeram como conseqüência mudanças na forma de encarar fenômenos em diversas áreas da ciência. As proposições mais recentes de meta-teorias da ciência levam à reconsideração de fatores como a informação e o feedback em sistemas abertos. Frentes de pesquisa como a organização hierárquica em sistemas abertos (e.g. KOESTLER, 1969), a complexidade (PRIGOGINE, 1996) e a transição de fase e auto-organização (HAKEN, 1977) trouxeram conhecimentos e questões pertinentes para o estudo de sistemas em diferentes níveis de análise. Para Prigogine (1996), enquanto a ciência clássica privilegiava a ordem e a estabilidade, se reconhece agora o papel fundamental das flutuações e da instabilidade.

Seja uma ferramenta metodológica para compreender sistemas abertos ou mesmo um novo paradigma científico (VASCONCELOS, 2002) de acordo com a concepção de Kuhn (1970), é certo que tais avanços repercutiram na investigação em comportamento motor (TANI; CORRÊA; BENDA; MANOEL, 2005). Tani (1999) ressalta a influência destas teorias para o entendimento dos processos de mudança 
em direção a estágios mais complexos de organização, como a evolução, a aprendizagem e o desenvolvimento. Segundo Tani (1999), nestes processos a incerteza é transformada em informação, a entropia em entropia negativa, a desordem em ordem. O quadro proposto por Miller (1978) apresenta a relação entre os fatores atribuídos à relação entre informação e entropia (TABELA 1).

TABELA 1 - Informação versus entropia (adaptado de Miller, 1978)

\begin{tabular}{r|r|l}
\hline $\mathrm{H}$ & $=$ & $-\mathrm{S}$ \\
\hline $\begin{array}{r}\text { informação } \\
\text { entropia negativa } \\
\text { sinal } \\
\text { precisão } \\
\text { forma }\end{array}$ & $\begin{array}{l}\text { incerteza } \\
\text { entropia } \\
\text { ruído } \\
\text { erro } \\
\text { regularidade } \\
\text { caos } \\
\text { aleatoriedade } \\
\text { falta de padrão ou forma forma } \\
\text { ordem } \\
\text { organização } \\
\text { desordem } \\
\text { desorganização } \\
\text { simplicidade irregular } \\
\text { homogeneidade } \\
\text { probabilidade } \\
\text { imprevisibilidade } \\
\text { heterogeneidade } \\
\text { improbabilidade } \\
\text { previsibilidade }\end{array}$ \\
\hline $\mathrm{H}=$ informação & & S = entropia \\
\hline
\end{tabular}

No estudo do comportamento motor os elementos relacionados à entropia, como a incerteza e a desordem, eram, de forma similar, vistos como elementos negativos cuja eliminação era necessária para que a ordem prevalecesse (NEWELL; CORCOS, 1993). Contudo, em virtude dos avanços nas meta-teorias da ciência acima descritos, Tani (1999) sugere que uma reconsideração dos fatores relacionados à desordem está em andamento. As incertezas que desafiam o sistema não são apenas elementos que devem ser eliminados para a manutenção da estabilidade, mas podem representar fontes de ordem (YATES, 1987). Tani (1995, 2005) argumenta que os organismos, na busca por estados mais complexos de organização, são capazes de atingir ou manter determinados estados de organização via mecanismos auto-regulatórios, baseados em feedback negativo. Contudo, aponta que a quebra da estabilidade é necessária para a formação de estruturas mais 
complexas a partir das estruturas já existentes. Em conseqüência, a capacidade de responder às mudanças do ambiente se dá, basicamente, por dois tipos de resposta: a) tentar manter a estabilidade neutralizando a perturbação; ou b) utilizar a perturbação como fonte de ordem na elevação a níveis superiores de complexidade. A desestabilização e a estabilização subseqüente num nível superior de complexidade, ou seja, a adaptação, é um passo essencial na busca de estados mais complexos de organização.

Embora possa ser observada em períodos breves, a aprendizagem motora não é um processo finito. Observando indivíduos altamente habilidosos, como atletas de alto nível, músicos profissionais ou grandes dançarinos, e comparando seu desempenho com pessoas que não apresentam o mesmo nível de habilidade, é fácil perceber as diferenças em termos de metas e desempenho ainda que ambos executem as mesmas habilidades. Acompanhando a aprendizagem de uma habilidade, como andar de patins ou de bicicleta, percebemos a melhora no desempenho na mesma habilidade ao longo do tempo. Se inicialmente o aprendiz apresenta dificuldade em equilibrar-se e pouco se desloca, em pouco tempo pode ser capaz de deslocar-se mantendo o equilíbrio ao enfrentar obstáculos intencionalmente. Podemos indagar que mudanças ocorrem na estrutura adquirida frente às demandas crescentemente complexas.

A formação de uma estrutura e a conseqüente padronização do comportamento a partir das experiências passadas permite a manutenção do desempenho eliminando as discrepâncias entre o desempenho obtido e o desempenho desejado, através da utilização de mecanismos de feedback negativo. Nas teorias clássicas de aprendizagem motora (ADAMS, 1971; SCHMIDT, 1975) uma vez atingido o estado desejado, a busca é a manutenção do mesmo pelo mecanismo descrito acima, não sendo concebida a necessidade de modificações na estrutura adquirida, onde o quadro de referência entre o desempenho obtido e o desejado deve ser alterado (FREUDENHEIM, 1994, 2005) nem tampouco uma preocupação, nestas teorias, em entender como se dá a reorganização dessa estrutura (SCHMIDT, 2003). Fica clara, a partir dessa fundamentação teórica, a ênfase dada à formação e manutenção de uma estrutura nas descrições correntes do processo de aquisição de ações habilidosas (ADAMS, 1971; FITTS; POSNER, 1967; 
SCHMIDT, 1975). Em razão do caráter voltado à manutenção da estabilidade destas proposições, tais modelos de aprendizagem motora foram denominados modelos de equilíbrio (TANI, 2005; FREUDENHEIM, 2005). Estes modelos são capazes de explicar a aprendizagem até a formação de uma estrutura, mas não a formação de estruturas mais complexas mediante a reorganização das já existentes. A ênfase em processos baseados em feedback negativo deixa de contemplar a quebra da estabilidade necessária à modificação da estrutura adquirida (FREUDENHEIM, 2005; TANI, 2005). Ao considerar a natureza contínua do processo de aquisição de habilidades motoras, é necessária a utilização de um modelo que contemple a possibilidade de aumento de complexidade.

\subsection{Processo adaptativo em aprendizagem motora}

Choshi e Tani (1983) ${ }^{4}$ citados por Tani (1995), Manoel (1989) e Tani (1982, 1989) têm proposto um modelo de não-equilíbrio em aprendizagem motora que compreende duas fases: estabilização e adaptação. A estabilização representa o aumento da consistência e a busca por estabilidade funcional, que tem como resultado a padronização espacial e temporal do movimento e a estabilização do desempenho com sucesso no alcance da meta. A partir da estabilização funcional, caracterizada acima, infere-se a formação de uma estrutura. O mecanismo fundamental, nesse momento, é o feedback negativo.

A fase de adaptação refere-se a um ajuste ou reorganização dessa estrutura em função de um novo objetivo. A formação de estruturas mais complexas a partir das já existentes pressupõe a quebra da estabilidade seguida de sua recuperação, que ocorre, entretanto, em um nível superior de complexidade. Ao reconhecer a capacidade de desestabilizar a estrutura anteriormente adquirida como meio de alcançar um nível mais alto de organização, a estabilização é vista como um passo fundamental, porém não terminal, em direção ao aumento da complexidade do comportamento motor.

4 CHOSHI, K.; TANI, G. Stable system and adaptive system in motor learning. In: JAPANESE ASSOCIATION OF BIOMECHANICS (Ed.) The science of movement V. Tokyo: Kyorin, 1983. (em japonês) 
A adaptação da estrutura adquirida pode ser realizada a partir de sua flexibilidade, modificando-se apenas os parâmetros do movimento. Nesse caso, ela é denominada adaptação paramétrica. Por outro lado, quando a instabilidade é superior à disponibilidade da estrutura adquirida, pode ocorrer a reorganização da estrutura, que resulta numa mudança qualitativa no sistema. Nessas circunstâncias, ela é denominada adaptação estrutural (TANI, 1982).

Nessa perspectiva, foram realizados estudos investigando tanto mecanismos e processos subjacentes à aquisição de habilidades motoras quanto fatores que influenciam a adaptação. Em relação à estabilização de habilidades motoras, foram apontadas evidências de tal processo leva a alterações significativas na estrutura da habilidade (TANI, 1995; FREUDENHEIM, 1999), e que a estabilização é um pré-requisito para a adaptação bem sucedida (TANI, 1995; UGRINOWITSCH, 2003). Todavia, segundo Freudenheim e Manoel (1999), parecem haver diferentes níveis de estabilização. Quando os participantes foram submetidos à prática extensiva em uma tarefa de reprodução de padrões gráficos os autores identificam diferentes níveis (patamares) de desempenho ao longo da prática. Ainda, Ugrinowitsch (2003) referiu-se a diferentes níveis de estabilização em seu delineamento utilizando grupos com prática até a estabilização inicial e após a mesma (super-estabilização) com base no alcance de diferentes critérios de desempenho, respectivamente três tentativas consecutivas na faixa de erro de $30 \mathrm{~ms}$ e seis blocos de três tentativas consecutivas com erro na faixa de $30 \mathrm{~ms}$. Os resultados mostram a diferença entre os diferentes níveis de estabilização do desempenho: enquanto nos grupos que praticaram a tarefa até a estabilização inicial há dificuldades na adaptação a determinados tipos de modificação (motora e perceptivo-motora), nos grupos que praticaram após a estabilização inicial (superestabilização) não houve diferença no desempenho dos grupos na fase de adaptação independente do tipo de perturbação.

Como resultado do processo de estabilização, é esperada uma diminuição na variabilidade do comportamento. Entretanto, a redução excessiva na variabilidade pode resultar em uma rigidez que torna o sistema incapaz de adaptar-se em direção a níveis superiores de complexidade. Consistência e variabilidade têm sido apontadas como características das ações habilidosas (CONNOLLY, 1977; 
GLENCROSS, 1980; TURVEY, 1977). O aumento da consistência na padronização espaço-temporal do movimento é essencial para a consistência no alcance de resultados no ambiente. Por sua vez, a variabilidade é essencial para fazer frente às demandas ambientais em constante mudança e possibilita aumento de complexidade. Contudo, a variabilidade no alcance da meta é negativa para a obtenção do desempenho desejado. Nesse sentido, é necessário distinguir o significado de ao menos três tipos de variabilidade: a variabilidade do desempenho, observada anteriormente à estabilização do desempenho e à formação de uma estrutura, a variabilidade funcional, que permanece após a estabilização e permite a produção de movimentos flexíveis e a formação de estruturas mais complexas (MANOEL; CONNOLY, 1995) e a variabilidade de erro, que é inerente ao sistema (ruído) e não pode ser controlada (TANI, 1995, 2005).

Uma questão fundamental, nesse sentido, é como promover a aquisição de habilidades motoras de forma a favorecer a variabilidade funcional do comportamento. Que condições de prática podem promover a formação de estruturas que permitam conciliar consistência e flexibilidade? Estudos apontam que a resposta pode estar na consideração de condições de prática que incluam certa possibilidade de realizar escolhas por parte do aprendiz.

\subsection{Aprendizagem auto-regulada}

$O$ conceito de aprendizagem auto-regulada tem emergido como um importante construto na pesquisa psicológica, educacional e sociológica. A capacidade de regular o próprio aprendizado tem sido considerada a chave para o aprendizado bem-sucedido em um ambiente escolar, e em relação à aprendizagem verbal ou cognitiva, o consenso parece ser de que a aprendizagem auto-regulada tem efeitos positivos em diferentes aspectos do processo de aprendizagem (BOEKAERTS, 1999). Aprendizes que auto-regulam a aprendizagem seriam capazes de monitorar e avaliar sua aprendizagem (processos metacognitivos), seriam mais intrinsecamente motivados e possuiriam maior auto-eficácia (processos motivacionais) e buscariam ambientes que pudessem favorecer a aprendizagem (processos comportamentais) (ZIMMERMAN, 1989, 1994). Nesse sentido, a 
aprendizagem auto-regulada tem sido definida como a capacidade dos aprendizes de serem participantes metacognitivamente, motivacionalmente e comportamentalmente ativos do próprio processo de aprendizagem (ZIMMERMAN, 1989).

Mas, a despeito das vantagens obtidas por aprendizes ao regular as diferentes dimensões relacionadas ao processo de aprendizagem, o conceito de aprendizagem auto-regulada possui algumas inconsistências. Apesar do consenso em relação à natureza inerentemente construtiva e autodirigida da aprendizagem auto-regulada, se reconhece que ainda há muito a fazer na descrição e explanação dos processos-chave do conceito (BOEKAERTS, 1999). Tal problema seria derivado de sua investigação por diferentes campos de pesquisa, cada qual com sua história. Isto implica que pesquisadores de tradições de pesquisa amplamente diferentes conceituam a aprendizagem auto-regulada de suas próprias maneiras, utilizando diferentes terminologias para facetas similares do conceito.

Numa tentativa de integrar os connhecimentos produzidos sobre a aprendizagem auto-regulada, Zimmerman (1989) sugere uma definição de dimensões psicológicas da aprendizagem auto-regulada como forma de analisar a pesquisa de aprendizagem auto-regulada e delinear as condições necessárias para a auto-regulação de cada componente (TABELA 2)

TABELA 2 - Análise conceitual das dimensões da auto-regulação acadêmica (adaptado de Zimmerman, 1989)

\begin{tabular}{l|l|l}
\hline Questões científicas & Dimensões psicológicas & Condições da tarefa \\
\hline Por quê? & Motivo & Escolher participar \\
\hline Como? & Método & Escolher método \\
\hline O quê? & Resultados [outcomes] do & $\begin{array}{l}\text { Escolher resultados do } \\
\text { desempenho }\end{array}$ \\
\hline Onde? & Ambiental (social) & $\begin{array}{l}\text { Controlar ambiente físico e } \\
\text { social }\end{array}$ \\
\hline
\end{tabular}

Para o autor, a partir desta análise dimensional é possível questionar aspectos específicos e observar dimensões específicas da aprendizagem autoregulada, desde que a tarefa também possua condições para a regulação da dimensão investigada. 
Contudo, as limitações metodológicas e teóricas para análise simultânea de diversas dimensões da aprendizagem auto-regulada têm levado a pesquisas realizadas em dimensões específicas do fenômeno. Embora o conceito de aprendizagem auto-regulada apresentado por Zimmerman (1989) seja independente de concepções teóricas, ele não soluciona o problema, pois concepções teóricas distintas do processo de aprendizagem especificam diferentes processos, estratégias ou respostas como base para o processo de auto-regulação. Embora esta tentativa de aumentar o controle experimental possa dificultar a apreensão da dinâmica da aprendizagem auto-regulada e da interação entre seus processos (SCHUNK; ZIMMERMAN, 1994) os autores sugerem que a adoção de procedimentos metodológicos simples (como questionários) permitiriam a observação de processos em dimensões diferentes do foco principal do estudo.

Estudos investigando dimensões específicas da aprendizagem autoregulada têm sido desenvolvidos no âmbito da aprendizagem motora. Os estudos realizados a partir de uma perspectiva de equilíbrio, investigando a auto-regulação em diversas variáveis de prática, instrução e feedback têm adotado a denominação auto-controle para as condições experimentais onde há possibilidade de autoregulação. Os realizados na perspectiva de processo adaptativo em aprendizagem motora investigam especificamente a possibilidade de escolher entre elementos de uma seqüência. A variável experimental em que há possibilidade de auto-regulação tem sido denominada de liberdade na escolha da resposta. Estudos realizados em ambas as perspectivas serão apresentados nos capítulos seguintes.

\section{$2.4 \quad$ Auto-controle em aprendizagem motora}

Diversos estudos têm sido realizados em aprendizagem motora de forma a dar ao aprendiz algum controle sobre a variável investigada. Entre outros, por exemplo, vêm sendo investigadas condições relacionadas à instrução (e.g. BOYCE, 1992), à prática (e.g. TITZER; SHEA; ROMACK, 1993) e ao feedback (e.g. CHIVIACOWSKY; WULF, 2002). Mas, nos estudos de aprendizagem motora o problema apontado por Boekaerts (1999) relacionado à existência de diferentes terminologias e concepções de aprendizagem (por vezes implícitas) está presente; 
mesmo a denominação da classe de estudos é divergente, com muitos dos estudos utilizando o termo auto-controle para a situação em que o aprendiz tem somente algum controle sobre determinada variável. Mais especificamente, embora o conceito de auto-controle tenha diferentes definições na teorização psicológica (e.g. THORESEN; MAHONEY 1974), e seja entendido como oposto à auto-regulação em determinadas concepções teóricas da aprendizagem auto-regulada (KEHR; BLES; ROSENTIEL, 1999), o termo é amplamente utilizado nas pesquisas em aprendizagem motora.

A não utilização do termo auto-regulada na área de aprendizagem motora pode ser conseqüência do foco em aspectos específicos da auto-regulação. Mas embora, como visto acima, seja possível observar aspectos específicos da aprendizagem auto-regulada a partir de uma análise dimensional (ZIMMERMAN, 1989), para manter coerência com a literatura existente o termo auto-controlado será utilizado nesse trabalho para descrever os estudos que focam uma dimensão específica da aprendizagem auto-regulada em aprendizagem motora. Porém, no presente trabalho, haverá menção da condição ou variável manipulada. Nesse sentido, tal denominação não deve ser entendida como referência a concepções mais amplas de auto-controle.

De forma geral, as investigações realizadas com o auto-controle de alguma condição ou variável em aprendizagem motora permitem ao participante ter em algum grau controle sobre a situação de aprendizagem. De acordo com Bund e Wiemeyer (2004), em contraste às condições de prática normalmente impostas por um professor ou instrutor, a existência deste controle possibilita que o aprendiz tornese um participante mais ativo no processo de aprendizagem. Ainda que não haja, em alguns destes estudos, a referência explícita ao conceito de aprendizagem autoregulada, parte-se da hipótese de que o controle de determinado aspecto da condição experimental pelo participante pode trazer benefícios à aprendizagem. Nesse contexto, foram objeto de investigação em aprendizagem motora variáveis como o estabelecimento de metas, a utilização de auxílio físico, a apresentação de modelos e o fornecimento de feedback aumentado (conhecimento de resultados e conhecimento de performance). 
Boyce (1992) parte da literatura existente em estabelecimento de metas para questionar se o estabelecimento de metas pelos participantes traz melhores resultados que $\mathrm{o}$ estabelecimento de metas propostas pelo experimentador e $\mathrm{o}$ estabelecimento de metas genéricas ("do-your-best") em uma tarefa de tiro ao alvo. Locke (1968) citado por Boyce (1992) sugere que a origem da meta não é importante, mas sim seu nível de dificuldade. Desse modo, permitir aos sujeitos escolher suas próprias metas teria apenas um efeito indireto no seu nível de desempenho, e este seria superior apenas se as metas escolhidas fossem mais difíceis que as metas estabelecidas pelo experimentador. O grupo de metas estabelecidas pelos participantes tinha a ajuda de um líder de classe escolhido pelo grupo e tinha acesso às metas de longo prazo utilizadas para o grupo de metas específicas. A cada sessão, o participante do grupo de metas definidas pelos participantes definia a meta para a sessão com o auxílio do líder do grupo. O grupo de metas específicas e o grupo de metas escolhidas pelos participantes foram significativamente superiores ao grupo de metas genéricas em dois blocos da aquisição e na retenção (uma semana depois), mas não diferiram entre si.

Poe sua vez, Boyce, Wayda, Johnston, Bunker e Eliot (2001) investigam os efeitos do estabelecimento de metas na aprendizagem do saque do tênis em uma situação de campo. Três diferentes condições de estabelecimento de metas foram atribuídas aos grupos: metas de curto e longo prazo estabelecidas pelo instrutor; metas de curto prazo auto-estabelecidas e metas de longo prazo estabelecidas pelo instrutor; e metas genéricas ("do your best"). Uma técnica de amostragem aleatória de dois estágios foi utilizada para permitir a utilização de classes como unidade de aplicação do tratamento experimental: inicialmente as classes (turmas de alunos) foram aleatoriamente atribuídas a uma das condições experimentais descritas, e em seguida $80 \%$ dos participantes foram aleatoriamente selecionados de cada classe para a análise dos dados. Embora os grupos de metas estabelecidas pelo instrutor e metas auto-estabelecidas tenham sido superiores ao grupo de metas genéricas na aquisição e retenção, não houve diferença entre o grupo de metas estabelecidas pelo instrutor e o grupo de metas auto-estabelecidas na retenção. Assim, em ambos os estudos os participantes que estabeleceram suas próprias metas tiveram 
desempenho semelhante aos participantes cujas metas foram externamente estabelecidas.

De forma geral, os achados em relação ao auto-estabelecimento de metas em aprendizagem motora estão de acordo com a teoria de metas (LOCKE; LATHAM, 1990 citado por LOCKE; LATHAM, 2002; LOCKE; LATHAM, 2006) segundo a qual o efeito do estabelecimento de metas depende, principalmente, não de quem a atribui e sim de sua dificuldade. Além disso algumas condições parecem ser necessárias para que haja efeito do auto-estabelecimento de metas no desempenho de diferentes tarefas. Locke e Latham (1990, citado por LOCKE; LATHAM, 2002) argumentam que os efeitos do estabelecimento de metas são mediados pelo potencial de autoavaliação, isto é, pela disponibilidade de feedback. Harkins e Lowe (2000) sugerem outras condições como necessárias para a observação dos efeitos do autoestabelecimento de metas: algum conhecimento da tarefa por parte dos participantes antes da definição das metas (representado pela existência de um pré-teste no delineamento experimental) e conhecimento por parte do experimentador das metas e dos desempenhos dos participantes. A eficácia do auto-estabelecimento de metas na aprendizagem motora também parece depender do recebimento de feedback sobre o desempenho (BOYCE; WAYDA; JOHNSTON; BUNKER; ELIOT, 2001).

Wulf e Toole (1999), a partir dos resultados de estudos que encontraram benefícios na utilização de um implemento de auxílio, investigam o auto-controle na escolha da utilização deste implemento. Como os autores argumentam, diversas espécies de objetos de auxílio podem ser encontrados em ambientes de intervenção em campos relacionados à aprendizagem e reabilitação. Permitir aos participantes controlar a utilização dos aparelhos poderia trazer os benefícios relacionados à aprendizagem auto-regulada. Os participantes praticaram uma tarefa de descolamento lateral num aparelho simulador de esqui. Os participantes do grupo auto-controlado podiam escolher a cada tentativa se utilizariam ou não bastões de apoio, enquanto os participantes do grupo yoked realizavam as tentativas de acordo com a utilização dos bastões dos participantes do grupo auto-controlado. $\mathrm{O}$ grupo yoked é um artifício usado nas pesquisas em aprendizagem motora que investigam o auto-controle de diferentes variáveis; para cada participante capaz de selecionar determinada característica da situação de aprendizagem, há um participante no 
grupo yoked que recebe, sem possibilidade de escolha, a opção daquela característica selecionada pelo outro participante. Isto permite que os efeitos da autoregulação sejam distintos da variável manipulada já que a prática dos participantes do grupo yoked tem as mesmas características do grupo auto-regulado.O objetivo da tarefa era realizar as maiores amplitudes possíveis, e a aprendizagem foi observada num teste de retenção um dia após a prática, sem utilização dos bastões.

Durante a prática não foi observada diferença entre os grupos. Os participantes do grupo de utilização de auxílio auto-controlado, informados previamente que deveriam executar a tarefa sem os bastões no terceiro dia, diminuíram progressivamente a utilização do auxílio ao longo das tentativas. A possibilidade de escolher a utilização do auxílio também não influiu nas respostas de um questionário destinado a avaliar a confiança dos participantes em relação à possibilidade de quedas e ao alcance de amplitudes máximas. Todavia, na retenção, os participantes do grupo auto-controlado alcançaram amplitudes superiores às do grupo yoked. Os autores sugerem que os participantes do grupo auto-controlado podem ter se engajado em atividades de processamento de informação diferentes das realizadas pelo grupo yoked, se concentrando em aumentar a amplitude do movimento ao invés de preocupar-se apenas com o equilíbrio ao utilizar o auxílio, e testando estratégias de movimento intencionalmente na condição sem auxílio.

Por sua vez, Wulf, Claus, Shea e Whitacre (2001) questionam se o autocontrole na utilização de um auxílio físico idêntico ao de Wulf e Toole (1999) na mesma tarefa resultaria em benefícios similares quando a prática era realizada em duplas (díades). A prática em duplas consiste na execução das tentativas de forma alternada, ou seja, com alternância de prática física e prática observacional. Neste experimento, um dos participantes da dupla tinha controle sobre a utilização do implemento, enquanto o outro realizava a tentativa de acordo com a escolha de utilização ou não realizada pelo outro participante, ou seja, praticava na condição yoked. Os benefícios da prática em duplas em relação à prática individual têm sido atribuídos à possibilidade de observar o outro participante da dupla e à competição entre participantes. Wulf, Claus, Shea e Whitacre (2001) questionam se os benefícios do auto-controle na utilização do implemento resultam em diferentes características observáveis do movimento, caso em que os participantes do grupo yoked poderiam 
imitar tais características. Entretanto, caso a prática com auto-controle levasse à exploração de estratégias ou diferenças não observáveis na eficiência do movimento seriam esperadas diferenças entre o grupo auto-controlado e o grupo yoked.

Durante a prática não foi observada diferença entre o grupo com autocontrole na utilização de auxílio e o grupo yoked em nenhuma das medidas de desempenho - freqüência, amplitude e início relativo da aplicação de força (relative force onset). Contudo, foram observadas diferenças para o início relativo da aplicação de força na retenção; enquanto o grupo yoked iniciava a aplicação de força a aproximadamente $20 \%$ do deslocamento entre o centro do aparato e a amplitude máxima alcançada, em média, o grupo com auto-controle da utilização de implemento iniciava a aplicação de força apenas quando atingia em média próximo de $50 \%$ desta distância. Para os autores, isto sugere uma maior eficiência na realização do movimento. Ainda de acordo com os autores, a prática em duplas pode anular algumas das vantagens da prática auto-controlada, porém de forma restrita às características acessíveis à observação. Características sutis ou não observáveis do movimento podem manter-se despercebidas, o que sugere uma limitação da prática em duplas. Por fim, os autores sugerem haver evidência adicional para os efeitos positivos do auto-controle na utilização de auxílios físicos na aprendizagem motora.

O auto-controle na freqüência de apresentação de um modelo em vídeo foi outra variável contrastada com seu controle por parte do experimentador. Wrisberg e Pein (2002) investigaram o auto-controle da freqüência de apresentação do modelo utilizando o saque do badminton, comparando um grupo que via o modelo em todas as tentativas, um grupo com auto-controle da freqüência de apresentação (que poderia escolher antes de cada tentativa se desejava ver o modelo) e um grupo que não viu o modelo.

Durante a aquisição, o grupo auto-controle apresentou desempenho superior ao grupo que não viu o modelo na medida de desempenho relacionada à precisão, e os grupos auto-controlado e apresentação de modelo em todas as tentativas foram superiores ao grupo que não viu o modelo na medida relacionada à forma. Contudo, na fase de retenção não houve diferenças entre os grupos na precisão, com diferenças apenas na forma (grupos auto-controle da apresentação de modelo e apresentação de modelo em todas as tentativas superiores ao grupo sem 
modelagem). A partir da ausência de diferenças entre os grupos que viram o modelo, os autores argumentam que a equivalência entre ambos mesmo com uma baixa freqüência de apresentação do modelo no grupo auto-controlado $(9,8 \%)$ sugere que permitir que os aprendizes controlem os auxílios de aprendizagem pode proporcionar uma maior eficiência na instrução.

O estudo de Wulf, Raupach e Pfeiffer (2005) deu continuidade à investigação sobre o auto-controle na apresentação de um modelo em vídeo. Analisando o estudo de Wrisberg e Pein (2002), os autores argumentam que a ausência de um grupo yoked não permite dissociar os efeitos do auto-controle da apresentação do modelo das baixas freqüências de apresentação solicitadas pelos participantes. Para dissociar os efeitos da freqüência de solicitação e do autocontrole, Wulf, Raupach e Pfeiffer (2005) realizam um experimento utilizando como tarefa o salto com arremesso do basquete. Os participantes foram divididos em dois grupos: grupo auto-controle da freqüência de apresentação do modelo e grupo yoked.

A ausência de diferenças entre os grupos durante a prática não persistiu durante a retenção, com o grupo que controlou a própria freqüência de apresentação de modelo apresentando desempenho superior na medida relacionada à forma do movimento. A partir dos resultados, os autores sugerem que as diferenças entre os grupos na retenção podem ser resultado de diferentes atividades de processamento de informação empreendidas pelos grupos.

O fornecimento de feedback aumentado também foi objeto de investigação como variável auto-controlada. Janelle, Kim e Singer (1995) investigaram o fornecimento verbal de conhecimento de performance em uma tarefa de arremesso, na qual o resultado do arremesso no meio ambiente era visível. A partir do referencial da aprendizagem auto-regulada, os autores questionam se o fornecimento de conhecimento de performance auto-regulado é superior a outras formas de fornecimento de feedback. Os participantes foram divididos em cinco grupos: grupo de conhecimento de performance auto-controlado, grupo de $50 \%$ de freqüência de conhecimento de performance, grupo de conhecimento de performance sumário, grupo yoked e grupo controle (sem fornecimento de conhecimento de performance). Embora não tenha havido diferenças entre os grupos na fase de aquisição do estudo 
de Janelle, Kim e Singer (1995), o grupo de auto-controle de fornecimento de conhecimento de performance foi superior aos demais grupos na retenção, ainda que tenham solicitado e recebido feedback em apenas $7 \%$ das tentativas.

Janelle, Barba, Frehlich, Tennant e Caraugh (1997) dão continuidade à investigação sobre o auto-controle de fornecimento do conhecimento de performance, porém utilizando como meio de fornecimento de conhecimento de performance a exibição das duas últimas tentativas em vídeo. $O$ delineamento consistia em quatro grupos semelhantes aos grupos do estudo anterior: grupo de conhecimento de performance auto-controlado, grupo de conhecimento de performance sumário, grupo yoked e grupo controle (sem fornecimento de conhecimento de performance). $O$ resultado da tarefa (arremesso sobre o ombro com a mão não-preferida) no meio ambiente também era visível.

O grupo de conhecimento de performance auto-controlado solicitou feedback em aproximadamente $11 \%$ das tentativas, mas foi semelhante aos grupos de conhecimento de performance sumário e yoked com relação ao padrão do arremesso na aquisição. Os três grupos também foram superiores ao grupo controle (conhecimento de resultados apenas) nesta medida durante a aquisição. Com relação ao erro, embora haja diferenças entre grupos em blocos específicos houve uma tendência geral (para todos os grupos) de melhora do desempenho durante a aquisição. Entretanto, na fase de retenção o grupo de conhecimento de perfomance auto-controlado foi superior aos demais grupos tanto no padrão quanto no erro radial médio. Os demais grupos também foram superiores ao grupo controle em ambas as medidas na retenção.

Chiviacowsky e Wulf (2002), dando continuidade à investigação sobre o auto-controle do fornecimento de feedback, buscam investigar as razões da superioridade do auto-controle do conhecimento de resultados em uma tarefa de timing seqüencial. Os participantes deveriam tocar as teclas 2, 4, 8 e 6 do teclado numérico com tempos de movimento parciais alvo, recebendo feedback sobre os tempos de movimento executados e os tempos de movimento alvo quando solicitassem (no caso do grupo com auto-controle do fornecimento de conhecimento de resultados) ou recebendo as mesmas informações em algumas das tentativas sem controle sobre seu oferecimento (no caso dos participantes yoked). Além disso, 
os participantes responderam a um questionário sobre quando pediram ou não pediram conhecimento de resultados (para o grupo com auto-controle desta variável) ou sobre quando receberam a mesma informação (para o grupo yoked).

Os resultados mostram desempenho superior do grupo com auto-controle de conhecimento de resultados no erro absoluto referente aos tempos parciais no último bloco da aquisição. $\mathrm{Na}$ transferência, quando os participantes de ambos os grupos deveriam realizar a tarefa com um novo tempo total, mas mantendo o tempo relativo entre os toques, o grupo com auto-controle de conhecimento de resultados também apresentou menor aumento no erro absoluto referente ao tempo total de movimento. Os resultados do questionário, por sua vez, apontam um padrão para a solicitação de conhecimento de resultados: os participantes do grupo autocontrolado, em sua maioria, responderam solicitar feedback após as tentativas em que tinham um bom desempenho. Este padrão foi confirmado em uma análise do erro referente ao tempo absoluto por grupos e da solicitação ou não de feedback, que mostrou que o erro do grupo auto-controlado foi menor nas tentativas em que solicitou feedback, ao contrário do grupo yoked que não apresentou tal padrão. A estratégia de solicitar feedback após tentativas com melhor desempenho mostrou-se, em estudos subseqüentes, superior a decidir antes da realização da tentativa (CHIVIACOWSKY; WULF, 2005) ou em tentativas com desempenho inferior (CHIVIACOWSKY; WULF, 2007). As respostas ao questionário dos participantes do grupo yoked do estudo de Chiviacowsky e Wulf (2002) sugerem, ainda, que estes em sua maioria não consideraram ter recebido conhecimento de resultados nas tentativas adequadas, e prefeririam também receber feedback após as tentativas mais bem-sucedidas. Para as autoras, além de confirmar a tendência de superioridade do auto-controle do fornecimento de conhecimento de resultados encontrada em estudos anteriores, os resultados sugerem a existência de estratégias para a solicitação de feedback e apóiam a hipótese de que o auto-controle de variáveis de prática é mais adequado às necessidades e preferências dos praticantes do que o controle externo destas variáveis.

Chen, Hendrick e Lidor (2002) também investigam o auto-controle do fornecimento de conhecimento de resultados na aprendizagem de uma tarefa de timing, na qual os participantes deveriam apertar uma seqüência de cinco teclas no 
teclado numérico $(5,2,4,6$ e 8$)$ num tempo total alvo de $800 \mathrm{~ms}$. Os autores argumentam que o conhecimento de resultados é recebido predominantemente de forma passiva, em contraste à natureza ativa dos processos de auto-regulação. Formas de utilização mais ativas por parte dos participantes seriam, de acordo com os autores, mais eficazes para a aprendizagem do que o recebimento passivo ou induzido pelo experimentador. Para investigar esta hipótese, Chen, Hendrick e Lidor (2002) empregam quatro grupos experimentais: grupo com conhecimento de resultados auto-iniciado (os participantes deveriam apertar um botão $2 \mathrm{~s}$ após a tentativa para receber conhecimento de resultados), grupo de conhecimento de resultados induzido pelo experimentador (após cada tentativa, o experimentador lembrava que o participante poderia solicitar conhecimento de resultados), grupo yoked do conhecimento de resultados auto-iniciado e grupo yoked do conhecimento de resultados induzido pelo experimentador. Mais uma vez, os grupos yoked não tinham nenhum controle sobre os aspectos auto-controlados nos outros grupos, tendo a prática atrelada às escolhas dos participantes dos grupos auto-controlados.

O desempenho dos grupos foi semelhante na aquisição. Todavia, os grupos com conhecimento de resultados auto-iniciado e induzido pelo experimentador foram superiores a ambos os grupos yoked na retenção imediata na medida de erro absoluto constante, e o mesmo aconteceu no teste de retenção atrasada dois dias depois. Embora não tenha havido diferenças entre a solicitação auto-iniciada de feedback e o lembrete por parte do experimentador sobre a possibilidade de seu fornecimento, em contraste a uma das hipóteses do estudo, ambas as formas foram superiores aos fornecimentos equivalentes que não envolviam escolha por parte do aprendiz.

Bund e Wiemeyer (2004) questionam se o auto-controle de um aspecto preferido pelo aprendiz traz mais benefícios à aprendizagem e à auto-eficácia do que o auto-controle de um aspecto menos preferido. A auto-eficácia, de acordo com uma visão social-cognitiva da aprendizagem (BANDURA, 1986), pode ser entendida como a expectativa pessoal sobre a própria capacidade de aprender ou executar habilidades em determinado nível. Os autores sugerem que o auto-controle de diferentes aspectos da aprendizagem poderia ter conseqüências diversas no aprendizado e na auto-eficácia dependendo da preferência pelo controle deste 
aspecto. Utilizando como tarefa uma rebatida do tênis de mesa (forehand top-spin stroke), os autores determinaram por meio de questionário aplicado aos participantes que o aspecto da aprendizagem que os participantes mais gostariam de controlar, dentre os apresentados, foi o fornecimento de instrução em vídeo, enquanto o menos preferido foi a variabilidade de prática, isto é, a direção e a velocidade da bola a ser rebatida. Com base nestes resultados, os participantes foram divididos aleatoriamente em quatro grupos: grupo auto-controle do aspecto preferido, grupo auto-controle do aspecto menos preferido, grupo yoked em relação ao aspecto preferido, grupo yoked em relação ao aspecto menos preferido.

A despeito da ausência de diferenças no desempenho entre os grupos no pré-teste e durante a prática, ambos os grupos auto-controlados foram superiores aos grupos yoked na medida relacionada à forma do movimento na retenção atrasada (após $1 \mathrm{dia}$ ). Além disso, os participantes dos grupos auto-controlados mostraram níveis mais altos de auto-eficácia comparados aos grupos yoked durante todo o experimento. Os resultados relacionados à auto-eficácia divergem do questionário aplicado por Wulf e Toole (1999), que não encontraram diferenças no que diz respeito à confiança em não cair e alcançar grandes amplitudes ao final da prática na tarefa de simulador de esqui. Contudo, permitem inferir sobre possíveis fatores motivacionais associados ao auto-controle de aspectos da aprendizagem. Outro aspecto relevante apontado por Bund e Wiemeyer (2004) é a ausência de diferenças entre os grupos auto-controlados, que sugeriria que os benefícios do autocontrole de diferentes aspectos da aprendizagem não se restringem apenas aos que possam ser considerados relevantes pelos aprendizes. Para os autores, os benefícios do auto-controle têm sido observados em diferentes aspectos da aprendizagem e parecem ser resultado do processo de auto-controle em si, não estando restritos a determinadas características.

Outros estudos investigando o auto-controle de diversos aspectos da aprendizagem motora tiveram seus resultados parcialmente publicados - em forma de síntese ou resumo (e.g. TITZER; SHEA; ROMACK, 1993; WU; MAGILL, 2004, 2005), e de forma geral vão ao encontro dos achados descritos acima, com desempenho superior na retenção dos grupos que puderam escolher determinada característica da instrução, da prática ou do feedback. Uma síntese das 
características dos estudos encontrados que contrastam o auto-controle de variáveis da aprendizagem motora ao controle pelo experimentador a partir de uma visão orientada ao equilíbrio é apresentada na TABELA 3.

TABELA 3 - Síntese dos estudos sobre auto-controle em aprendizagem motora em uma perspectiva orientada ao equilíbrio

\begin{tabular}{|c|c|c|c|c|c|}
\hline Estudo & $N$ & Grupos & Tarefa & $\begin{array}{l}\text { Resultados } \\
\text { (aquisição) }\end{array}$ & $\begin{array}{c}\text { Resultados } \\
\text { (retenção e } \\
\text { transferência) }\end{array}$ \\
\hline Boyce (1992) & 138 & $\begin{array}{l}\text { Metas estabelecidas } \\
\text { pelos participantes } \\
\text { [1]; metas atribuídas } \\
\text { pelo experimentador } \\
\text { [2]; metas genéricas } \\
\text { [3]. }\end{array}$ & $\begin{array}{l}\text { Tiro ao } \\
\text { alvo }\end{array}$ & $\begin{array}{l}\text { [1] e [2] } \\
\text { superiores } \\
\text { a [3] em } 2 \\
\text { blocos. }\end{array}$ & $\begin{array}{l}\text { [1] e [2] } \\
\text { superiores a [3] } \\
\text { na retenção } \\
\text { (sem transfer.). }\end{array}$ \\
\hline $\begin{array}{l}\text { Boyce, } \\
\text { Wayda, } \\
\text { Johnston, } \\
\text { Bunker e Eliot } \\
(2001)\end{array}$ & 156 & $\begin{array}{l}\text { Metas de curto prazo } \\
\text { estabelecidas pelos } \\
\text { participantes e de } \\
\text { longo prazo pelo } \\
\text { instrutor [1]; metas de } \\
\text { curto e longo prazo } \\
\text { estabelecidas pelo } \\
\text { instrutor [2]; metas } \\
\text { genéricas [3] }\end{array}$ & $\begin{array}{l}\text { Saque do } \\
\text { tênis }\end{array}$ & $\begin{array}{l}\text { [1] e [2] } \\
\text { superiores } \\
\text { a [3] em } \\
\text { dois blocos; } \\
\text { [2] superior } \\
\text { a [1] em um } \\
\text { deles. }\end{array}$ & $\begin{array}{l}\text { Sem diferenças } \\
\text { na retenção (sem } \\
\text { transfer.) }\end{array}$ \\
\hline $\begin{array}{l}\text { Wulf e Toole } \\
\text { (1999) }\end{array}$ & 26 & $\begin{array}{l}\text { Auto-controle da } \\
\text { utilização de auxílio } \\
\text { físico [1]; yoked [2]. }\end{array}$ & $\begin{array}{l}\text { Simulador } \\
\text { de esqui } \\
\text { (slalom) }\end{array}$ & $\begin{array}{l}\text { Sem } \\
\text { diferenças. }\end{array}$ & $\begin{array}{l}\text { [1] superior a [2] } \\
\text { na retenção (sem } \\
\text { transfer.). }\end{array}$ \\
\hline $\begin{array}{l}\text { Wulf, Clauss, } \\
\text { Shea e } \\
\text { Whitacre } \\
(2001)\end{array}$ & 26 & $\begin{array}{l}\text { Auto-controle da } \\
\text { utilização de auxílio } \\
\text { físico [1]; yoked [2] } \\
\text { (duplas com uma } \\
\text { pessoa em cada } \\
\text { condição) }\end{array}$ & $\begin{array}{l}\text { Simulador } \\
\text { de esqui } \\
\text { (slalom) }\end{array}$ & $\begin{array}{l}\text { Sem } \\
\text { diferenças. }\end{array}$ & $\begin{array}{l}\text { [1] superior a [2] } \\
\text { na retenção (sem } \\
\text { transfer.). }\end{array}$ \\
\hline $\begin{array}{l}\text { Wrisberg e } \\
\text { Pein (2002) }\end{array}$ & 30 & $\begin{array}{l}\text { Auto-controle da } \\
\text { apresentação de um } \\
\text { modelo [1]; } \\
\text { apresentação do } \\
\text { modelo antes de } \\
\text { todas as tentativas } \\
\text { [2]; controle (sem } \\
\text { modelo) [3]. }\end{array}$ & $\begin{array}{l}\text { Saque do } \\
\text { badminton }\end{array}$ & $\begin{array}{l}\text { [1] e [2] } \\
\text { superiores } \\
\text { a [3] no } \\
\text { último dia. }\end{array}$ & $\begin{array}{l}\text { [1] e [2] } \\
\text { superiores a [3] } \\
\text { na retenção (sem } \\
\text { transfer.) }\end{array}$ \\
\hline $\begin{array}{l}\text { Wulf, Raupach } \\
\text { e Pfeiffer } \\
\text { (2005) }\end{array}$ & 26 & $\begin{array}{l}\text { Auto-controle da } \\
\text { apresentação de um } \\
\text { modelo [1]; grupo } \\
\text { yoked [2]. }\end{array}$ & $\begin{array}{l}\text { Salto com } \\
\text { arremesso } \\
\text { do } \\
\text { basquete }\end{array}$ & $\begin{array}{l}\text { Sem } \\
\text { diferenças. }\end{array}$ & $\begin{array}{l}\text { [1] superior a [2] } \\
\text { na retenção (sem } \\
\text { transfer.) }\end{array}$ \\
\hline
\end{tabular}




\begin{tabular}{|c|c|c|c|c|c|}
\hline Estudo & $N$ & Grupos & Tarefa & $\begin{array}{l}\text { Resultados } \\
\text { (aquisição) }\end{array}$ & $\begin{array}{c}\text { Resultados } \\
\text { (retenção e } \\
\text { transferência) }\end{array}$ \\
\hline $\begin{array}{l}\text { Janelle, Kim e } \\
\text { Singer (1995) }\end{array}$ & 60 & $\begin{array}{l}\text { Auto-controle do } \\
\text { fornecimento de } \\
\text { conhecimento de } \\
\text { performance (CP) [1]; } \\
50 \% \text { de freqüência } \\
\text { de CP [2]; CP } \\
\text { sumário [3]; CP } \\
\text { yoked [4]; controle } \\
\text { (apenas } \\
\text { conhecimento de } \\
\text { resultados) [5]. }\end{array}$ & $\begin{array}{l}\text { Arremesso } \\
\text { de bola } \\
\text { por baixo }\end{array}$ & $\begin{array}{l}\text { Sem } \\
\text { diferenças. }\end{array}$ & $\begin{array}{l}\text { [1] superior aos } \\
\text { demais na } \\
\text { retenção } \\
\text { (sem transfer.). }\end{array}$ \\
\hline $\begin{array}{l}\text { Janelle, } \\
\text { Barba, } \\
\text { Frehlich, } \\
\text { Tennant e } \\
\text { Caraugh } \\
(1997)\end{array}$ & 48 & $\begin{array}{l}\text { Auto-controle do } \\
\text { fornecimento de } \\
\text { conhecimento de } \\
\text { performance (CP) [1]; } \\
\text { CP sumário [2]; CP } \\
\text { yoked [3]; controle } \\
\text { (apenas } \\
\text { conhecimento de } \\
\text { resultados) [4]. }\end{array}$ & $\begin{array}{l}\text { Arremesso } \\
\text { com a } \\
\text { mão não- } \\
\text { dominante }\end{array}$ & $\begin{array}{l}\text { [1], [2] e [3] } \\
\text { superiores } \\
\text { a [4] no } \\
\text { padrão. } \\
\text { Sem } \\
\text { diferenças } \\
\text { no erro. }\end{array}$ & $\begin{array}{l}\text { [1] superior aos } \\
\text { demais; todos } \\
\text { superiores a [4] } \\
\text { tanto no erro } \\
\text { quanto no padrão } \\
\text { na retenção (sem } \\
\text { transfer.). }\end{array}$ \\
\hline $\begin{array}{l}\text { Chiviacowsky } \\
\text { e Wulf (2002) }\end{array}$ & 30 & $\begin{array}{l}\text { Auto-controle do } \\
\text { fornecimento de } \\
\text { conhecimento de } \\
\text { resultados (CR) [1]; } \\
\text { CR yoked [2]. }\end{array}$ & $\begin{array}{l}\text { Timing } \\
\text { sequencial } \\
\text { (toques no } \\
\text { teclado } \\
\text { numérico) } \\
\end{array}$ & $\begin{array}{l}\text { [1] superior } \\
\text { a [2] em um } \\
\text { bloco. }\end{array}$ & $\begin{array}{l}\text { [1] superior a [2] } \\
\text { na transferência } \\
\text { (sem diferenças } \\
\text { na retenção). }\end{array}$ \\
\hline $\begin{array}{l}\text { Chen, } \\
\text { Hendrick e } \\
\text { Lidor (2002) }\end{array}$ & 37 & $\begin{array}{l}\text { Conhecimento de } \\
\text { resultados auto- } \\
\text { iniciado [1]; } \\
\text { conhecimento de } \\
\text { resultados induzido } \\
\text { pelo experimentador } \\
\text { [2]; grupo yoked do } \\
\text { grupo auto-iniciado } \\
\text { [3]; grupo yoked do } \\
\text { grupo induzido pelo } \\
\text { experimentador [4]. }\end{array}$ & $\begin{array}{l}\text { Timing } \\
\text { seqüencial } \\
\text { (toques no } \\
\text { teclado } \\
\text { numérico) }\end{array}$ & $\begin{array}{l}\text { Sem } \\
\text { diferenças. }\end{array}$ & $\begin{array}{l}\text { [1] e [2] } \\
\text { superiores a [3] e } \\
\text { [4] na retenção } \\
\text { imediata e } \\
\text { atrasada (sem } \\
\text { transfer.) }\end{array}$ \\
\hline $\begin{array}{l}\text { Bund e } \\
\text { Wiemeyer } \\
\text { (2004) }\end{array}$ & 52 & $\begin{array}{l}\text { Auto-controle do } \\
\text { aspecto preferido [1]; } \\
\text { auto-controle do } \\
\text { aspecto menos } \\
\text { preferido [2]; grupo } \\
\text { yoked do aspecto } \\
\text { preferido [3]; grupo } \\
\text { yoked do aspecto } \\
\text { menos preferido [4]. }\end{array}$ & $\begin{array}{l}\text { Rebatida } \\
\text { do tênis } \\
\text { de mesa } \\
\text { (forehand } \\
\text { top-spin } \\
\text { stroke) }\end{array}$ & $\begin{array}{l}\text { Sem } \\
\text { diferenças. }\end{array}$ & $\begin{array}{l}\text { [1] e [2] } \\
\text { superiores a [3] e } \\
\text { [4] na retenção } \\
\text { atrasada (sem } \\
\text { diferenças na } \\
\text { retenção imediata } \\
\text { e sem transfer.) }\end{array}$ \\
\hline
\end{tabular}


Em síntese, como apontam Bund e Wiemeyer (2004), a superioridade de grupos auto-controlados quando comparados a grupos yoked é um fenômeno robusto. Os autores observam que na maior parte dos estudos os efeitos positivos do auto-controle não são observáveis na aquisição, surgindo na fase de retenção ou transferência. Focando a intervenção na reabilitação, Wulf (2007) sugere que embora estudos mais aplicados ainda não tenham sido realizados, os resultados relativamente robustos dos benefícios do auto-controle de aspectos da aprendizagem sugerem que os resultados possam ser generalizáveis a outros grupos de indivíduos. Wulf (2007) sugere ainda que o emprego do auto-controle (que requer mudanças relativamente simples) pode melhorar substancialmente a eficiência da intervenção.

As explicações para os benefícios do auto-controle de diferentes aspectos da aprendizagem são, entretanto, divergentes. As hipóteses vão de aumento na motivação que teria como conseqüência um processamento de informação mais elaborado a condições mais adequadas às necessidades dos aprendizes. Bund e Wiemeyer (2004) argumentam que hipóteses baseadas em exploração de estratégias de movimento não explicam adequadamente o auto-controle de variáveis como o feedback, onde o aspecto cognitivo ou relacionado ao processamento de informação é mais relevante. Com base na literatura de aprendizagem auto-regulada, os autores apontam os aspectos cognitivo e motivacional como os mais relevantes para a superioridade do auto-controle de aspectos da aprendizagem em relação à aprendizagem que não envolve auto-controle (yoked). Os autores propõem ainda um modelo em que a interação entre os aspectos cognitivo e motivacional explica os resultados encontrados.

Para Bund e Wiemeyer (2004), os resultados dos estudos investigando o auto-controle tipicamente mostram efeitos atrasados, observáveis apenas na retenção, sem diferenças entre grupos durante a prática. Segundo os autores, estes resultados podem ser explicados apenas ao assumir uma relação antagonística entre processos cognitivos e motivacionais. $\mathrm{O}$ aumento na motivação intrínseca decorrente do auto-controle de aspectos da aprendizagem leva os aprendizes a empregar maior esforço na tarefa. Contudo, o auto-controle traz consigo maior demanda cognitiva, pois o aprendiz deve tomar decisões a respeito das características que controla além das demandas relacionadas ao aprendizado em si, dividindo a atenção entre estes 
aspectos. Os autores sustentam que os efeitos contrários da cognição e da motivação podem levar a desempenhos similares dos grupos auto-controlados e yoked durante a fase de aquisição. Já na retenção, não há efeitos motivacionais positivos para o auto-controle, porém não há também demandas cognitivas adicionais. Nesse momento, o auto-controle resulta em benefícios relacionados à possibilidade de praticar de acordo com as próprias necessidades e preferências (BUND; WIEMEYER, 2004; CHIVIACOWSKY; WULF, 2002).

A despeito dos motivos ainda não esclarecidos, há evidências robustas que muitos aspectos da aprendizagem podem ser controlados pelos aprendizes trazendo benefícios ou ao menos não trazendo prejuízos em relação ao seu controle por parte do experimentador. Contudo, os estudos até aqui considerados no foram desenvolvidos em uma perspectiva finita do processo de aquisição de habilidades motoras. Como o controle de aspectos da aprendizagem por parte do aprendiz pode ser encarado a partir de uma visão sistêmica e de um modelo de Processo Adaptativo em aprendizagem motora?

\subsection{Liberdade na escolha da resposta}

Se há atualmente uma preocupação, nos estudos realizados a partir de uma perspectiva de equilíbrio em aprendizagem motora, relativa aos efeitos do autocontrole em variáveis da instrução, da prática e do feedback, também existe tal preocupação quando o fenômeno da aprendizagem motora é abordado a partir do modelo denominado Processo Adaptativo. Entretanto, ao focar a reorganização das habilidades adquiridas num nível superior de complexidade, a transferência da estrutura anteriormente adquirida e não só a transferência das funções deve ser considerada (TANI, 1982). Nessa perspectiva, a aprendizagem deve permitir, portanto, que a estrutura formada concilie características aparentemente contraditórias como a consistência e a variabilidade, favorecendo assim uma adaptação bem-sucedida. Mas, como a prática pode promover a formação de uma estrutura com estas características?

A preocupação com condições de prática que favoreçam a adaptação é característica central no estudo de Tani (1982), que realizou seis experimentos, dos 
quais quatro (experimentos 1, 2, 3 e 4) manipulam a liberdade na escolha dos movimentos que compõem a resposta. A hipótese central no estudo de Tani (1982) é que para se adquirir padrões de movimento flexíveis seria necessário certo grau de liberdade na escolha das respostas durante o processo de estabilização funcional. Os padrões de movimento flexíveis têm sido entendidos como resultado de uma estrutura em que a coexistência de ordem e desordem assume papel explanatório fundamental (TANI, 2000) na qual dois níveis complementares - macro e micro seriam responsáveis, respectivamente, pela consistência e pela flexibilidade dos padrões de movimento (MANOEL; CONNOLLY, 1995, 1997; TANI, 1995). A redução excessiva dos graus de liberdade poderia levar, de acordo com Tani (1982), a uma ênfase na consistência da habilidade, tornando os padrões de movimento adquiridos pouco adaptáveis. Por outro lado, o aumento excessivo nos graus de liberdade poderia prejudicar a estabilização funcional, já que certa redução na variabilidade é necessária para alcançar o desempenho com sucesso.

Os experimentos 1, 2, 3 e 4 de Tani (1982) foram realizados com estudantes universitárias utilizando como tarefa habilidades do basquetebol. A variável manipulada em todos os experimentos foi a liberdade na escolha dos componentes que compunham a seqüência de habilidades do basquetebol.

Nos experimentos 1 e 2 os participantes foram atribuídos aleatoriamente a uma das três condições experimentais: (a) ordem dos elementos na seqüência e subelementos escolhidos pelo sujeito; (b) ordem dos elementos na seqüência determinada pelo experimentador e subelementos escolhidos pelo próprio sujeito; (c) ordem dos elementos na seqüência e subelementos determinados pelo experimentador. No experimento 1 , o grupo que apresentou maior queda no desempenho na adaptação foi o grupo na condição de maior liberdade, o que segundo o autor reflete um padrão não devidamente organizado. No experimento 2 , a mesma condição experimental apresentou desempenho superior aos demais grupos na adaptação.

Com intuito de verificar se o estado do sistema influencia o efeito da liberdade na escolha da resposta, Tani (1982) realizou dois outros experimentos. Nos experimentos 3 e 4 os participantes foram divididos aleatoriamente entre as seguintes condições experimentais: (a) ordem dos elementos na seqüência e os 
subelementos determinados pelo experimentador; (b) ordem dos elementos na seqüência e subelementos escolhidos pelo participante na primeira metade da prática, e seqüência determinada pelo experimentador e subelementos escolhidos pelos participantes na segunda metade da prática. Em ambos os experimentos os grupos com prática na condição de maior liberdade apresentaram desempenho superior na adaptação.

Em conjunto, os resultados de Tani (1982) evidenciam que condições de maior liberdade na escolha da resposta favorecem a adaptação a novas situações. Ao mesmo tempo, indicam que um grau excessivo de liberdade na escolha da resposta pode dificultar a estabilização funcional. Sugerem, adicionalmente, a existência de um grau ótimo de liberdade na escolha da resposta.

Bastos (2007) retoma a investigação sobre a liberdade na escolha da resposta utilizando uma tarefa de timing coincidente seqüencial (Aparelho de timing coincidente em tarefas complexas - CORREAA \& TANI, 2004), que consistia em tocar uma seqüência de seis sensores de modo que o último toque correspondesse ao acendimento do último led em uma canaleta com 90 leds de acendimento seqüencial que simulam movimento. Para investigar os efeitos da liberdade na escolha da resposta frente a diferentes modificações na tarefa, Bastos (2007) realizou três experimentos. Os três tiveram condições experimentais definidas a partir da liberdade para compor a seqüência de seis toques nos sensores que compunham a resposta motora. Na condição SEM - sem liberdade na escolha da resposta - todo o seqüenciamento da tarefa (ordem dos toques nos sensores) foi definido pelo experimentador. Na condição MED - condição intermediária na liberdade de escolha da resposta - os dois primeiros toques e o último toque (sensor alvo) foram definidos pelo experimentador, com a ordem dos toques remanescentes sendo definida pelo participante. Na condição ALT - condição com maior liberdade na escolha da resposta - apenas o último toque foi determinado, com a ordem dos toques restantes escolhida pelos participantes.

Os três experimentos foram constituídos de duas fases: estabilização e adaptação. Na fase de estabilização os participantes praticavam a tarefa de acordo com a condição experimental até alcançarem um desempenho critério. Contudo, os experimentos diferiram quanto à modificação da tarefa na fase de adaptação. No 
experimento 1 foi empregada uma modificação perceptiva (velocidade do estímulo visual reduzida); no experimento 2 a modificação empregada foi efetora (nova seqüência determinada pelo experimentador); e, no experimento 3 , foi empregada uma modificação perceptivo-efetora (nova seqüência determinada pelo experimentador e velocidade do estímulo visual reduzida).

No experimento 1 não foi verificada diferença entre grupos frente à modificação perceptiva da tarefa. Assim, a liberdade na escolha da resposta não teve efeito na capacidade de adaptação dos indivíduos a uma modificação perceptiva após a estabilização do comportamento.

No experimento 2 houve indicativos de pior desempenho na adaptação para o grupo SEM, com aumento dos erros de execução no terceiro bloco e da magnitude do erro absoluto no quinto bloco da adaptação. Esse resultado sugere que a ausência de liberdade na escolha da resposta leva à formação de uma estrutura mais rígida, com maior dificuldade em adaptar-se a uma nova exigência motora da tarefa.

Por outro lado, no experimento 3, o grupo ALT exibiu maior erro absoluto e maior variabilidade no desempenho quando comparado aos outros grupos na fase de adaptação. Nesse caso, a maior liberdade na escolha da resposta levou a uma adaptação menos eficiente perante uma modificação nos aspectos perceptivo e efetor da tarefa.

Em relação ao conjunto de resultados, Bastos (2007) considera que as diferentes modificações da tarefa resultam em níveis distintos de perturbação, convergindo com os resultados de Tani (1995) e Ugrinowitsch (2003). O autor considera ainda que os resultados apresentam indícios da existência de graus ótimos de liberdade na escolha da resposta, mas que estes dependem do nível da perturbação. Ressalta ainda que a diferença entre os grupos não pode ser atribuída nesse caso a prejuízos no alcance da estabilidade, dada a utilização de critérios de desempenho e o número similar de tentativas dos grupos na estabilização.

Walter (2007), com base nas vantagens da possibilidade de controlar aspectos da prática, questiona se estruturas de prática que permitam ao aprendiz escolher a resposta ou a ordem de componentes que compõem a resposta trazem benefícios no processo adaptativo em aprendizagem motora. Para isso, a autora 
realizou um experimento que contrastou grupos de prática constante e constante seguida de aleatória, que em grande parte dos estudos realizados apresenta melhores resultados na adaptação, a grupos similares em que os participantes poderiam escolher entre diferentes respostas ou diferentes componentes da resposta. O experimento, realizado com crianças com média de idade de 10 anos, também utilizava uma tarefa de timing coincidente sequencial (CORRÊA; TANI, 2004). O experimento consistia de duas fases: estabilização e adaptação. $\mathrm{Na}$ estabilização, todos os grupos praticavam a tarefa até um critério de desempenho, a partir da qual realizavam mais 36 tentativas. Contudo, o tipo de prática realizado em cada uma das partes da fase de estabilização variava de acordo com a condição experimental. A fase de adaptação foi idêntica para todos os grupos, consistindo de 36 tentativas com uma nova seqüência e uma modificação na velocidade do estímulo visual.

O delineamento experimental consistia de 6 grupos. $O$ grupo de prática constante e o grupo de prática constante seguida de aleatória realizavam a tarefa com a(s) seqüência(s) determinada pelo experimentador durante toda a estabilização. O grupo de prática constante realizava uma única seqüência em ambas as partes da fase de estabilização, enquanto o grupo de prática constante seguida de aleatória realizava três seqüências diferentes em ordem aleatória após atingir o critério. Os grupos de prática constante com liberdade na escolha da seqüência e prática constante com liberdade na escolha da seqüência seguida de liberdade na escolha da seqüência tinham a possibilidade de escolher entre seqüências predeterminadas para realizar a resposta. $\mathrm{O}$ grupo de prática constante com liberdade na escolha da seqüência utilizava a seqüência escolhida em ambas as etapas da fase de estabilização, enquanto o grupo de prática constante com liberdade na escolha da seqüência seguida de liberdade na escolha da seqüência poderia escolher, após atingir o critério de desempenho, entre três seqüências idênticas às utilizadas no grupo de prática constante seguida de aleatória. Por fim, os grupos de prática constante com liberdade na escolha dos componentes que formam a seqüência e prática constante com liberdade na escolha dos componentes que formam a seqüência seguida de liberdade na escolha dos componentes que formam uma ou mais seqüências tinha a possibilidade de escolher a ordem dos elementos 
(toques) que compunham a resposta. O primeiro grupo deveria compor uma sequência escolhendo a ordem dos toques tendo apenas primeiro e o último toque determinados, utilizando a seqüência composta em ambas as etapas da fase de estabilização. Já o segundo realizava o mesmo procedimento na primeira parte da fase de estabilização, tendo a possibilidade de compor uma nova seqüência a cada tentativa após atingir o critério de desempenho.

Os resultados de Walter (2007) mostram que a prática constante com liberdade de escolha dos componentes que formam a seqüência apresentou 0 melhor desempenho na adaptação. O grupo foi mais preciso, na medida de erro absoluto, que o grupo de prática constante com liberdade na escolha da seqüência seguida de liberdade na escolha da(s) seqüência(s) no primeiro bloco da adaptação, que todos os outros grupos no segundo bloco e que todos os outros grupos com exceção do grupo de prática constante com liberdade de escolha da seqüência no terceiro bloco, além de reduzir a variabilidade do tempo total de movimento do primeiro para o último bloco da adaptação. Para a autora, embora a prática tenha sido realizada de forma constante em relação ao padrão de resposta, a possibilidade de escolher os elementos que compunham a resposta permitiu a aquisição de um padrão flexível Dessa forma, a prática constante, freqüentemente associada aos fatores relacionados à ordem, quando realizada em uma condição em que era possível escolher os componentes da resposta, permitiu o alcance da estabilidade num conjunto de soluções apropriadas (TANI, 1999) e ao mesmo tempo flexibilidade para adaptar-se a novas condições. A autora sugere ainda que os resultados corroboram as evidências de Tani (1982) e Bastos (2007) de uma pior adaptação para grupos sem liberdade na escolha da resposta, assim como algumas condições de liberdade na escolha da resposta não apresentarem benefícios para a adaptação. A síntese dos estudos investigando a liberdade na escolha da resposta está apresentada na TABELA 4.

TABELA 4 - Síntese dos estudos sobre liberdade na escolha da resposta no processo adaptativo em aprendizagem motora

\begin{tabular}{c|c|c|c|c}
\hline Estudo & $N$ & Grupos & Tarefa & $\begin{array}{c}\text { Resultados } \\
\text { (adaptação) }\end{array}$ \\
\hline
\end{tabular}




\begin{tabular}{|c|c|c|c|c|}
\hline Estudo & $N$ & Grupos & Tarefa & $\begin{array}{l}\text { Resultados } \\
\text { (adaptação) }\end{array}$ \\
\hline $\begin{array}{l}\text { Tani (1982) - } \\
\text { Experimento } 1\end{array}$ & 36 & $\begin{array}{l}\text { Ordem dos elementos na } \\
\text { seqüência e subelementos } \\
\text { escolhidos pelo participante [1]; } \\
\text { ordem dos elementos na } \\
\text { seqüência determinada pelo } \\
\text { experimentador e subelementos } \\
\text { escolhidos pelo participante [2]; } \\
\text { ordem dos elementos na } \\
\text { seqüência e subelementos } \\
\text { determinados pelo } \\
\text { experimentador [3]. }\end{array}$ & $\begin{array}{l}\text { Habilidades } \\
\text { seqüenciais do } \\
\text { basquetebol. }\end{array}$ & $\begin{array}{l}\text { [1] inferior aos } \\
\text { demais } \\
\text { grupos. }\end{array}$ \\
\hline $\begin{array}{l}\text { Tani (1982) - } \\
\text { Experimento } 2\end{array}$ & 60 & Idênticos ao experimento 1 & $\begin{array}{l}\text { Idêntica ao } \\
\text { experimento } 1\end{array}$ & $\begin{array}{l}\text { [1] superior } \\
\text { aos demais } \\
\text { grupos. }\end{array}$ \\
\hline $\begin{array}{l}\text { Tani (1982) - } \\
\text { Experimento } 3\end{array}$ & 24 & $\begin{array}{l}\text { Ordem dos elementos na } \\
\text { seqüência e os subelementos } \\
\text { determinados pelo } \\
\text { experimentador [1]; ordem dos } \\
\text { elementos na seqüência e } \\
\text { subelementos escolhidos pelo } \\
\text { participante na primeira metade } \\
\text { da prática, e seqüência } \\
\text { determinada pelo } \\
\text { experimentador e subelementos } \\
\text { escolhidos pelos participantes } \\
\text { na segunda metade da prática } \\
\text { [2]. }\end{array}$ & $\begin{array}{l}\text { Idêntica ao } \\
\text { experimento } 1\end{array}$ & $\begin{array}{l}\text { [2] superior a } \\
\text { [1]. }\end{array}$ \\
\hline $\begin{array}{l}\text { Tani }(1982)- \\
\text { Experimento } 4\end{array}$ & 40 & Idênticos ao experimento 3 & $\begin{array}{l}\text { Idêntica ao } \\
\text { experimento } 1\end{array}$ & $\begin{array}{l}\text { [2] superior a } \\
\text { [1]. }\end{array}$ \\
\hline $\begin{array}{l}\text { Bastos (2007) - } \\
\text { Experimento } 1\end{array}$ & 46 & $\begin{array}{l}\text { Sem liberdade na escolha da } \\
\text { resposta [1]; grau intermediário } \\
\text { de liberdade na escolha da } \\
\text { resposta [2]; grau alto de } \\
\text { liberdade na escolha da } \\
\text { resposta [3]. }\end{array}$ & $\begin{array}{l}\text { Timing } \\
\text { coincidente em } \\
\text { tarefas } \\
\text { complexas }\end{array}$ & $\begin{array}{l}\text { Sem } \\
\text { diferenças } \\
\text { entre grupos. }\end{array}$ \\
\hline $\begin{array}{l}\text { Bastos (2007) - } \\
\text { Experimento } 2\end{array}$ & 48 & Idênticos ao experimento 1 & $\begin{array}{l}\text { Idêntica ao } \\
\text { experimento } 1\end{array}$ & $\begin{array}{l}\text { Indicativos de } \\
\text { pior } \\
\text { desempenho } \\
\text { para [1]. }\end{array}$ \\
\hline $\begin{array}{l}\text { Bastos (2007) - } \\
\text { Experimento } 3\end{array}$ & 45 & Idênticos ao experimento 1 & $\begin{array}{l}\text { Idêntica ao } \\
\text { experimento } 1\end{array}$ & $\begin{array}{l}\text { Pior } \\
\text { desempenho } \\
\text { para [3]. }\end{array}$ \\
\hline
\end{tabular}




\begin{tabular}{|c|c|c|c|c|}
\hline Estudo & $N$ & Grupos & Tarefa & $\begin{array}{l}\text { Resultados } \\
\text { (adaptação) }\end{array}$ \\
\hline $\begin{array}{l}\text { Walter (em } \\
\text { preparação) }\end{array}$ & 120 & $\begin{array}{l}\text { Prática constante [1]; prática } \\
\text { constante seguida de aleatória } \\
\text { [2]; prática constante com } \\
\text { liberdade na escolha da } \\
\text { seqüência [3]; prática constante } \\
\text { com liberdade na escolha da } \\
\text { seqüência seguida de liberdade } \\
\text { na escolha da seqüência [4]; } \\
\text { prática constante com liberdade } \\
\text { na escolha dos componentes } \\
\text { que formam a seqüência [5]; } \\
\text { Prática constante com liberdade } \\
\text { na escolha dos componentes } \\
\text { que formam a seqüência } \\
\text { seguida de liberdade na } \\
\text { escolha dos componentes que } \\
\text { formam uma ou mais } \\
\text { seqüências [6]. }\end{array}$ & $\begin{array}{l}\text { Timing } \\
\text { coincidente em } \\
\text { tarefas } \\
\text { complexas }\end{array}$ & $\begin{array}{l}\text { Melhor } \\
\text { desempenho } \\
\text { para [5] }\end{array}$ \\
\hline
\end{tabular}

Em conjunto, como os resultados dos estudos realizados podem ser interpretados a partir do modelo teórico adotado? O auto-controle de diferentes aspectos da aprendizagem pode permitir ao aprendiz regular e enfrentar a incerteza ainda durante o processo de estabilização. O papel construtivo da incerteza tem sido associado, por exemplo, aos benefícios de baixas freqüências de conhecimento de resultados (CHIVIACOWSKY, 2000; MEIRA JR., 2005). O controle pelo aprendiz de variáveis da aprendizagem pode diminuir a ênfase na redução da variabilidade resultante do controle destes aspectos pelo experimentador. Tal redução excessiva na variabilidade, conforme apontam evidências anteriores (e.g. TANI, 1989), pode levar a uma rigidez excessiva que dificulta a adaptação a novas situações. A capacidade de enfrentar a incerteza pode trazer benefícios na adaptação da habilidade adquirida a diferentes situações ou tarefas motoras e mesmo favorecer a mudança para níveis de complexidade superiores.

Por outro lado, há indícios da existência de níveis ótimos de liberdade de escolha para a adaptação bem sucedida. Bund e Wiemeyer (2004) reconhecem o aumento da demanda cognitiva associada ao auto-controle. No referencial teórico adotado, graus excessivos de liberdade na escolha da resposta - relacionados a 
grande incerteza ou redução insuficiente da variabilidade de desempenho - podem dificultar a estabilização funcional (TANI, 1982).

Contudo, uma variável essencial no estudo da liberdade na escolha da resposta na aprendizagem motora não tem sido freqüentemente abordada: o nível de estabilização. Mais especificamente, não foram realizadas investigações sobre os efeitos da liberdade na escolha da resposta na prática após a estabilização inicial do desempenho. Se a partir dos estudos de Bastos (2007), Tani (1982) e Walter (2007) há um mapeamento relevante de diversas interações dos efeitos da liberdade na escolha da resposta, ainda não há estudos que investiguem a interação entre a liberdade na escolha da resposta e o nível de estabilização do comportamento.

Como visto, a estabilização do desempenho é um pré-requisito para a adaptação bem sucedida, e a estabilização num nível superior de desempenho pode facilitar a adaptação frente a modificações na tarefa com maiores demandas (TANI, 1995; UGRINOWITSCH, 2003). A partir da estabilização do desempenho, as restrições a níveis mais altos de incerteza ou instabilidade - mais especificamente, altos níveis de liberdade de escolha - em razão de sua capacidade de dificultar a estabilização funcional inicial podem deixar de fazer sentido. A consideração da interação entre a liberdade na escolha da resposta e a prática após a estabilização gera diversas indagações. Há nível ótimo de liberdade na escolha da resposta quando a prática é conduzida após a estabilização inicial do desempenho? Quais seriam os níveis mais adequados para os períodos de prática antes e após a estabilização inicial do desempenho para uma adaptação bem-sucedida? O presente estudo visa responder a estas questões.

Investigar o efeito da liberdade na escolha da resposta em diferentes momentos do processo de estabilização, no processo adaptativo em aprendizagem motora.

Com base no objetivo geral apresentado, propõe-se os seguintes objetivos específicos: 
(1) Investigar se há efeito da liberdade na escolha da resposta no processo adaptativo em aprendizagem motora quando a prática vai além da estabilização inicial do desempenho;

(2) Investigar se há efeito da liberdade na escolha da resposta no processo adaptativo em aprendizagem motora nos diferentes momentos do processo de estabilização (antes e após a estabilização inicial do desempenho).

4

MÉTODO

4.1 Participantes

Foram incluídos na análise 135 adultos universitários com média de idade de $22( \pm 4,1)$ anos, de ambos os gêneros, alunos de diferentes cursos do Campus Fátima da Universidade do Vale do Sapucaí e da Escola de Educação Física e Esporte da Universidade de São Paulo. Foram considerados como critérios de exclusão a presença de algum transtorno motor ou de visão (autodeclarado) não corrigido. Ainda, os participantes que alcançaram o desempenho critério em menos de 10 tentativas ou não conseguiram alcançá-lo ao final de 100 tentativas realizaram o experimento normalmente mas foram excluídos da amostra. Os participantes foram conduzidos a uma sala previamente preparada, onde foram informados pelo experimentador sobre seus direitos como voluntários de pesquisa de acordo com a Declaração de Helsinque. A coleta de dados foi individual, realizada após a obtenção do consentimento informado. O presente estudo foi aprovado pelo Comitê de Ética da Comissão de Ética e Pesquisa da Escola de Educação Física e Esporte da Universidade de São Paulo (Protocolo $n^{\circ}$ 2008/14)

\subsection{Procedimentos e tarefa}

A tarefa consistiu em realizar cinco toques em seqüência no Aparelho de timing coincidente em tarefas complexas (CORRÊA; TANI, 2004; Patente P.I. 0.403.1330-04) de modo a coincidir o último toque com a chegada de um estímulo visual. O Aparelho de timing coincidente em tarefas complexas é composto por uma 
mesa de resposta onde são dispostos sensores e uma canaleta de $200 \mathrm{~cm}$ sobre a qual estão dispostos em linha reta 90 leds. $\mathrm{O}$ aparelho dispõe ainda de um software capaz de controlar o acendimento dos leds e registrar o tempo de reação, o tempo dos toques nos sensores e a seqüência de sensores tocados. Os sensores acendemse e apagam-se sucessivamente criando a ilusão de movimento, cuja velocidade pode ser controlada, contando ainda com um led de alerta para o início da tentativa. O software do aparelho também permite controlar a faixa temporal em que o movimento é considerado correto, além do tempo de exibição do conhecimento de resultados e o tempo entre tentativas. O objetivo da tarefa é tocar os sensores após o início do movimento de modo que o último toque coincida com o acendimento do último led. Nesse sentido o aparelho também conta com um dispositivo para fornecimento de conhecimento de resultados com cinco luzes abaixo das quais podem ser lidas as palavras: "muito antes", "um pouco antes", "certo", "um pouco depois" e "muito depois", que correspondem ao momento do último toque realizado em relação ao acendimento do último led. No presente estudo, o último toque na faixa de $\pm 30 \mathrm{~ms}$ foi considerado "correto", na faixa de $\pm 31 \mathrm{~ms}$ a $\pm 60 \mathrm{~ms}$ "um pouco antes" ou "um pouco depois" e além de \pm 60 ms "muito antes" ou "muito depois".

\subsection{Delineamento}

As condições experimentais seguiram o padrão utilizado por Bastos (2007), ou seja, compreenderam três níveis de liberdade na escolha da resposta, operacionalizados através do número de toques, dentre os seis toques disponíveis, cuja ordem pode ser escolhida pelo participante. $\mathrm{Na}$ condição sem liberdade na escolha da resposta (SEM) toda a ordem da seqüência foi definida pelo experimentador. A seqüência definida equivaleu à mais utilizada pelos sujeitos do grupo com maior liberdade de escolha dos experimentos de Bastos (2007). $\mathrm{Na}$ condição de liberdade na escolha da resposta intermediária (MED) somente os dois primeiros toques e o último toque (sensor-alvo) foram os definidos pelo experimentador. Por fim, a condição de maior liberdade de escolha (ALT) teve apenas o último toque determinado. Uma representação da tarefa experimental é apresentada na FIGURA 1 (sensor-alvo em preto, sensor de tempo de reação em 
branco). Uma representação semelhante foi apresentada ao participante de acordo com a condição experimental em que era realizada a prática e permaneceu visível durante toda a participação no experimento.

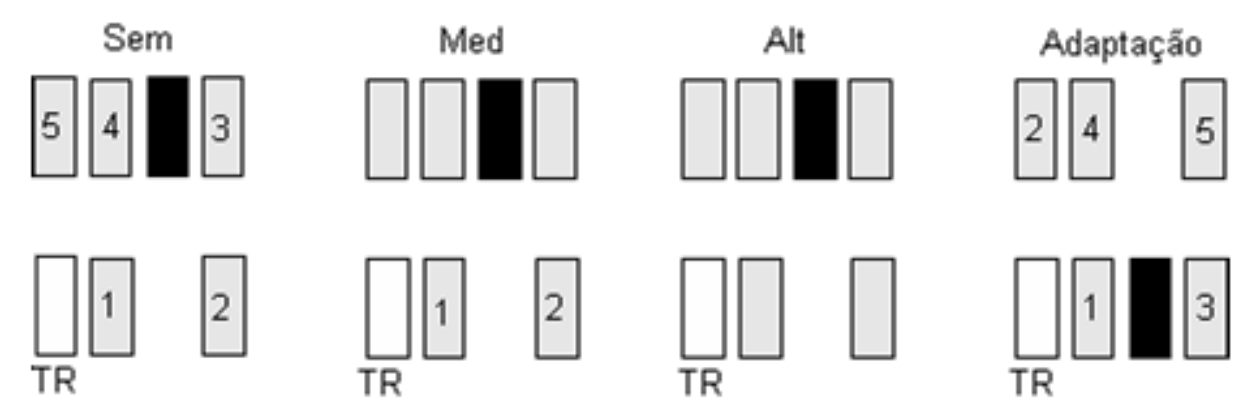

FIGURA 1 - Representação esquemática das condições de realização da tarefa (adaptado de Bastos, 2007)

O experimento consistiu de duas fases: estabilização e adaptação. A fase de estabilização foi dividida em duas partes. Na primeira parte, o participante praticou a tarefa com o estímulo em velocidade constante de $1,33 \mathrm{~m} / \mathrm{s}$ (a mesma utilizada por BASTOS, 2007). de acordo com a condição experimental, até conseguir realizar três tentativas consecutivas na faixa de erro de $\pm 30 \mathrm{~ms}$, a partir da qual o comportamento é considerado estabilizado (UGRINOWITSCH, 2003). Na segunda parte da fase de estabilização o participante continuou a prática por mais 36 tentativas, porém mantendo ou alterando a condição experimental de acordo com o grupo para o qual foi alocado. Nove grupos foram constituídos a partir das combinações possíveis entre as três condições nas duas partes da fase de estabilização (SEM-SEM; SEM-MED; SEM-ALT; MED-SEM, MED-MED; MED-ALT; ALT-SEM; ALT-MED; ALT-ALT). Uma síntese do delineamento experimental é apresentada na TABELA 5. 
TABELA 5 - Delineamento e condições experimentais

\begin{tabular}{|c|c|c|c|}
\hline \multirow[t]{2}{*}{ Grupo } & \multicolumn{2}{|c|}{ Fase de Estabilização } & Fase de Adaptação \\
\hline & Até critério & 36 tentativas & 30 tentativas \\
\hline SEM-SEM & SEM & SEM & Idêntica para todos \\
\hline SEM-MED & SEM & MED & os grupos: \\
\hline SEM-ALT & SEM & ALT & \\
\hline MED-SEM & MED & SEM & Alteração na \\
\hline MED-MED & MED & MED & velocidade do \\
\hline MED-ALT & MED & $\mathrm{ALT}$ & estímulo \\
\hline ALT-SEM & $\mathrm{ALT}$ & SEM & \\
\hline ALT-MED & ALT & MED & Alteração na \\
\hline ALT-ALT & $\mathrm{ALT}$ & $\mathrm{ALT}$ & seqüência de toques \\
\hline
\end{tabular}

$\mathrm{Na}$ fase de adaptação foram modificadas a velocidade do estímulo e a seqüência de toques nos sensores, que foram iguais para todos os grupos. A velocidade foi reduzida para $1,17 \mathrm{~m} / \mathrm{s}$, pois em estudos anteriores sua redução gerou maior perturbação do que o aumento da velocidade (ARAUJO; BASTOS; FREUDENHEIM, 2004) e a seqüência de toques empregada foi definida pelo experimentador e não praticada anteriormente. A modificação de ambos os aspectos - perceptivo e motor - tem mostrado provocar perturbações maiores do que seu emprego isolado (BASTOS, 2007; UGRINOWITSCH, 2003) e foi empregada em razão do aumento na capacidade de resistir a perturbações com a continuidade da estabilização (UGRINOWITSCH, 2003) Nesta fase não foi fornecido, ainda, o conhecimento de resultados.

Os participantes foram alocados aos grupos alternadamente, em uma seqüência pré-determinada, até incluir 15 participantes por grupo. Após o consentimento informado, foi fornecida instrução aos participantes sobre a realização da tarefa na condição experimental da primeira parte da fase de estabilização Informação adicional foi oferecida quando houve mudança na condição experimental, da primeira parte para a segunda parte da fase de estabilização e da segunda parte da fase de estabilização para a fase de adaptação. Após a coleta, os participantes foram informados sobre os objetivos do estudo e puderam fazer perguntas sobre outros aspectos do estudo. Um participante na condição inicial SEM, cinco participantes na condição inicial MED e cinco participantes na condição inicial ALT alcançaram o desempenho critério antes de 10 tentativas. Dez participantes na 
condição inicial ALT, um participante na condição inicial MED e nove participantes na condição inicial SEM não foram capazes de atingir o desempenho critério. Em ambos os casos, tais participantes realizaram normalmente o restante do experimento, passando à fase de adaptação, mas foram excluídos da amostra, não sendo computados no número mínimo de participantes por grupo.

\subsection{Medidas}

A partir dos registros dos toques nos sensores, foram calculadas três medidas de desempenho e quatro medidas complementares. Os erros de execução, o erro absoluto, e o erro variável referem-se ao desempenho no alcance da meta. $O$ erro de execução reflete o número de tentativas em que o padrão de toques não foi realizado corretamente (seqüência incompleta ou ordem incorreta) ou não foi executado. $\mathrm{O}$ erro absoluto e o erro variável são medidas amplamente utilizadas em aprendizagem motora, e refletem, respectivamente, a precisão e a consistência no alcance da meta. No presente estudo, foram calculadas a partir do intervalo de tempo entre o acendimento do último led e o toque no sensor-alvo.

A variabilidade da macroestrutura a variabilidade da microestrutura, o número de tentativas necessárias para se alcançar o critério de estabilização e a variabilidade do seqüenciamento foram utilizadas como medidas complementares. A variabilidade da macroestrutura deriva da proporção de tempo entre os toques e refere-se ao padrão da interação entre os componentes da tarefa, e foi calculada a partir da média do desvio-padrão dos tempos de movimento relativos. A variabilidade da microestrutura deriva dos tempos de movimento dos toques e refere-se aos componentes da tarefa em si, sendo calculada a partir da média do desvio-padrão dos tempos de movimento absolutos.

O número de tentativas necessário ao alcance do critério de estabilização representa a eficiência na estabilização funcional do comportamento. Por sua vez, a variabilidade do seqüenciamento representa a manutenção ou modificação da seqüência de toques empregada nas condições em que houve possibilidade de variar a seqüência (MED e ALT) e foi calculada a partir da média da razão entre o número de mudanças na ordem dos toques realizados quando comparados à última 
tentativa válida (de 0 a 5) entre as possíveis (5), sendo apresentada para fins de clareza em forma de porcentagem (multiplicadas por 100).

Todas as medidas foram calculadas a partir de blocos de 10 tentativas.

\subsection{Análise}

Após a inspeção inicial dos dados, as medidas derivadas foram calculadas e os valores para blocos de 10 tentativas foram organizados para entrada nos pacotes estatísticos utilizados (SPSS 13, SPSS Inc. e STATISTICA 7.0, Statsoft Inc.). Foram considerados para análise o primeiro bloco da primeira parte da fase de estabilização (as primeiras 10 tentativas de prática), o primeiro e o último bloco da segunda parte da estabilização (primeiras 10 tentativas após o alcance do desempenho critério e últimas 10 tentativas da fase de estabilização) e os três blocos da fase de adaptação. Os dados ausentes - missing values - foram substituídos pela média de todos os participantes dos 9 grupos no bloco, com substituição de 6 valores $(0,13 \%$ do total de dados) (ANEXO IX). Em seguida, os outliers extremos foram detectados. Apenas um extremo por grupo por bloco em cada medida considerada foi substituído, de acordo com o método acima, resultando em 64 substituições $(1,44 \%$ do total de dados) (ANEXO X).

Após a análise descritiva dos dados, foi realizada a checagem dos pressupostos para realização de análises paramétricas. Dado o número mínimo de 15 participantes por grupo e a natureza escalar das medidas, assumiu-se a distribuição normal dos dados. Em seguida, a homogeneidade de variância foi verificada por meio do teste de Levene. Nos casos em que houve violação do pressuposto da homogeneidade de variância, a variância dos grupos na medida em questão e a razão entre a maior e a menor variância foram calculadas. Exceto em dois casos (erro absoluto no terceiro bloco da fase de adaptação e erro variável no terceiro bloco da fase de adaptação nas análises para grupos - ver abaixo), a razão não excedeu a razão recomendada (PEAT; BARTON, 2005). A ANOVA foi empregada em virtude de sua robustez a violações moderadas da homogeneidade de variância (VINCENT, 1999). Portanto, a análise inferencial foi realizada por meio de análises de variância (ANOVA) de dois fatores (Grupos X Blocos) com medidas 
repetidas no segundo fator, para os blocos da fase de estabilização, e ANOVAs de dois fatores com medidas repetidas para o último bloco da fase de estabilização e os três blocos da fase de adaptação. Para todas as análises foi utilizada, quando necessário, a correção de Greenhouse-Geisser para o pressuposto da esfericidade (homogeneidade de variância e de covariância), com consequente ajuste nos graus de liberdade empregados na análise.

Foram também realizadas ANOVAs a partir do desempenho nos três blocos da fase de adaptação agrupando os participantes a partir da prática realizada até o critério, desconsiderando a condição posterior. Assim, foram agrupados todos os 45 participantes que iniciaram a prática na condição ALT, todos os 45 participantes que iniciaram a prática na condição MED e os 45 participantes que iniciaram a prática na condição SEM, compondo uma ANOVA de dois fatores (Início $X$ Blocos) com medidas repetidas no segundo fator. Ainda, foram realizadas análises semelhantes para as medidas empregadas considerando apenas a condição de prática realizada após o alcance do desempenho critério, isto é, agrupando os participantes a partir da condição de prática realizada na segunda parte da fase de estabilização, ignorando a condição de prática realizada anteriormente. Neste caso também foram realizadas ANOVAs de dois fatores (Fim X Blocos) com medidas repetidas no segundo fator, considerando também apenas o desempenho na fase de adaptação. O objetivo destas análises complementares foi melhor discernir o efeito da prática antes e após o alcance do desempenho critério no desempenho na fase de estabilização, de acordo com um dos objetivos específicos do estudo. Para todas as ANOVAs foi utilizado como post hoc o teste de Tukey HSD.

Para duas medidas (tentativas até o alcance do critério e variações no sequenciamento) foram realizadas análises diferentes das descritas acima, pois as medidas em questão se referem apenas à fase de estabilização. No caso da medida do número de tentativas até alcance do critério, há apenas um valor por participante, e em conseqüência foi realizada uma ANOVA de um fator (Grupo) utilizando estes valores agrupados por grupo. Para a medida variações do seqüenciamento, há um valor para cada bloco de tentativas na fase de estabilização. Entretanto, em conseqüência da ausência de variações no sequenciamento dos grupos que realizaram a prática na condição SEM, a disparidade entre tais grupos e os demais 
no que tange à homogeneidade de variância e à variância em si foi superior ao recomendado para a realização de testes paramétricos. Em virtude dessas violações, foram utilizados testes não paramétricos na análise desta variável. Mais especificamente, foi realizada uma ANOVA de Kruskal-Wallis para cada um dos blocos de tentativas da fase de estabilização empregando como teste post-hoc o teste U de Mann-Whitney.

\section{RESULTADOS}

5.1

\section{Erro absoluto}

É possível observar na FIGURA 2 que a média do erro absoluto dos grupos apresenta maior disparidade no início da prática, isto é, no primeiro bloco de tentativas da fase de estabilização, com destaque para um maior erro nos grupos SEM-SEM e SEM-ALT. Já nos blocos seguintes da fase de estabilização todos os grupos apresentam redução do erro em relação ao bloco inicial.

A análise inferencial não detectou diferenças entre grupos $[F(8 ; 126)=$ $1,48 ; p=0,16]$ ou interação $[F(8,50 ; 133,98)=1,79 ; p=0,07]$, assinalando diferenças apenas entre blocos $[F(1,06 ; 133,98)=69,51 ; p<0,001]$, localizadas pelo teste posthoc entre o primeiro bloco de tentativas e os demais blocos da fase de estabilização ( $p<0,001$ em ambas as comparações).

Analisando as médias do erro absoluto na adaptação se observa que todos os grupos apresentaram aumento de erro do último bloco da fase de estabilização para o primeiro bloco da fase de adaptação, com destaque para o menor erro nos grupos MED-MED e ALT-MED. Ainda, todos os grupos foram capazes de reduzir a magnitude do erro do primeiro bloco da fase de adaptação para os blocos seguintes, porém sem alcançar desempenho semelhante ao obtido no final da fase de estabilização, o que sugere que a modificação perceptivo-motora na tarefa foi capaz de provocar alterações no desempenho a despeito da quantidade de prática realizada.

Todavia, as diferenças entre grupos na fase de adaptação não foram confirmadas pela ANOVA, [Grupo: $F(8 ; 126)=1,22 ; p=0,29$; Grupo X Blocos: 
$F(12,73 ; 200,53)=1,03 ; p=0,41]$, que apontou diferenças discerníveis estatisticamente apenas entre blocos $[F(1,59 ; 200,53)=43,50 ; p<0.001]$. O post-hoc realizado para o fator Blocos localizou as diferenças entre o último bloco da estabilização e os demais blocos da adaptação ( $p<0.001 \mathrm{em}$ todas as comparações) e entre o primeiro bloco da adaptação e o segundo e terceiro blocos da mesma ( $p<0,001$ em ambos os casos), o que corrobora as observações da análise descritiva relacionadas ao aumento inicial do erro do último bloco da fase de estabilização para o primeiro bloco da adaptação e à redução do erro após o primeiro bloco da adaptação.

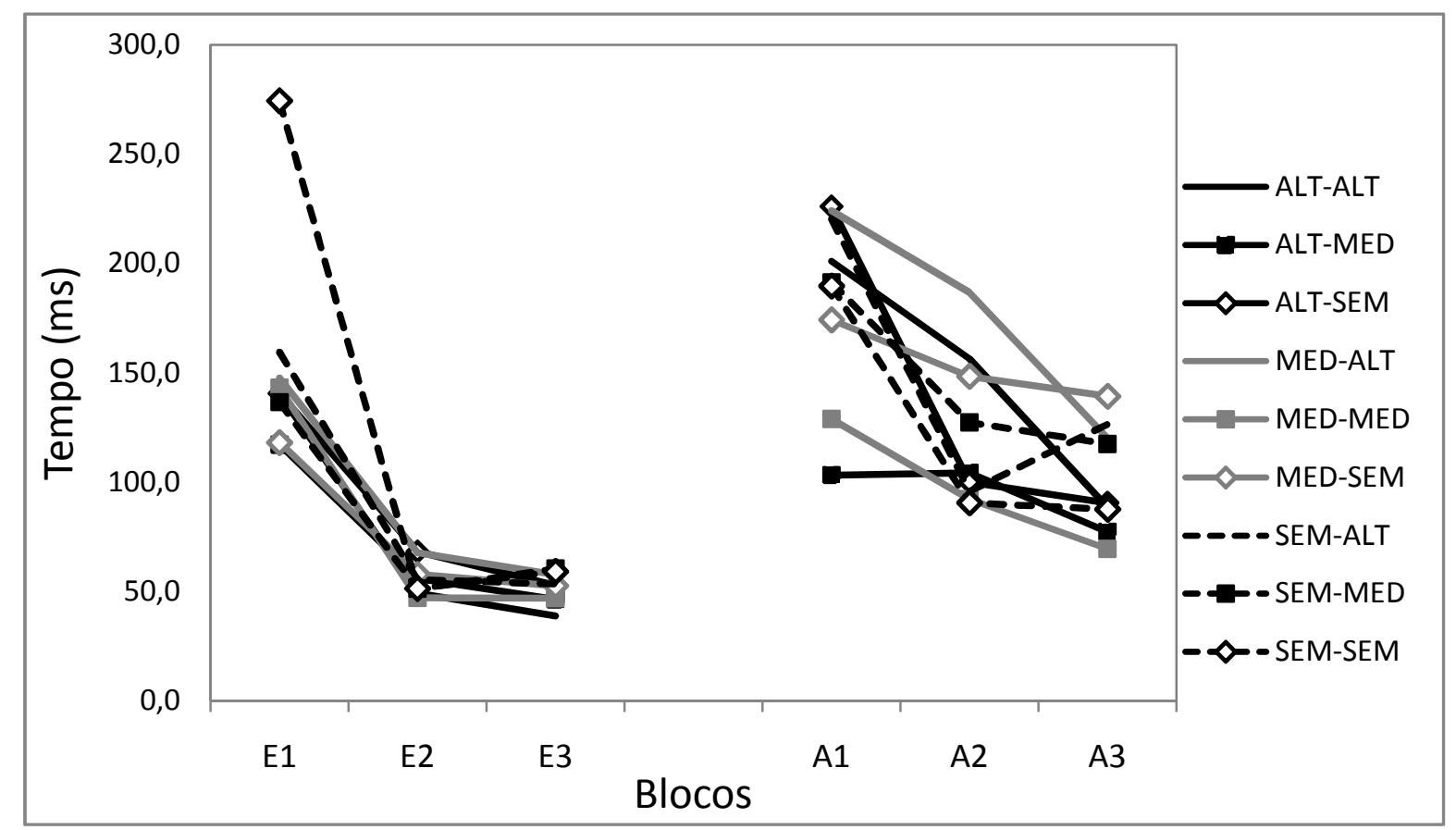

FIGURA 2 - Média do erro absoluto dos grupos ALT-ALT, ALT-MED, ALT-SEM, MED-ALT, MED-MED, MED-SEM, SEM-ALT, SEM-MED e SEM-SEM na fase de estabilização (E1, E2 e E3) e na fase de adaptação (A1, A2 e A3) por blocos de dez tentativas.

O desempenho na fase de adaptação em razão da condição de prática no início da fase de estabilização (FIGURA 3) foi semelhante para as condições iniciais ALT e MED, com a tendência de diminuição do erro já apontada na análise dos grupos Porém, o erro na condição inicial sem parece se manter do segundo para o terceiro bloco. Os resultados da análise inferencial não corroboram a análise 
descritiva, não apontando diferenças detectáveis no erro absoluto na adaptação em conseqüência das condições iniciais [Início: $F(2 ; 132)=0,30 ; p=0,73$; Início $X$ Blocos: $F(2,68 ; 177,08)=1,19 ; p=0,31$ ] e detectando diferenças no fator Blocos $[F(1,34 ; 177,08)=22,86 ; p<0,001]$, localizadas pelo post-hoc entre o primeiro bloco da adaptação e os blocos seguintes ( $p<0,001$ para ambas as comparações).

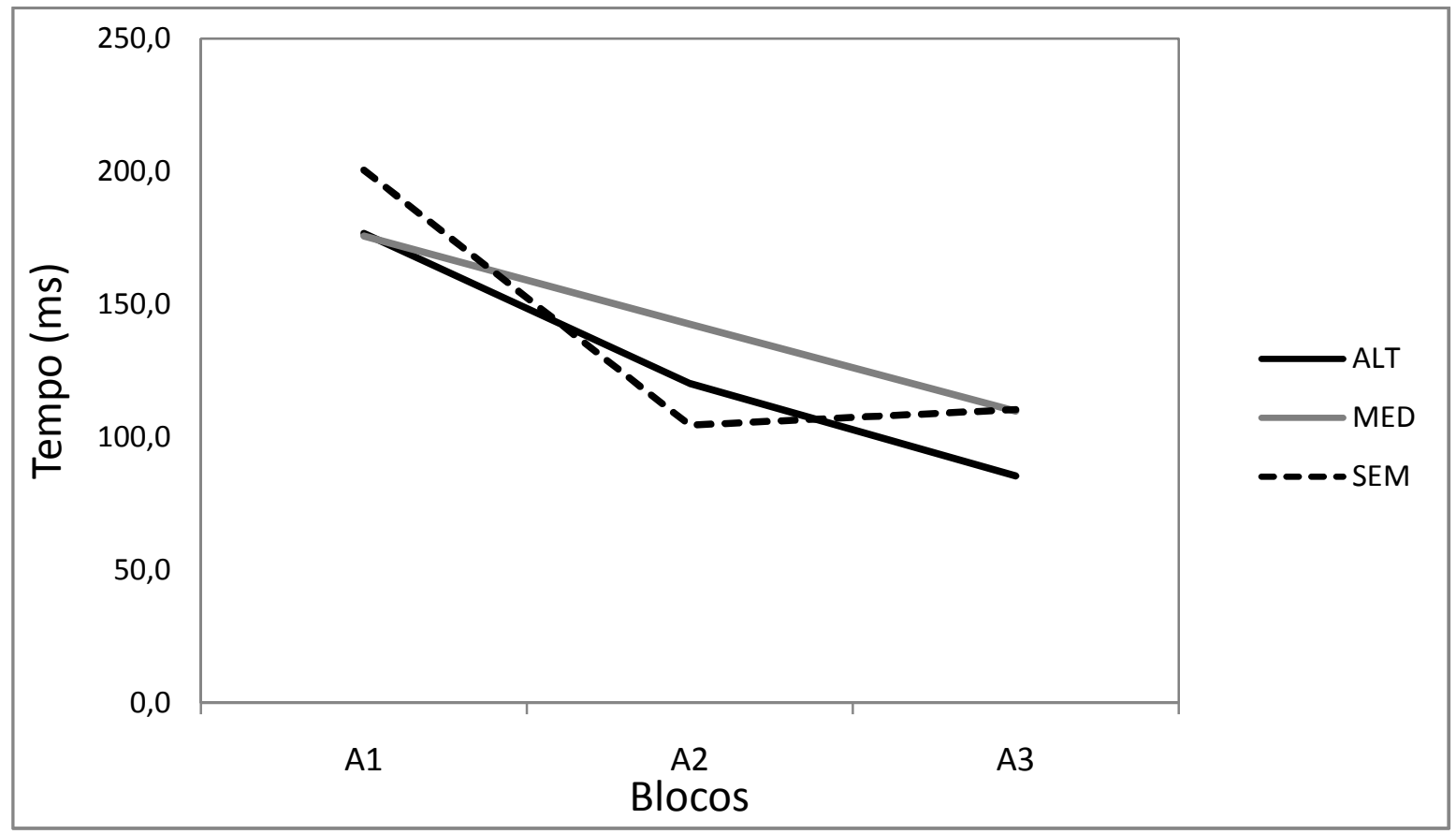

FIGURA 3 - Média do erro absoluto na fase de adaptação (A1, A2 e A3) por condição do início da fase de estabilização (ALT, MED e SEM) por blocos de dez tentativas.

O erro absoluto na adaptação em razão da condição no final da fase de estabilização (FIGURA 4) também mostra redução do erro ao longo da fase de adaptação, independentemente da prática realizada no final da estabilização. Além disso, os participantes que praticaram na condição MED no final da estabilização apresentam erro inferior em relação aos demais grupos.

Todavia, os resultados da análise inferencial não confirmam totalmente estas observações. A análise inferencial aponta como marginal a diferença no erro absoluto por condição do final da prática [Fim: $F(2 ; 132)=2,64 ; p=0,07]$, além de apontar diferença entre blocos [Blocos: $F(1,35 ; 179,45)=22,81 ; p<0,001$ ], localizada novamente entre o primeiro bloco da adaptação e os demais ( $p<0,001$ 
em ambos os casos). Não foi detectada interação [Fim X Blocos: $F(2,71 ; 179,45)=$ 1,$06 ; p=0,36$ ].

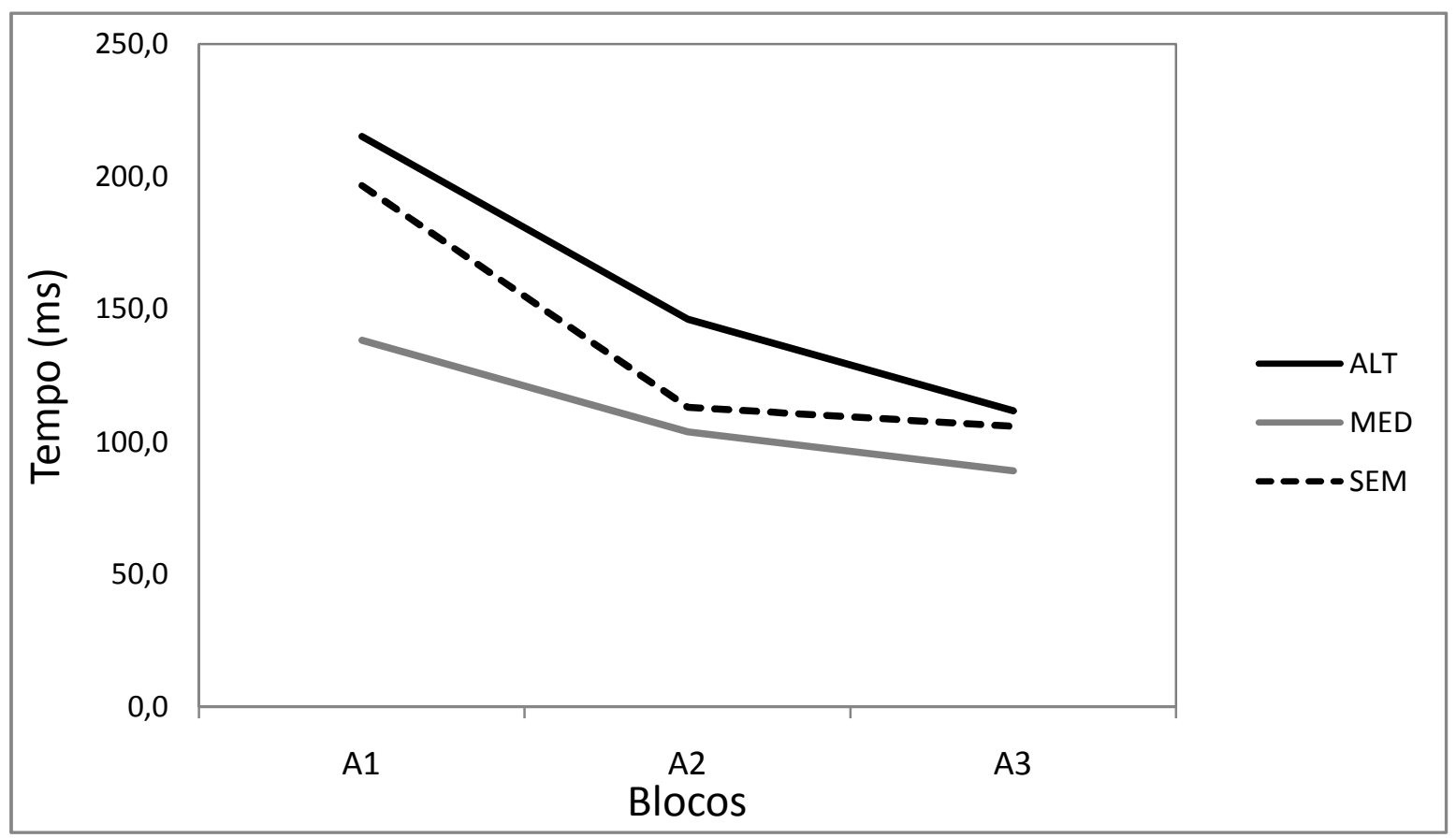

FIGURA 4 - Média do erro absoluto na fase de adaptação (A1, A2 e A3) por condição do final da fase de estabilização (ALT, MED e SEM) por blocos de dez tentativas.

\section{$5.2 \quad$ Erros de execução}

A FIGURA 5 apresenta a média de erros de execução por bloco dos diferentes grupos. De forma geral os grupos foram capazes de reduzir o número de tentativas erradas do primeiro para o segundo bloco da fase de estabilização, mas mantiveram ou aumentaram o número do segundo para o terceiro bloco, com exceção dos grupos ALT-MED, MED-MED e ALT-SEM, que diminuiram os erros de execução em todos os blocos além de apresentar um menor número de erros de execução no primeiro e último blocos (E1 e E3). É possível observar que no início da prática (primeiro bloco da fase de estabilização) os grupos que iniciaram a prática na condição SEM (SEM-ALT, SEM-MED e SEM-SEM) apresentam um número maior de erros de execução comparados aos demais grupos, porém nos blocos de tentativas 
após o alcance do desempenho critério os três grupos passam a ter número de erros próximo ao dos demais grupos.

Contudo, a análise inferencial confirma apenas os resultados referentes à melhora do desempenho de todos os grupos ao longo dos blocos $[F(1,79 ; 226,71)=$ 26,64; $p<0,001]$ com o teste post-hoc localizando a diferença entre o primeiro bloco da adaptação e os demais ( $p<0,001$ nas duas comparações). Assim, não foi detectada diferença entre grupos [Grupo: $F(8 ; 126)=1,29 ; p=0,25$; Grupo X Blocos: $F(14,39 ; 226,71)=1,30 ; p=0,20]$.

Na transição do último bloco da fase de estabilização para o primeiro bloco de adaptação todos os grupos apresentaram aumento observável no número de erros de execução, com redução no número de erros ao longo dos blocos da adaptação, em comportamento similar ao observado na medida de erro absoluto. Entre os grupos pode-se destacar o bom desempenho do grupo ALT-MED que se manteve entre os grupos com melhor desempenho em todos os blocos e o grupo MED-ALT que apresentou médias de erros de execução superiores aos demais grupos durante toda a adaptação.

Os resultados da análise inferencial corroboram parcialmente as observações da análise descritiva, detectando apenas a diferença entre blocos $[F(2,43 ; 306,86)=32,11 ; p<0,001]$, localizada pelo post-hoc entre o último bloco da fase de estabilização e todos os blocos da fase de adaptação ( $p<0,001$ nas comparações entre E3 e A1 e E3 e A2; p < 0,01 na comparação entre E3 e A3) e entre o primeiro bloco da fase adaptação e os demais blocos da mesma fase ( $p<$ 0,001 em ambas as comparações). O resultado confirma o aumento no número de erros de execução da fase de estabilização para a fase de adaptação e a redução do erro ao longo da última. Porém, as diferenças observadas entre o desempenho dos grupos não foram confirmadas [Grupo: $F(8 ; 126)=1,46 ; p=0,17$; Grupo X Blocos: $F(19,48 ; 306,86)=1,06 ; p=0,38]$. 


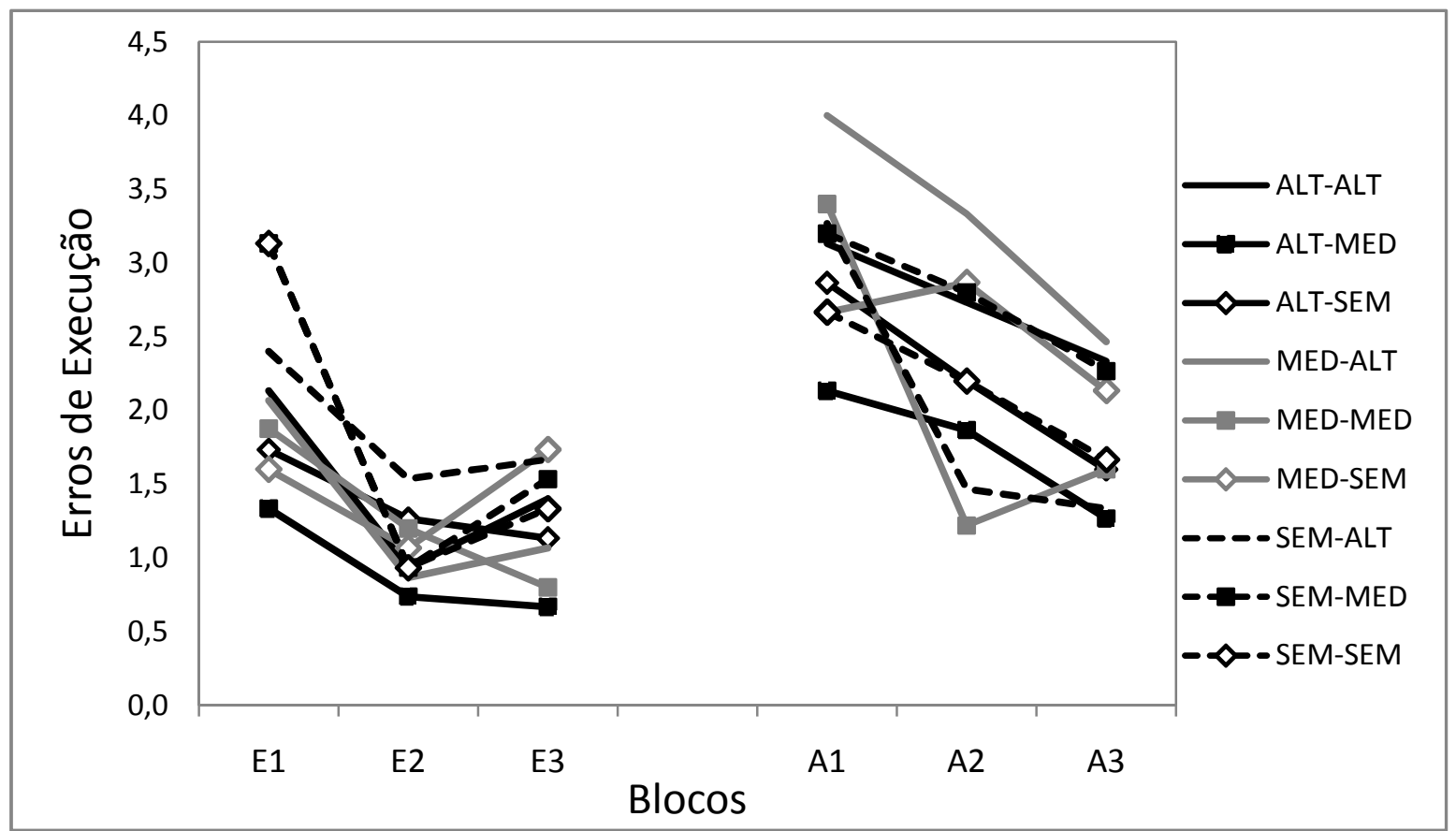

FIGURA 5 - Média dos erros de execucão dos grupos ALT-ALT, ALT-MED, ALTSEM, MED-ALT, MED-MED, MED-SEM, SEM-ALT, SEM-MED e SEMSEM na fase de estabilização (E1, E2 e E3) e na fase de adaptação (A1, A2 e A3) por blocos de dez tentativas.

A média dos erros de execução na fase de adaptação a partir da condição (ALT, MED ou SEM) no início da prática (FIGURA 6) não apresenta grandes variações em conseqüência da condição de prática realizada no início da fase de estabilização, denotando apenas a redução nos erros de execução ao longo da fase de adaptação. A análise inferencial valida as observações da análise descritiva, não apontando diferença entre condições iniciais [Início: $F(2 ; 132)=0,81 ; p=0,44$ ] ou interação [Início X Blocos: $F(3,35 ; 221,18)=0,35 ; p=0,80$ ]. A redução do número de erros de execução ao longo da fase de adaptação foi confirmada pela ANOVA $[F(1,67 ; 221,18)=22,29 ; p<0,001]$, sendo as diferenças localizadas pelo post-hoc entre $o$ primeiro bloco e os dois blocos seguintes $(p<0,001$ em ambas as comparações) e entre o segundo e o terceiro blocos $(p=0,03)$. 


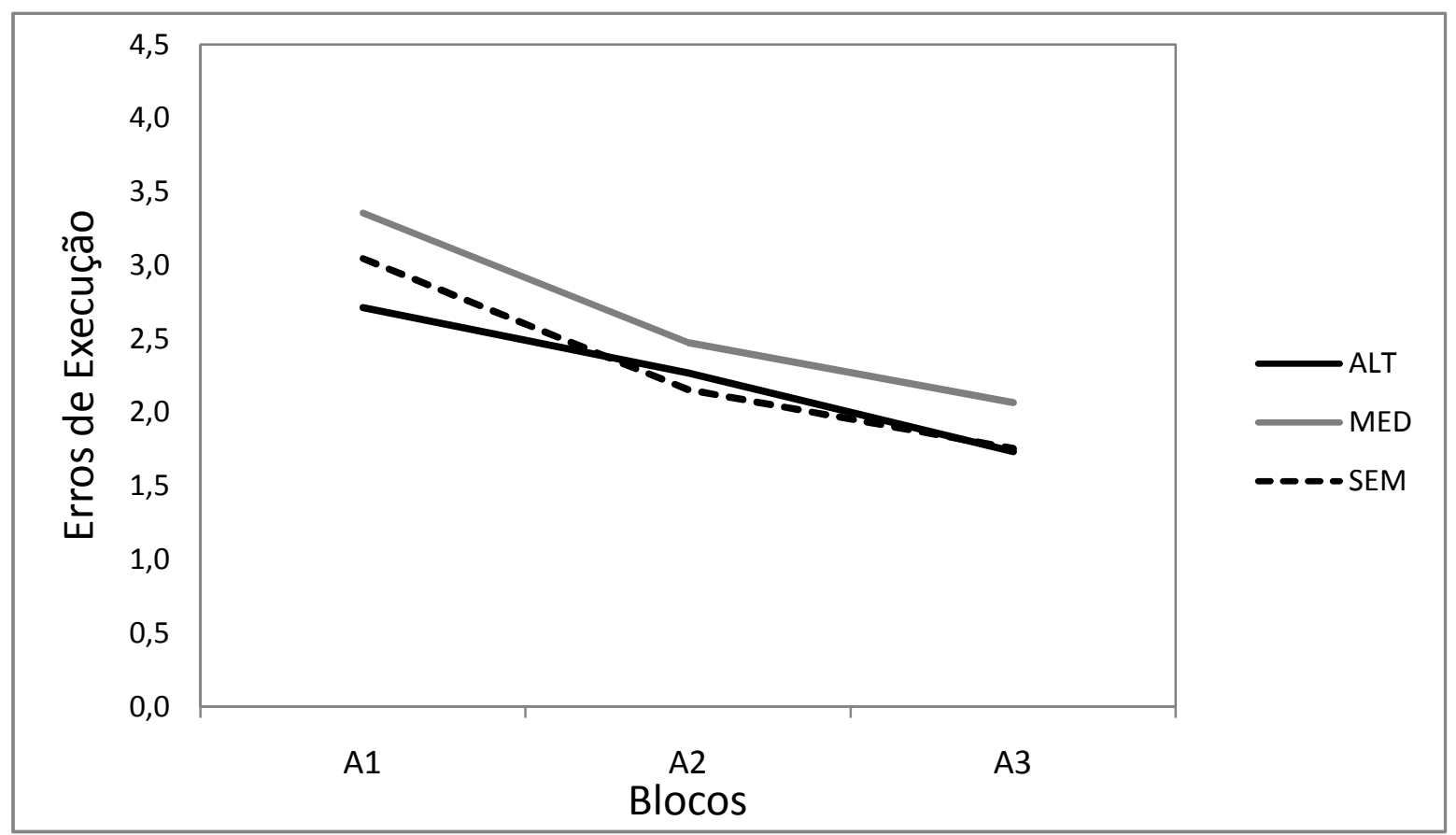

FIGURA 6 - Média dos erros de execução na fase de adaptação (A1, A2 e A3) por condição do início da fase de estabilização (ALT, MED e SEM) por blocos de dez tentativas.

Os erros de execução na adaptação também não mostram influência evidente da condição de prática do final da fase de estabilização (FIGURA 7). Novamente a tendência observável é a redução do erro para os três grupos ao longo da fase de adaptação. Os resultados da análise inferencial confirmam a análise descritiva não discernindo diferenças em razão da condição de prática no fim da fase de estabilização [Fim: $F(2 ; 132)=1,16 ; p=0,31$ ] ou detectando interação [Fim X Blocos: $F(3,34 ; 220,68)=0,80 ; p=0,50]$. A ANOVA aponta diferença detectável no fator Blocos $[F(1,67 ; 220,68)=22,45 ; p<0,001]$ localizada pelo teste de Tukey ${ }_{H S D}$ entre o primeiro bloco da adaptação e os demais blocos ( $p<0,001$ nas duas comparações) e entre o segundo e o terceiro blocos $(p=0,03)$, confirmando as observações da análise descritiva. 


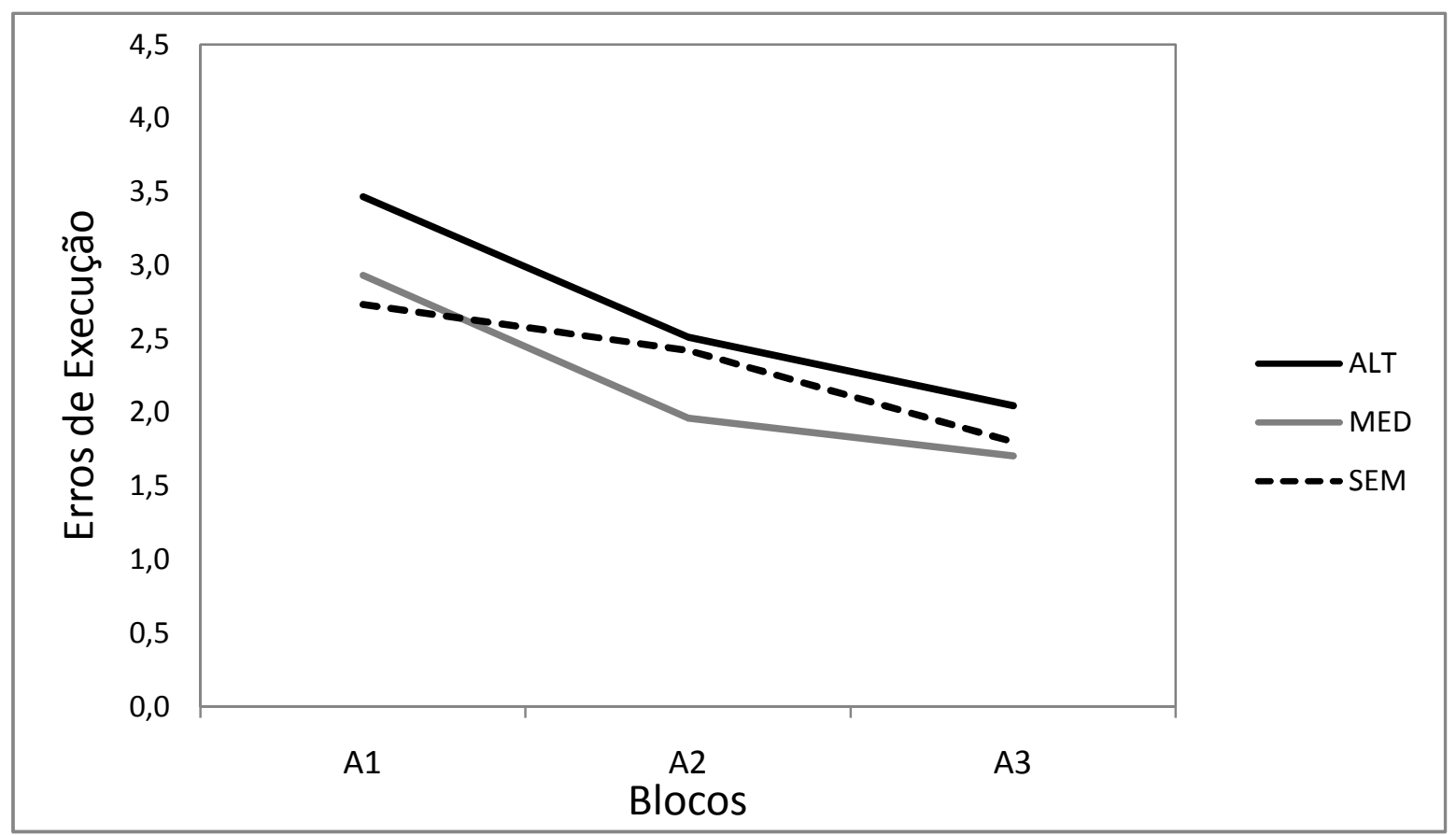

FIGURA 7 - Média dos erros de execução na fase de adaptação (A1, A2 e A3) por condição do final da fase de estabilização (ALT, MED e SEM) por blocos de dez tentativas.

\subsection{Erro variável}

A média do erro variável ao longo da fase de estabilização (FIGURA 8) apresentou redução similar à observada no erro absoluto, com uma redução marcante do erro variável do primeiro para o segundo bloco de tentativas, seguida de uma relativa estabilidade do segundo bloco para o terceiro bloco. Novamente um grupo que iniciou a prática na condição SEM (grupo SEM-ALT) apresentou a menor consistência no primeiro bloco da fase de estabilização, também reduzindo o erro para níveis semelhantes aos apresentados pelos demais grupos no segundo e terceiro blocos.

Entretanto, a análise inferencial não detectou diferenças entre grupos na fase de estabilização [Grupo: $F(8 ; 126)=1,08 ; p=0,37$; Grupo X Blocos: $F(8,44$; $132,98)=1,28 ; p=0,25]$, confirmando porém a redução do erro ao longo dos blocos $[F(1,05 ; 132,98)=83,74 ; p<0,001]$. As diferenças no fator Blocos foram localizadas pelo teste post-hoc entre o primeiro bloco da adaptação e ambos os blocos seguintes ( $p<0,001$ para ambas as comparações). 
$\mathrm{Na}$ transição entre a fase de estabilização e a fase de adaptação o erro variável aumentou consideravelmente para todos os grupos (diminuição da consistência), com redução posterior do primeiro para o último bloco para todos os grupos, embora alguns grupos apresentem aumento do erro do primeiro para 0 segundo bloco. Os grupos ALT-MED e MED-MED se mantiveram entre os grupos com menor erro variável em todos os blocos, enquanto o grupo MED-SEM se manteve entre os grupos com os maiores valores de erro.

A análise inferencial não detectou diferenças entre grupos $[\mathrm{F}(8 ; 126)=$ $0,81 ; p=0,58]$, porém detectou diferenças entre blocos $[F(2,05 ; 258,47)=41,31 ; p<$ $0,001]$ e interação Grupos X Blocos $[F(16,41 ; 258,47)=1,75 ; p=0,03]$. O teste posthoc realizado para a interação Grupos $X$ Blocos não apontou diferenças entre os grupos tanto no último bloco da fase de estabilização quanto nos blocos da fase de adaptação. O post-hoc detectou diferenças entre blocos nos grupos ALT-ALT, ALTSEM, MED-ALT, MED-SEM e SEM-ALT, porém não localizou diferenças entre blocos nos grupos ALT-MED, MED-MED, SEM-MED e SEM-SEM. No grupo ALT-ALT as diferenças entre blocos foram localizadas entre E3 e A1 ( $p<0,001)$. No grupo ALTSEM as diferenças foram localizadas entre E3 e A1 $(p<0,001)$, entre A1 e A2 ( $p=$ $0,01)$ e entre $A 1$ e $A 3(p<0,001)$. No grupo MED-ALT as diferenças foram localizadas entre E3 e A2 $(p<0,01)$. No grupo MED-SEM as diferenças foram localizadas entre E3 e A1 $(p=0,02)$. No grupo SEM-ALT, as diferenças foram localizadas entre E3 e A1 $(p<0,01)$. Em conjunto, os resultados indicam que os grupos foram afetados diferentemente com a introdução da modificação da tarefa. Alguns grupos mantiveram a consistência do final da fase de estabilização ao longo dos blocos da fase de adaptação (ALT-MED, MED-MED, SEM-MED e SEM-SEM) enquanto outros aumentaram o erro variável do último bloco da estabilização para o primeiro (ALT-ALT, ALT-SEM, MED-SEM, SEM-ALT) ou para o segundo (MED-ALT) bloco de tentativas da fase de adaptação. 


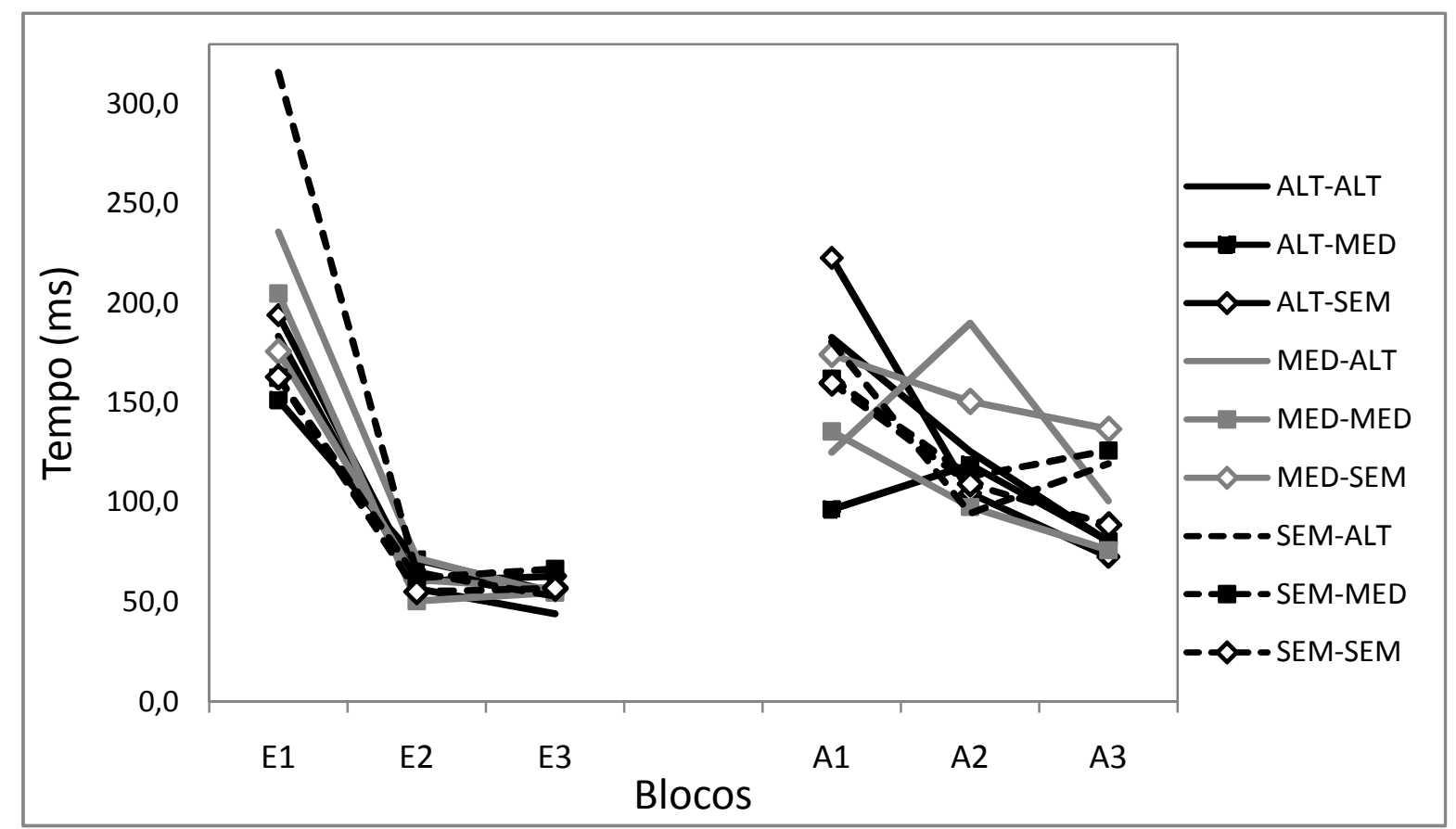

FIGURA 8 - Média do erro variável dos grupos ALT-ALT, ALT-MED, ALT-SEM, MED-ALT, MED-MED, MED-SEM, SEM-ALT, SEM-MED e SEM-SEM na fase de estabilização (E1, E2 e E3) e na fase de adaptação (A1, A2 e A3) por blocos de dez tentativas.

A média do erro variável na adaptação em razão da condição de prática do início da fase de estabilização (FIGURA 9) mostra redução mais acentuada do erro variável do primeiro para o segundo bloco nos participantes que praticaram a tarefa no início da estabilização nas condições ALT e SEM, e redução do erro do segundo para o terceiro bloco para as condições ALT e MED. Os resultados da análise inferencial não corroboraram estas observações, apontando como marginal a interação observada descritivamente [Grupo X Blocos: $F(3,25 ; 215,12)=2,41 ; p=$ $0,06]$. A análise também não detectou efeito do fator Início $[F(2 ; 132)=0,27 ; p=$ $0,75]$ mas apontou diferenças para o fator Blocos $[F(1,62 ; 215,12)=17,25 ; p<$ 0,001 ], localizadas pelo post-hoc entre o primeiro bloco e os blocos seguintes $(p<$ 0,01 para a comparação entre primeiro e segundo bloco, e $p<0,001$ para a comparação entre o primeiro e o terceiro bloco). 


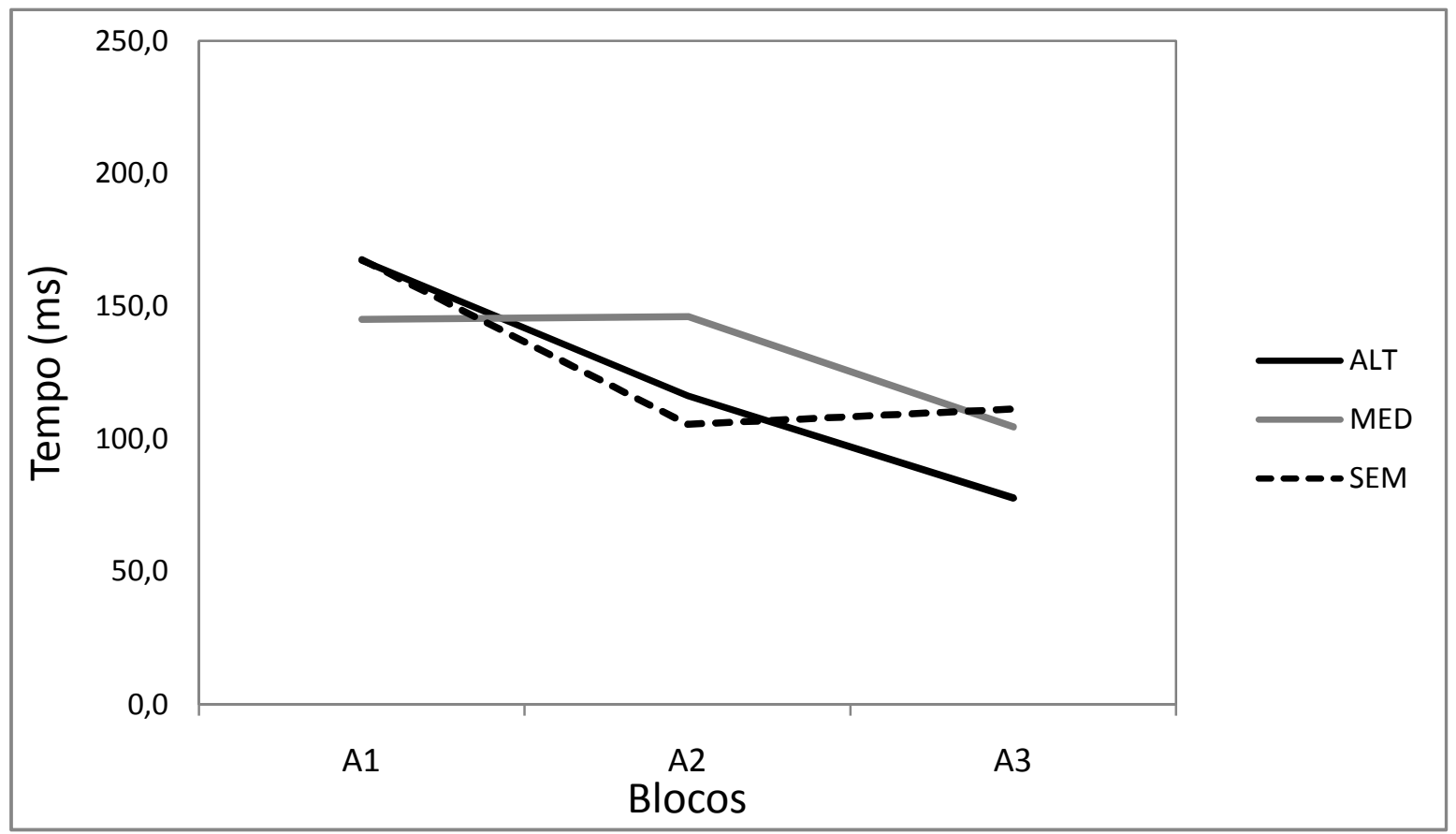

FIGURA 9 - Média do erro variável na fase de adaptação (A1, A2 e A3) por condição do início da fase de estabilização (ALT, MED e SEM) por blocos de dez tentativas.

O erro variável na fase de adaptação por condição de prática no final da fase de estabilização (FIGURA 10) apresenta-se semelhante para todas as condições, com os participantes que praticaram na condição SEM no período imediatamente anterior à fase de adaptação apresentando erro ligeiramente maior no primeiro bloco de tentativas da adaptação. Contudo, após o primeiro bloco o desempenho das três condições foi semelhante e tendeu a se igualar no final da fase de adaptação.

A análise inferencial confirmou as observações, detectando efeito do fator Blocos $[F(1,65 ; 217,99)=16,95 ; p<0,001]$. As diferenças foram localizadas pelo post-hoc entre o primeiro bloco da adaptação e os blocos seguintes $(p<0,01$ na comparação entre $A 1$ e A2, $p<0,001$ na comparação entre $A 1$ e A3). Não foi detectado efeito da condição no final da fase de estabilização [Fim: $F(2 ; 132)=1,42$; $p=0,24]$ ou interação [Fim X Blocos: $F(3,30 ; 217,99)=1,21 ; p=0,30]$. 


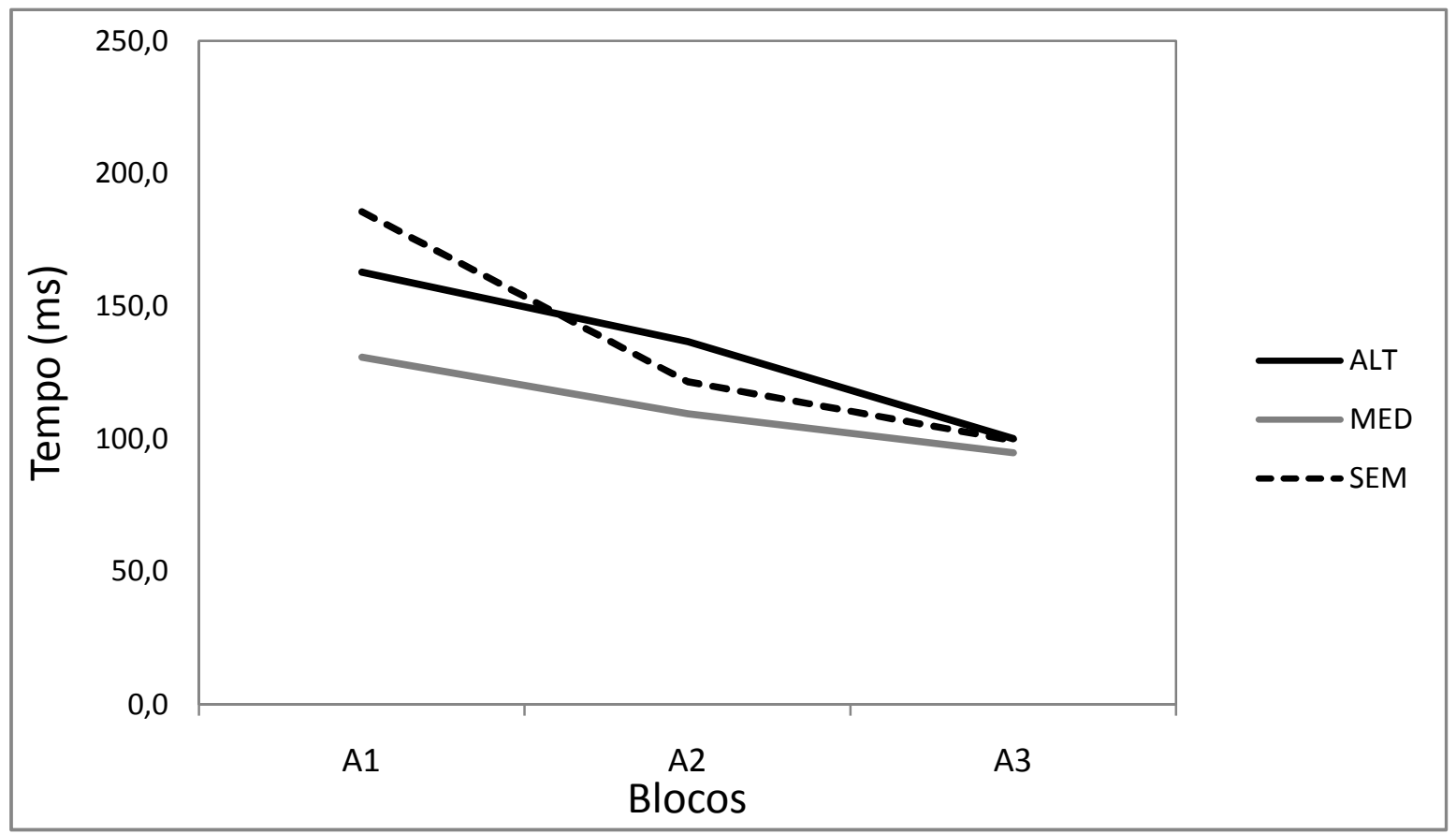

FIGURA 10 - Média do erro variável na fase de adaptacão (A1, A2 e A3) por condição do final da fase de estabilização (ALT, MED e SEM) por blocos de dez tentativas.

5.4 Número de tentativas até desempenho critério

O número de tentativas necessário ao alcance do critério de estabilização nos diferentes grupos é apresentado na FIGURA 11. É possível observar variação no número de tentativas entre os diferentes grupos, com menor número de tentativas nos grupos ALT-ALT e MED-MED e um maior número de tentativas necessário aos participantes dos grupos MED-SEM e SEM-MED. Pode-se observar também maior variação entre os participantes dos grupos MED-SEM e SEM-MED quando comparados aos demais grupos, e menor variação nos participantes do grupo ALTALT. Entretanto, as diferenças observadas entre grupos não foram corroboradas pela análise inferencial [Grupos: $F(8 ; 126)=1,19 ; p=0,30]$. 


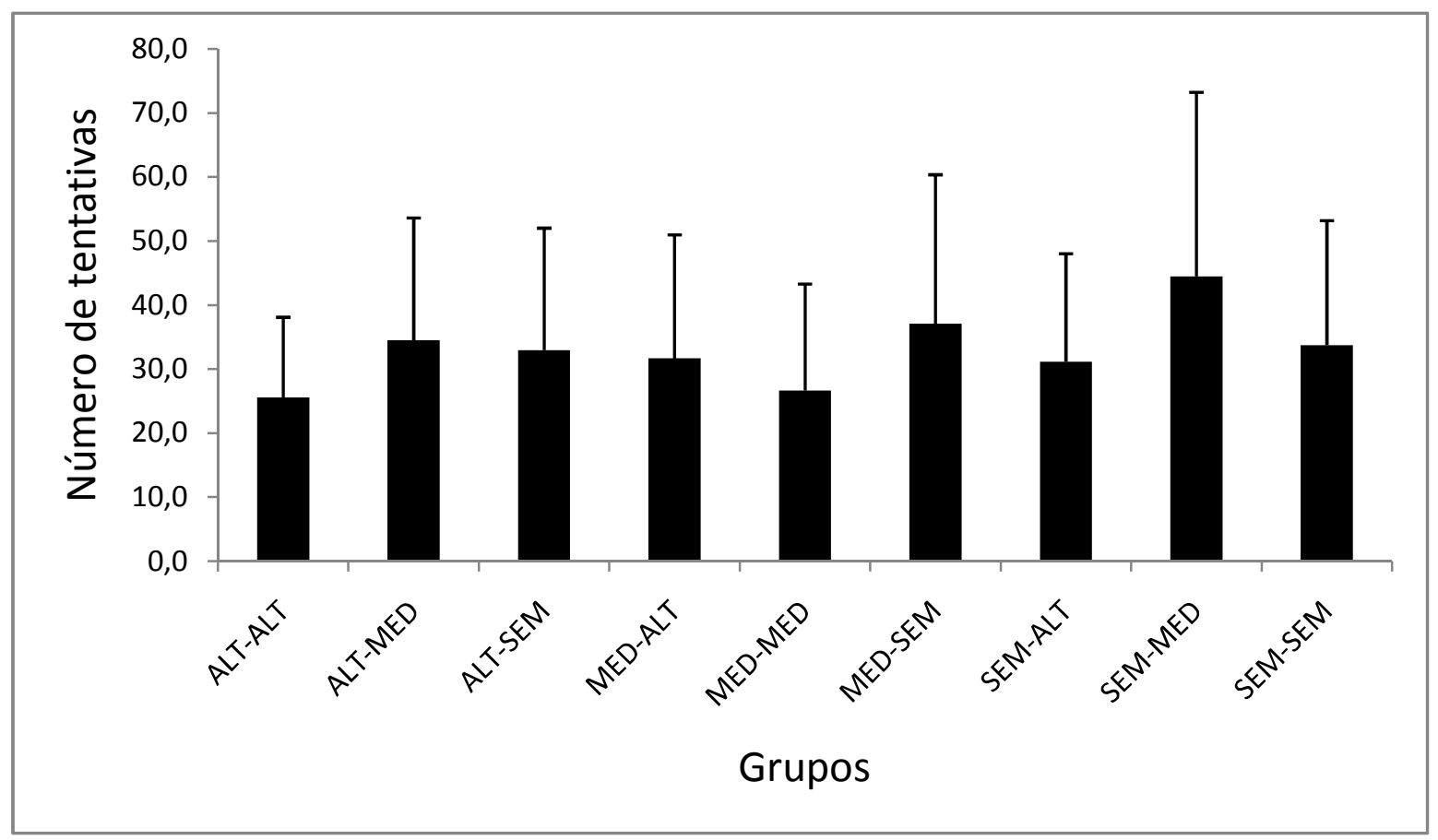

FIGURA 11 - Média e desvio-padrão do número de tentativas necessário ao alcance do critério de desempenho nos grupos ALT-ALT, ALT-MED, ALT-SEM, MED-ALT, MED-MED, MED-SEM, SEM-ALT, SEM-MED e SEM-SEM.

A partir da análise das variações executadas dentre as possíveis pelos participantes dos diversos grupos no primeiro (FIGURA 12), segundo (FIGURA 13) e terceiro (FIGURA 14) bloco da fase de estabilização é possível observar que a possibilidade de variar a seqüência de toques (nas condições ALT e MED) foi utilizada pela maioria dos participantes, com mediana abaixo de $20 \%$ nos blocos analisados. A utilização foi especialmente baixa no terceiro bloco da estabilização. Entretanto, a variação entre participantes foi considerável, especialmente no segundo e terceiro blocos nos grupos MED-ALT, SEM-ALT e SEM-MED.

No primeiro bloco da fase de estabilização, há distinção aparente entre as variações executadas pelos grupos que realizaram a prática em condições nas quais poderiam variar o seqüenciamento e os que não tinham esta possibilidade. Mais especificamente, os grupos nas condições iniciais ALT e MED apresentaram alguma amplitude de variação interna no que se refere aos percentis, o que indica que alguns 
participantes realizaram mudanças na seqüência executada. $O$ contraste entre aquelas condições e a condição SEM é evidente.

A ANOVA de Kruskal-Wallis confirma as diferenças entre grupos no primeiro bloco da estabilização $[H(G L=8 ; N=135)=37,42 ; p<0,001]$, localizadas pelo teste $\mathrm{U}$ de Mann-Whitney (comparações par-a-par empregadas como post-hoc) entre os grupos que realizaram a prática na condição SEM e os grupos que realizaram a prática nas demais condições (TABELA 6).

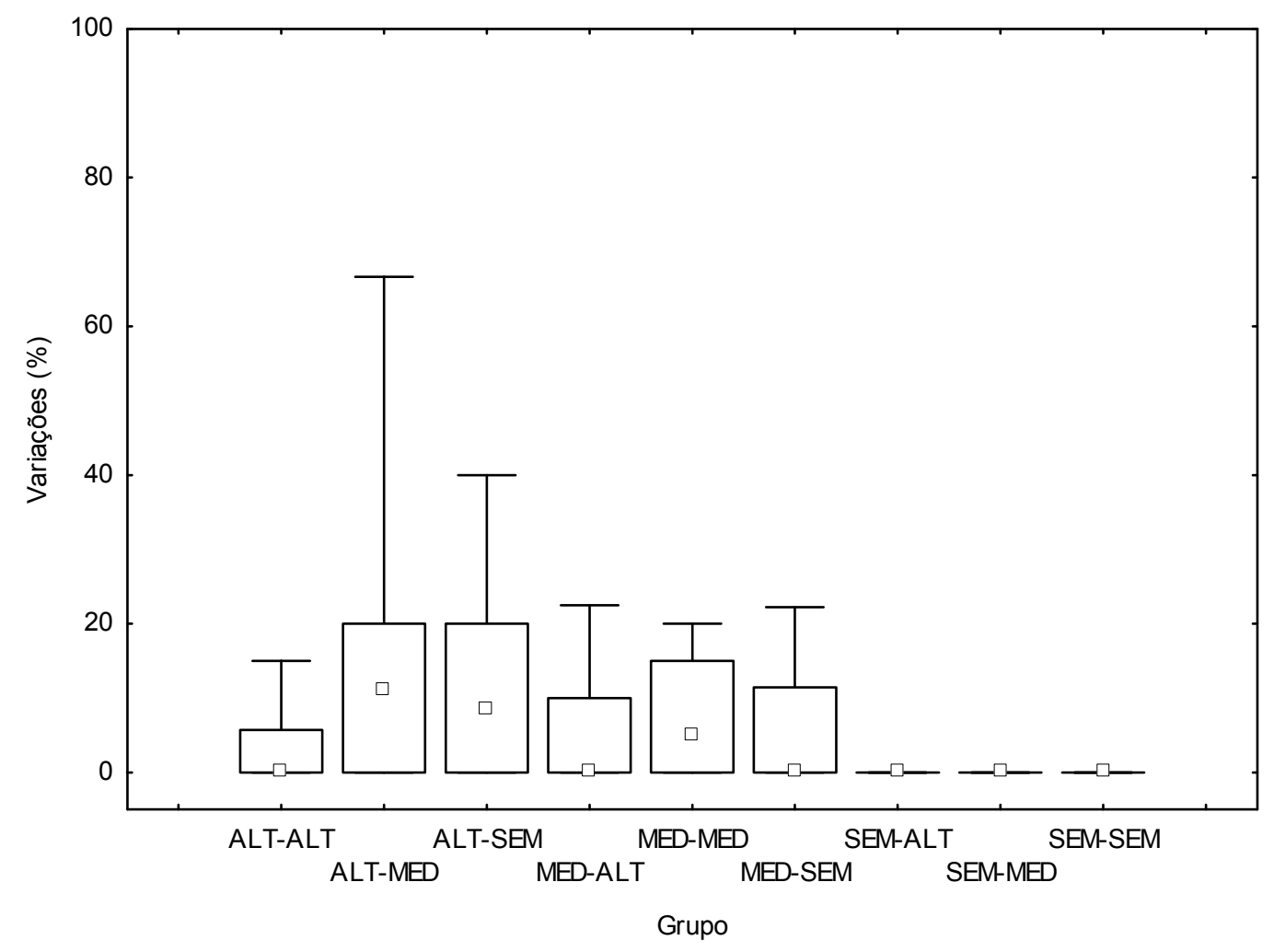

FIGURA 12 - Boxplot (mediana, percentis 25 e 75 e valores máximos e mínimos) da proporção de variações de seqüenciamento realizadas pelos grupos ALT-ALT, ALT-MED, ALT-SEM, MED-ALT, MED-MED, MED-SEM, SEM-ALT, SEM-MED e SEM-SEM no primeiro bloco da fase de estabilização. 
TABELA 6 - Resultados significativos do teste $U$ de Mann-Whitney para variações do seqüenciamento entre grupos no primeiro bloco da fase de estabilização

\begin{tabular}{|c|c|c|c|c|c|c|c|c|c|}
\hline & $\begin{array}{l}\text { ALT- } \\
\text { ALT }\end{array}$ & $\begin{array}{l}\text { ALT- } \\
\text { MED }\end{array}$ & $\begin{array}{l}\text { ALT- } \\
\text { SEM }\end{array}$ & $\begin{array}{l}\text { MED- } \\
\text { ALT }\end{array}$ & $\begin{array}{l}\text { MED- } \\
\text { MED }\end{array}$ & $\begin{array}{l}\text { MED- } \\
\text { SEM }\end{array}$ & $\begin{array}{l}\text { SEM- } \\
\text { ALT }\end{array}$ & $\begin{array}{l}\text { SEM- } \\
\text { MED }\end{array}$ & $\begin{array}{l}\text { SEM- } \\
\text { SEM }\end{array}$ \\
\hline $\begin{array}{l}\text { ALT- } \\
\text { ALT }\end{array}$ & & & & & & & $\begin{array}{l}Z=2,93 \\
p<0,01\end{array}$ & $\begin{array}{l}Z=2,93 \\
p<0,01\end{array}$ & $\begin{array}{l}Z=2,93 \\
p<0,01\end{array}$ \\
\hline $\begin{array}{l}\text { ALT- } \\
\text { MED }\end{array}$ & & & & & & & $\begin{array}{l}Z=3,45 \\
p<0,001\end{array}$ & $\begin{array}{l}Z=3,45 \\
p<0,001\end{array}$ & $\begin{array}{l}Z=3,45 \\
p<0,001\end{array}$ \\
\hline $\begin{array}{l}\text { ALT- } \\
\text { SEM }\end{array}$ & & & & & & & $\begin{array}{l}Z=3,45 \\
p<0,001\end{array}$ & $\begin{array}{l}Z=3,45 \\
p<0,001\end{array}$ & $\begin{array}{l}Z=3,45 \\
p<0,001\end{array}$ \\
\hline $\begin{array}{l}\text { MED- } \\
\text { ALT }\end{array}$ & & & & & & & $\begin{array}{l}Z=2,67 \\
p<0,01\end{array}$ & $\begin{array}{l}Z=2,67 \\
p<0,01\end{array}$ & $\begin{array}{l}Z=2,67 \\
p<0,01\end{array}$ \\
\hline $\begin{array}{l}\text { MED- } \\
\text { MED }\end{array}$ & & & & & & & $\begin{array}{l}Z=3,19 \\
p<0,01\end{array}$ & $\begin{array}{l}Z=3,19 \\
p<0,01\end{array}$ & $\begin{array}{l}Z=3,19 \\
p<0,01\end{array}$ \\
\hline $\begin{array}{l}\text { MED- } \\
\text { SEM }\end{array}$ & & & & & & & $\begin{array}{l}Z=2,93 \\
p<0,01\end{array}$ & $\begin{array}{l}Z=2,93 \\
p<0,01\end{array}$ & $\begin{array}{l}Z=2,93 \\
p<0,01\end{array}$ \\
\hline $\begin{array}{l}\text { SEM- } \\
\text { ALT }\end{array}$ & & & & & & & & & \\
\hline $\begin{array}{l}\text { SEM- } \\
\text { MED }\end{array}$ & & & & & & & & & \\
\hline $\begin{array}{l}\text { SEM- } \\
\text { SEM }\end{array}$ & & & & & & & & & \\
\hline
\end{tabular}

As variações nas seqüências executadas pelos grupos no segundo bloco de tentativas da fase de estabilização (FIGURA 13) são nitidamente menores nos grupos que mantém ou diminuem a possibilidade de variar em relação ao primeiro bloco (ALT-ALT, ALT-MED e MED-MED) quando comparadas aos grupos em que a possibilidade de variar a seqüência aumenta (MED-ALT, SEM-ALT e SEM-MED), o que provavelmente está ligado à possibilidade de testar novas seqüências. No que se refere aos grupos que realizaram a prática nas mesmas condições, os grupos na condição ALT no segundo bloco de tentativas apresentam comportamento divergente, com o grupo MED-ALT apresentando variabilidade de seqüenciamento superior aos grupos ALT-ALT e SEM-ALT. Por sua vez, os grupos na condição MED 
também apresentam um grupo que se destaca pela maior variabilidade (SEM-MED) enquanto os demais (ALT-MED e MED-MED) apresentam menor variabilidade.

A existência de diferenças entre grupos foi confirmada pela ANOVA de Kruskal-Wallis $[H(G L=8 ; N=135)=61,92 ; p<0,001]$. Os testes $U$ de Mann-Whitney empregados como post-hoc (TABELA 7) confirmam parcialmente as observações acima no que se refere ao aumento ou à diminuição na possibilidade de variação em razão da condição, pois foram observadas diferenças estatisticamente detectáveis entre os grupos ALT-ALT, ALT-MED e MED-MED para os grupos MED-ALT e SEMMED, porém não confirmadas para o grupo SEM-ALT. Na comparação entre grupos na mesma condição, os testes apontam diferenças entre o grupo ALT-ALT e o grupo MED-ALT mas não entre SEM-ALT e os demais, apontando também diferença entre o grupo SEM-MED e os demais na mesma condição (ALT-MED e MED-MED).

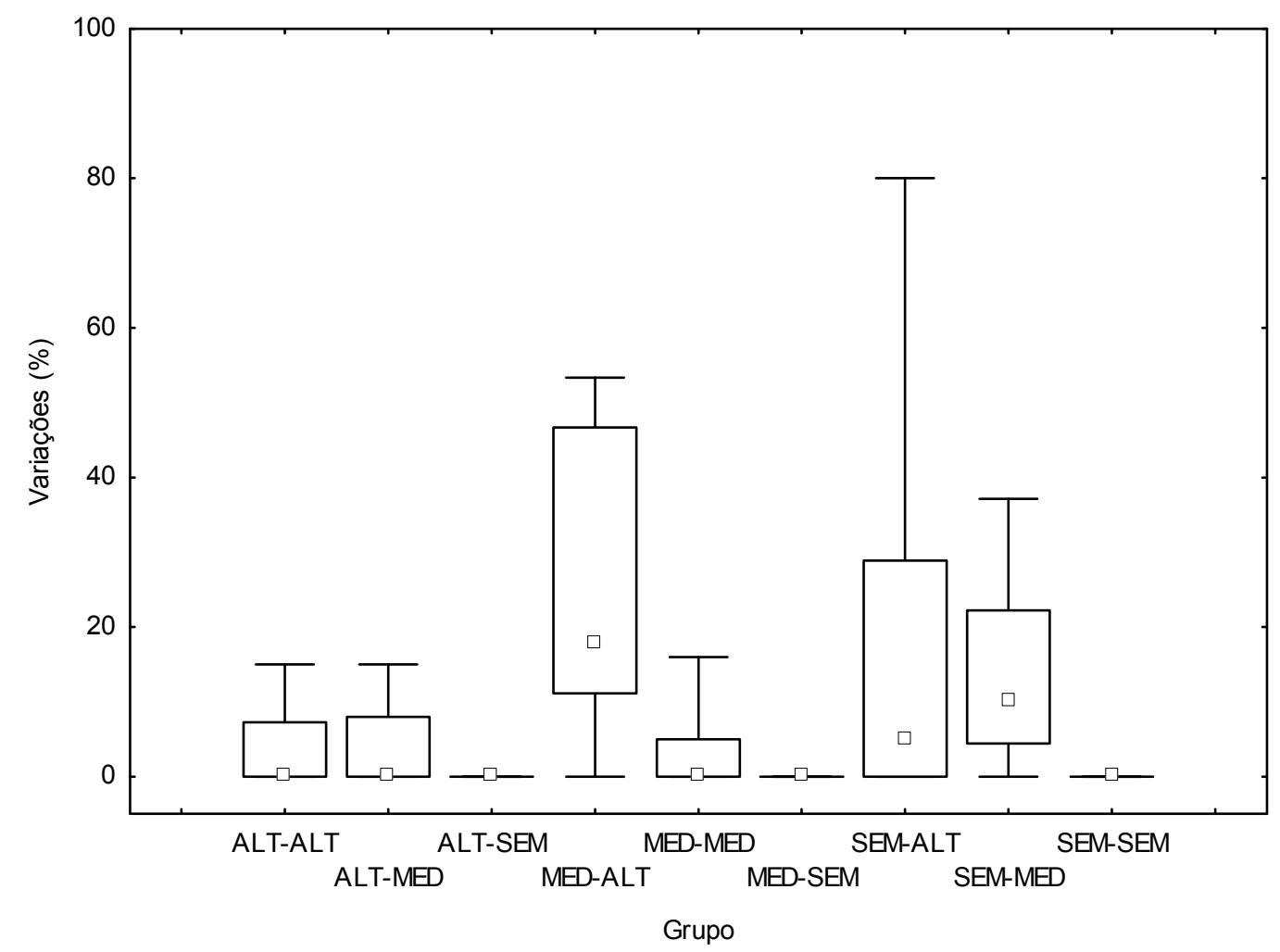

FIGURA 13 - Boxplot (mediana, percentis 25 e 75 e valores máximos e mínimos) da proporção de variações de seqüenciamento realizadas pelos grupos ALT-ALT, ALT-MED, ALT-SEM, MED-ALT, MED-MED, MED-SEM, SEM-ALT, SEM-MED e SEM-SEM no segundo bloco da fase de estabilização. 
TABELA 7 - Resultados significativos do teste $U$ de Mann-Whitney para variações do seqüenciamento entre grupos no segundo bloco da fase de estabilização

\begin{tabular}{|c|c|c|c|c|c|c|c|c|c|}
\hline & $\begin{array}{l}\text { ALT- } \\
\text { ALT }\end{array}$ & $\begin{array}{l}\text { ALT- } \\
\text { MED }\end{array}$ & $\begin{array}{l}\text { ALT- } \\
\text { SEM }\end{array}$ & $\begin{array}{l}\text { MED- } \\
\text { ALT }\end{array}$ & $\begin{array}{l}\text { MED- } \\
\text { MED }\end{array}$ & $\begin{array}{l}\text { MED- } \\
\text { SEM }\end{array}$ & $\begin{array}{l}\text { SEM- } \\
\text { ALT }\end{array}$ & $\begin{array}{l}\text { SEM- } \\
\text { MED }\end{array}$ & $\begin{array}{l}\text { SEM- } \\
\text { SEM }\end{array}$ \\
\hline $\begin{array}{l}\text { ALT- } \\
\text { ALT }\end{array}$ & & & $\begin{array}{l}Z=2,39 \\
p<0,01\end{array}$ & $\begin{array}{l}Z=3,77 \\
p<0,001\end{array}$ & & $\begin{array}{l}Z=2,39 \\
p<0,01\end{array}$ & & $\begin{array}{l}Z=2,85 \\
p<0,01\end{array}$ & $\begin{array}{l}Z=2,39 \\
p<0,01\end{array}$ \\
\hline $\begin{array}{l}\text { ALT- } \\
\text { MED }\end{array}$ & & & $\begin{array}{l}Z=2,93 \\
p<0,01\end{array}$ & $\begin{array}{l}Z=3,42 \\
p<0,001\end{array}$ & & $\begin{array}{l}Z=2,93 \\
p<0,01\end{array}$ & & $\begin{array}{l}Z=2,29 \\
p=0,02\end{array}$ & $\begin{array}{l}Z=2,93 \\
p<0,01\end{array}$ \\
\hline $\begin{array}{l}\text { ALT- } \\
\text { SEM }\end{array}$ & & & & $\begin{array}{l}Z=4,47 \\
p<0,001\end{array}$ & $\begin{array}{l}Z=2,39 \\
p<0,01\end{array}$ & & & $\begin{array}{l}Z=4,21 \\
p<0,001\end{array}$ & \\
\hline $\begin{array}{l}\text { MED- } \\
\text { ALT }\end{array}$ & & & & & $\begin{array}{l}Z=3,77 \\
p<0,001\end{array}$ & $\begin{array}{l}Z=4,47 \\
p<0,001\end{array}$ & & & $\begin{array}{l}Z=4,47 \\
p<0,001\end{array}$ \\
\hline $\begin{array}{l}\text { MED- } \\
\text { MED }\end{array}$ & & & & & & $\begin{array}{l}Z=2,39 \\
p<0,01\end{array}$ & & $\begin{array}{l}Z=2,96 \\
p<0,01\end{array}$ & $\begin{array}{l}Z=2,39 \\
p<0,01\end{array}$ \\
\hline $\begin{array}{l}\text { MED- } \\
\text { SEM }\end{array}$ & & & & & & & $\begin{array}{l}Z=3,19 \\
p<0,01\end{array}$ & $\begin{array}{l}Z=4,21 \\
p<0,001\end{array}$ & \\
\hline $\begin{array}{l}\text { SEM- } \\
\text { ALT }\end{array}$ & & & & & & & & & $\begin{array}{l}Z=3,19 \\
p<0,01\end{array}$ \\
\hline $\begin{array}{l}\text { SEM- } \\
\text { MED }\end{array}$ & & & & & & & & & $\begin{array}{l}Z=4,21 \\
p<0,001\end{array}$ \\
\hline $\begin{array}{l}\text { SEM- } \\
\text { SEM }\end{array}$ & & & & & & & & & \\
\hline
\end{tabular}

No terceiro bloco da fase de estabilização a distribuição das variações de seqüenciamento executadas por grupo (FIGURA 14) aponta que a maior parte dos participantes, nesse momento, realiza pequena ou nenhuma variação na ordem da seqüência de toques. Entretanto, ainda há variação considerável no seqüenciamento, especialmente nos grupos ALT-MED, MED-ALT, SEM-ALT e SEM-MED, mantendo a tendência do segundo bloco. Nas comparações entre grupos na mesma condição, os grupos MED-ALT e SEM-ALT apresentam variação superior à do grupo ALT-ALT, enquanto o grupo SEM-MED apresenta maiores variações no seqüenciamento que os demais na mesma condição (ALT-MED e MED-MED).

A análise inferencial confirma a existência de diferenças entre grupos $[H(G L=8 ; N=135)=24,78, p<0,01]$. As comparações par-a-par (teste $U$ de Mann- 
Whitney) empregadas como post-hoc (TABELA 8), em geral, não confirmam a maior variação dos grupos ALT-MED, MED-ALT, SEM-ALT e SEM-MED para os demais (exceto com relação aos na condição SEM). Na comparação entre grupos na mesma condição foi detectada diferença apenas entre os grupos MED-ALT e ALT-ALT, sem diferenças entre os grupos na condição MED.

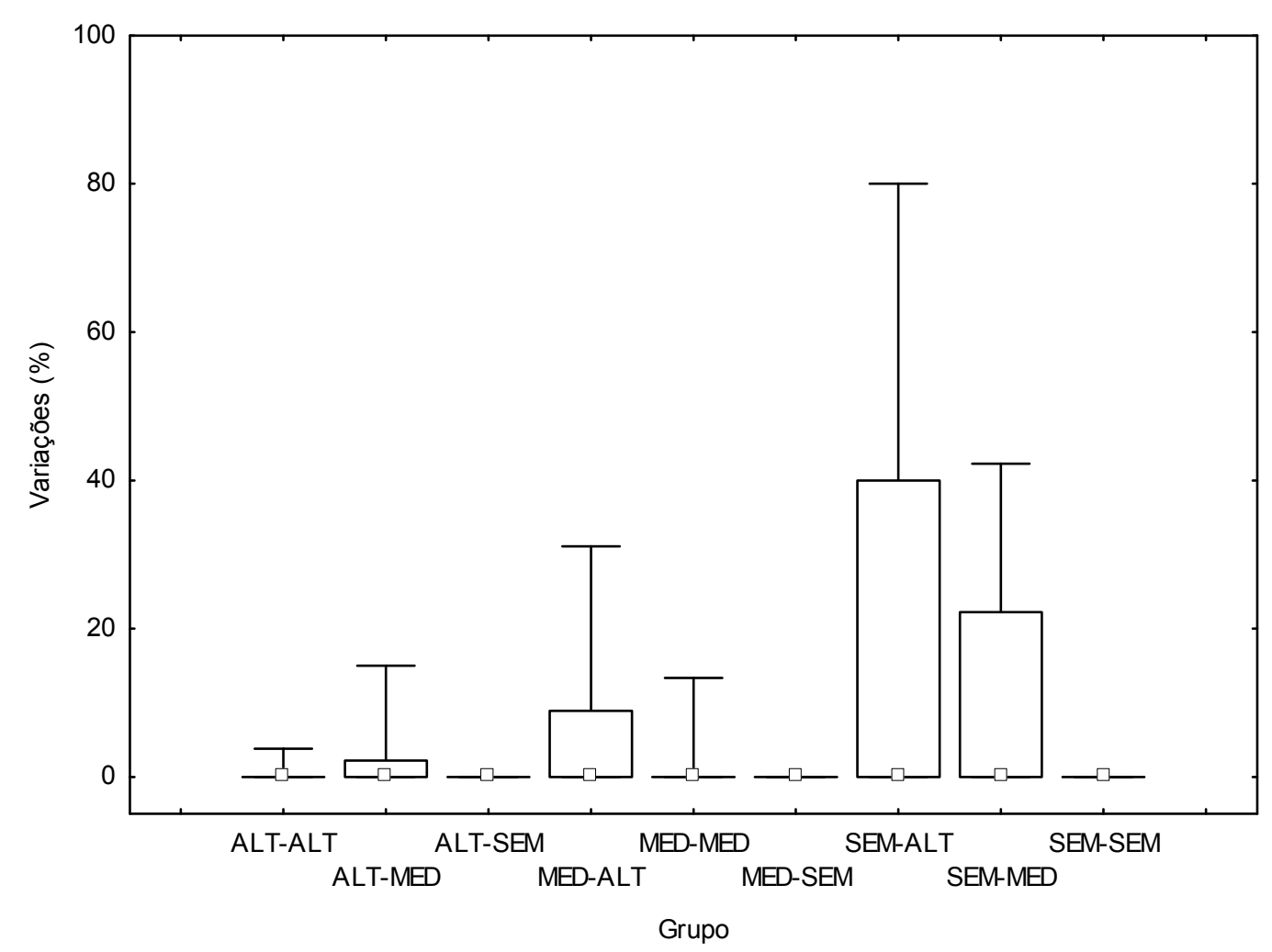

FIGURA 14 - Boxplot (mediana, percentis 25 e 75 e valores máximos e mínimos) da proporção de variações de seqüenciamento realizadas pelos grupos ALT-ALT, ALT-MED, ALT-SEM, MED-ALT, MED-MED, MED-SEM, SEM-ALT, SEM-MED e SEM-SEM no terceiro bloco da fase de estabilização. 
TABELA 8 - Resultados significativos do teste $U$ de Mann-Whitney para variações do seqüenciamento entre grupos no terceiro bloco da fase de estabilização

\begin{tabular}{|c|c|c|c|c|c|c|c|c|c|}
\hline & $\begin{array}{l}\text { ALT- } \\
\text { ALT }\end{array}$ & $\begin{array}{l}\text { ALT- } \\
\text { MED }\end{array}$ & $\begin{array}{l}\text { ALT- } \\
\text { SEM }\end{array}$ & $\begin{array}{l}\text { MED- } \\
\text { ALT }\end{array}$ & $\begin{array}{l}\text { MED- } \\
\text { MED }\end{array}$ & $\begin{array}{l}\text { MED- } \\
\text { SEM }\end{array}$ & $\begin{array}{l}\text { SEM- } \\
\text { ALT }\end{array}$ & $\begin{array}{l}\text { SEM- } \\
\text { MED }\end{array}$ & $\begin{array}{l}\text { SEM- } \\
\text { SEM }\end{array}$ \\
\hline $\begin{array}{l}\text { ALT- } \\
\text { ALT }\end{array}$ & & & & $\begin{array}{l}Z=2,26 \\
p=0,02\end{array}$ & & & & $\begin{array}{l}Z=2,26 \\
p=0,02\end{array}$ & \\
\hline $\begin{array}{l}\text { ALT- } \\
\text { MED }\end{array}$ & & & $\begin{array}{l}Z=2,10 \\
p=0,03\end{array}$ & & & $\begin{array}{l}Z=2,10 \\
p=0,03\end{array}$ & & & $\begin{array}{l}Z=2,10 \\
p=0,03\end{array}$ \\
\hline $\begin{array}{l}\text { ALT- } \\
\text { SEM }\end{array}$ & & & & $\begin{array}{l}Z=2,67 \\
p<0,01\end{array}$ & & & $\begin{array}{l}Z=2,39 \\
p=0,01\end{array}$ & $\begin{array}{l}Z=2,67 \\
p<0,01\end{array}$ & \\
\hline $\begin{array}{l}\text { MED- } \\
\text { ALT }\end{array}$ & & & & & & $\begin{array}{l}Z=2,67 \\
p<0,01\end{array}$ & & & $\begin{array}{l}Z=2,67 \\
p<0,01\end{array}$ \\
\hline $\begin{array}{l}\text { MED- } \\
\text { MED }\end{array}$ & & & & & & & & & \\
\hline $\begin{array}{l}\text { MED- } \\
\text { SEM }\end{array}$ & & & & & & & $\begin{array}{l}Z=2,39 \\
p=0,01\end{array}$ & $\begin{array}{l}Z=2,67 \\
p<0,01\end{array}$ & $\begin{array}{l}Z=2,67 \\
p<0,01\end{array}$ \\
\hline $\begin{array}{l}\text { SEM- } \\
\text { ALT }\end{array}$ & & & & & & & & & $\begin{array}{l}Z=2,39 \\
p=0,01\end{array}$ \\
\hline $\begin{array}{l}\text { SEM- } \\
\text { MED }\end{array}$ & & & & & & & & & $\begin{array}{l}Z=2,67 \\
p<0,01\end{array}$ \\
\hline $\begin{array}{l}\text { SEM- } \\
\text { SEM }\end{array}$ & & & & & & & & & \\
\hline
\end{tabular}

5.6 Variabilidade da macroestrutura

Observando a variabilidade da macroestrutura na fase de estabilização (FIGURA 15), é possível notar uma redução discreta para todos os grupos do primeiro bloco para os demais, sem diferenças marcantes entre os grupos. A análise inferencial confirma os resultados, não detectando diferenças no fator Grupos $[F(8$; $126)=0,46 ; p=0,87$ ] ou interação [Grupos X Blocos: $F(11,12 ; 175,14)=0,96 ; p=$ $0,43]$ detectando apenas efeito do fator Blocos $[F(1,39 ; 175,14)=24,47 ; p<0,001]$ cujas diferenças foram localizadas entre o primeiro bloco e os demais ( $p<0,001$ para ambas as comparações). 
$\mathrm{Na}$ passagem para a fase de adaptação, o desempenho dos grupos mostra a manutenção da variabilidade do último bloco da estabilização para o primeiro bloco da adaptação, com a manutenção ou ligeira redução da variabilidade ao longo dos blocos, com diferenças reduzidas entre os grupos. A análise inferencial corrobora estas observações, não detectando diferenças entre grupos [Grupos: $F(8$; $126)=1,08 ; p=0,38$; Grupos X Blocos: $F(19,98 ; 314,78)=1,33 ; p=0,13]$, com diferenças entre blocos $[F(2,49 ; 314,78)=5,43 ; p<0,01]$ localizadas pelo post-hoc entre o primeiro bloco da adaptação e os demais blocos desta fase $(p=0,01$ e $p<$ 0,001 respectivamente).

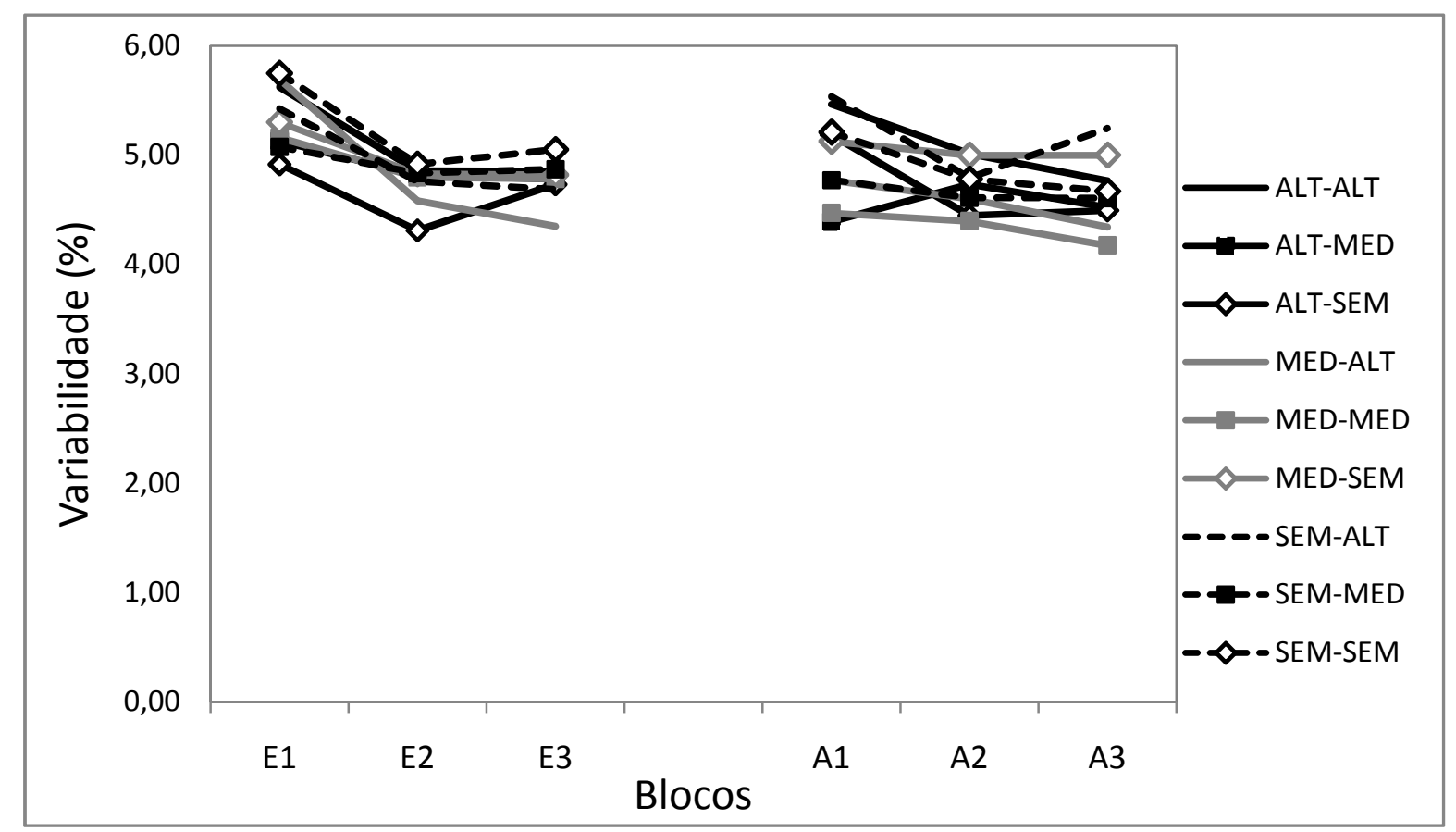

FIGURA 15 - Média da média do desvio padrão dos tempos de toques relativos dos grupos ALT-ALT, ALT-MED, ALT-SEM, MED-ALT, MED-MED, MEDSEM, SEM-ALT, SEM-MED e SEM-SEM na fase de estabilização (E1, E2 e E3) e na fase de adaptação (A1, A2 e A3) por blocos de dez tentativas.

A variabilidade da macroestrutura na fase de adaptação em conseqüência da condição no início da fase de estabilização (FIGURA 16) apresenta-se semelhante para todas as condições, sendo possível observar uma ligeira queda na variabilidade ao longo dos blocos. A ANOVA confirma a análise descritiva, não apontando interação [Início X Blocos: $F(3,35 ; 221,64)=0,87 ; p=0,47$ ] ou diferenças 
no fator Início $[F(2 ; 132)=0,83 ; p=0,43]$. As diferenças entre blocos $[F(1,67 ; 221,64)$ $=9,96 ; p<0,001]$ foram localizadas entre o primeiro bloco e os demais $(p<0,01$ para a comparação entre A1 e A2; $p<0,001$ para a comparação entre A1 e A3).

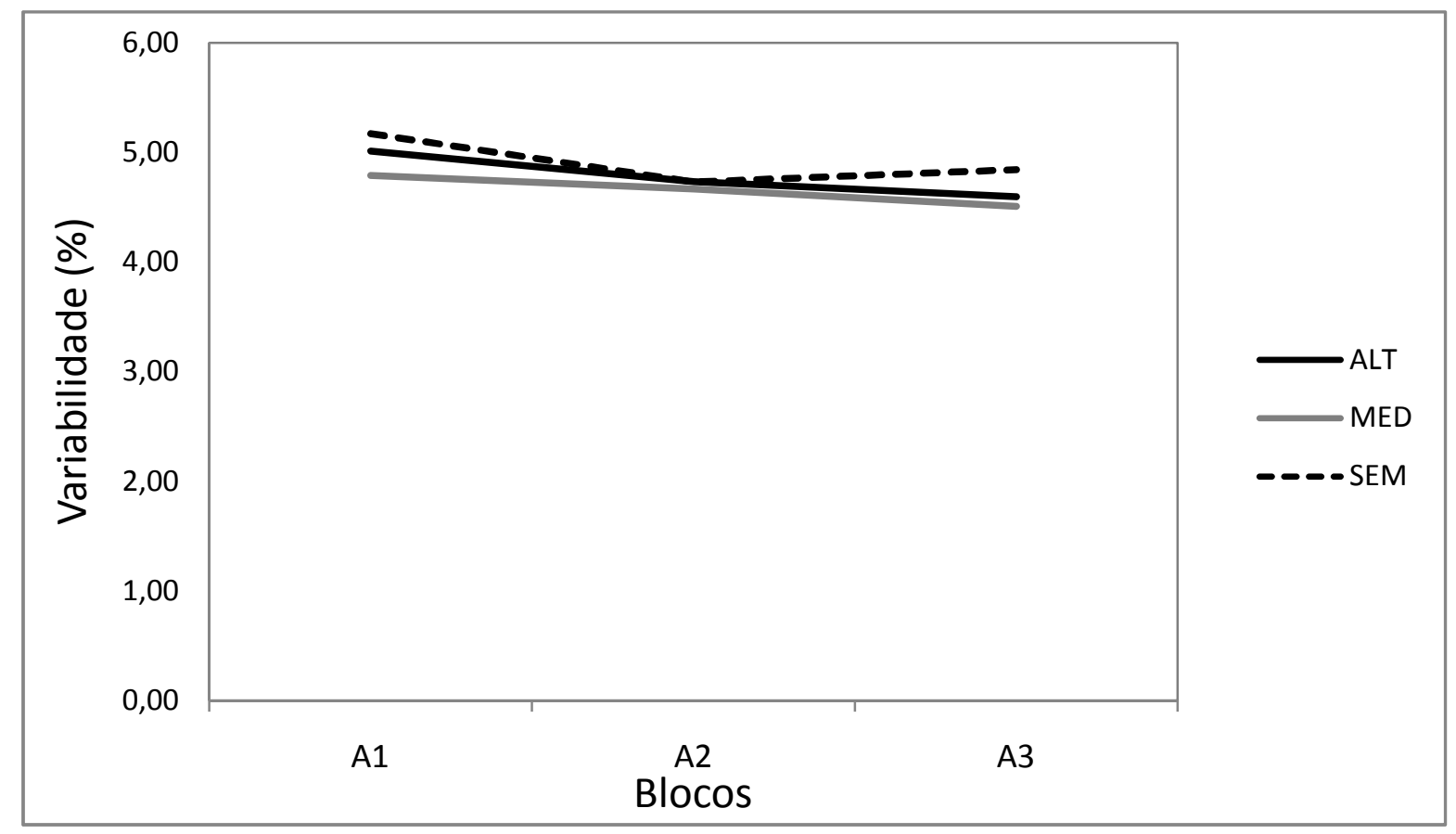

FIGURA 16 - Média da média do desvio padrão dos tempos de toques relativos na fase de adaptação (A1, A2 e A3) por condição do início da fase de estabilização (ALT, MED e SEM) por blocos de dez tentativas.

Por sua vez, a variabilidade da macroestrutura na fase de adaptação em virtude da condição experimental do final da estabilização (FIGURA 17) evidencia uma variabilidade ligeiramente menor da condição MED no primeiro bloco quando comparada às demais. Os resultados da ANOVA, entretanto, não corroboram a análise descritiva, apontando efeito marginal para o fator $\operatorname{Fim}[F(2 ; 132)=2,70 ; p=$ $0,07]$ e para a interação [Fim X Blocos: $F(3,39 ; 224,32)=2,05 ; p=0,08]$. A diferença entre blocos $[F(1,69 ; 224,32)=10,13 ; p<0,001]$ foi localizada entre A1 e A2 ( $p<$ $0,01)$ e entre $A 1$ e $A 3(p<0,001)$. 


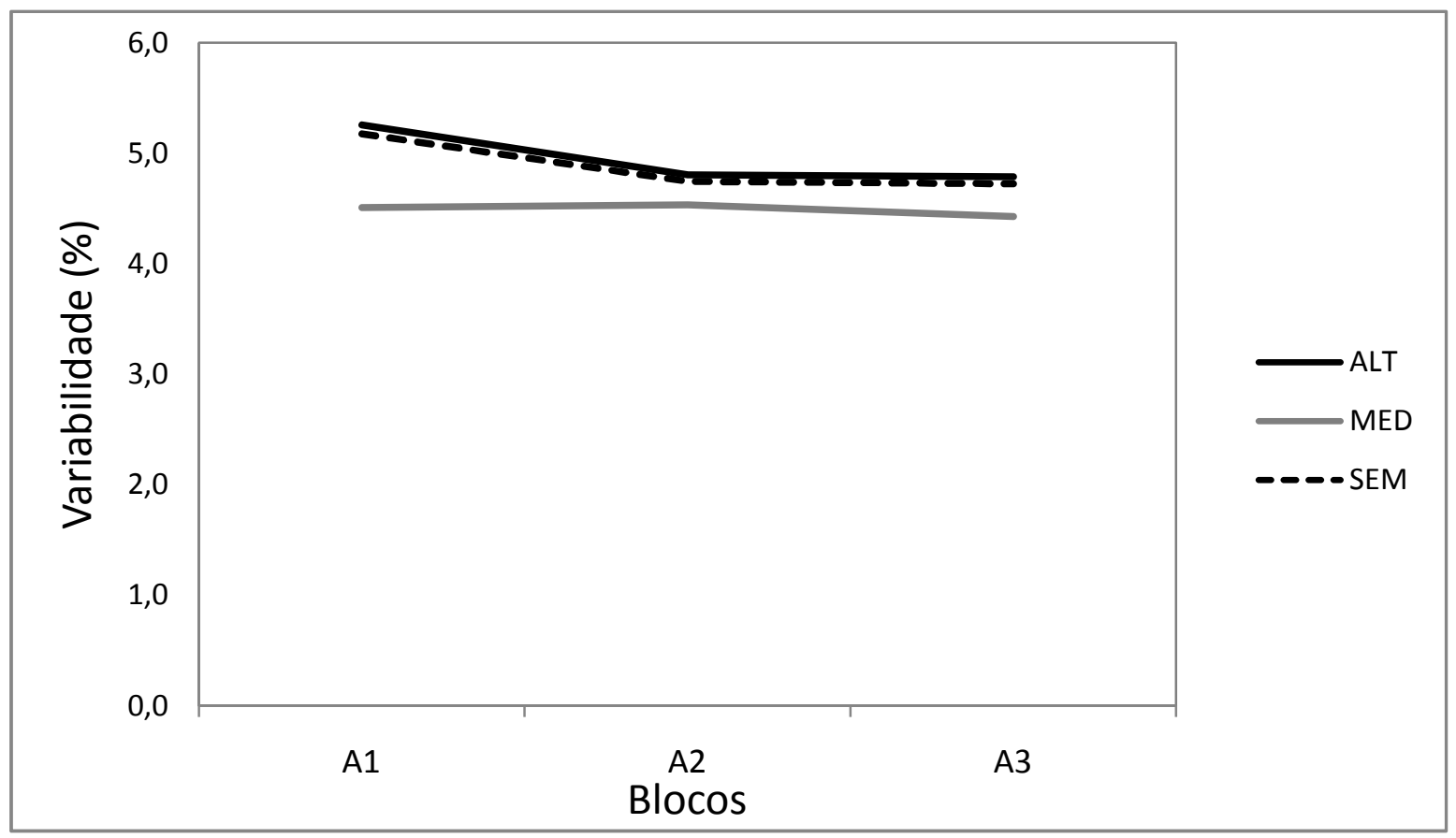

FIGURA 17 - Média da média do desvio padrão dos tempos de toques relativos na fase de adaptação (A1, A2 e A3) por condição do final da fase de estabilização (ALT, MED e SEM) por blocos de dez tentativas.

\subsection{Variabilidade da microestrutura}

A variabilidade da microestrutura dos diferentes grupos na fase de estabilização (FIGURA 18) mostra uma tendência de queda do primeiro bloco para os demais, com poucas diferenças entre a variabilidade dos grupos. A análise inferencial corrobora estes resultados, não apontando diferenças entre grupos [Grupos: $F(8 ; 126)=0,70 ; p=0,68$; Grupo X Blocos: $F(9,99 ; 157,35)=1,48 ; p=0,10$ ] e confirmando as diferenças entre blocos $[F(1,24 ; 157,35)=44,32 ; p<0,001]$ localizadas pelo post-hoc entre o primeiro bloco e ambos os seguintes $(p<0,001 \mathrm{em}$ ambas as comparações).

A transição da fase de estabilização para a fase de adaptação mostra um aumento da variabilidade em alguns grupos (ALT-ALT, SEM-ALT) e a manutenção de valores semelhantes aos do final da estabilização em outros (MED-MED). É possivel observar também uma ligeira redução da variabilidade ao longo dos blocos da adaptação. Porém, a análise inferencial aponta o efeito da interação como marginal [Grupo X Blocos: $F(20,27 ; 319,38)=1,41 ; p=0,09]$ também não detectando 
efeito do fator Grupos $[F(8 ; 126)=1,15 ; p=0,33]$. A diferença entre blocos $[F(2,53$; $319,38)=29,67 ; p<0,001]$ foi localizada entre o último bloco da establização e os blocos da adaptação ( $p<0,001$ para as três comparações) e entre o primeiro bloco da adaptação e os blocos seguintes ( $p<0,01$ na comparação entre A1 e A2, e $p<$ 0,001 na comparação entre A1 e A3).

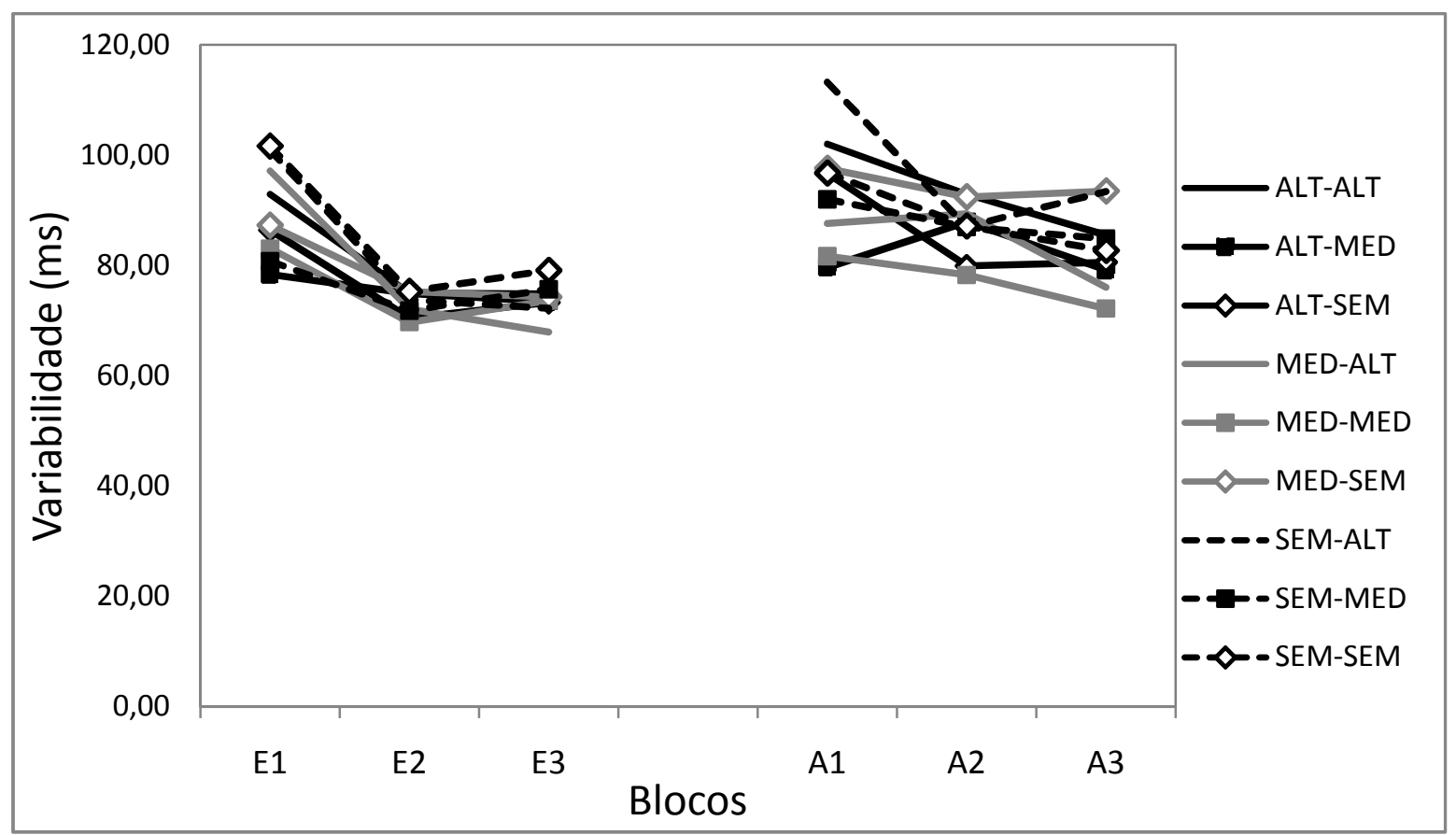

FIGURA 18 - Média da média do desvio padrão dos tempos de toques absolutos dos grupos ALT-ALT, ALT-MED, ALT-SEM, MED-ALT, MED-MED, MEDSEM, SEM-ALT, SEM-MED e SEM-SEM na fase de estabilização (E1, E2 e E3) e na fase de adaptação (A1, A2 e A3) por blocos de dez tentativas.

A variabilidade da microestrutura na adaptação em virtude da condição do início da fase de estabilização (FIGURA 19) mostra uma tendência similar à variabilidade da macroestrutura, com pequenas diferenças entre grupos e uma tendência de redução ao longo dos blocos. A ANOVA confirma estes resultados, não apontando diferenças entre grupos [Início: $F(2 ; 132)=0,96 ; p=0,38$; Início $X$ Blocos: $F(3,48 ; 229,80)=1,19 ; p=0,32]$ e detectando diferença entre blocos $[F(1,74 ; 229,80)$ $=13,18 ; p<0,001]$. A diferença entre blocos foi localizada pelo post-hoc entre 0 primeiro bloco e ambos os blocos seguintes $(p<0,01$ na comparação entre $A 1$ e $A 2$, $P<0,001$ na comparação entre A1 e A3). 


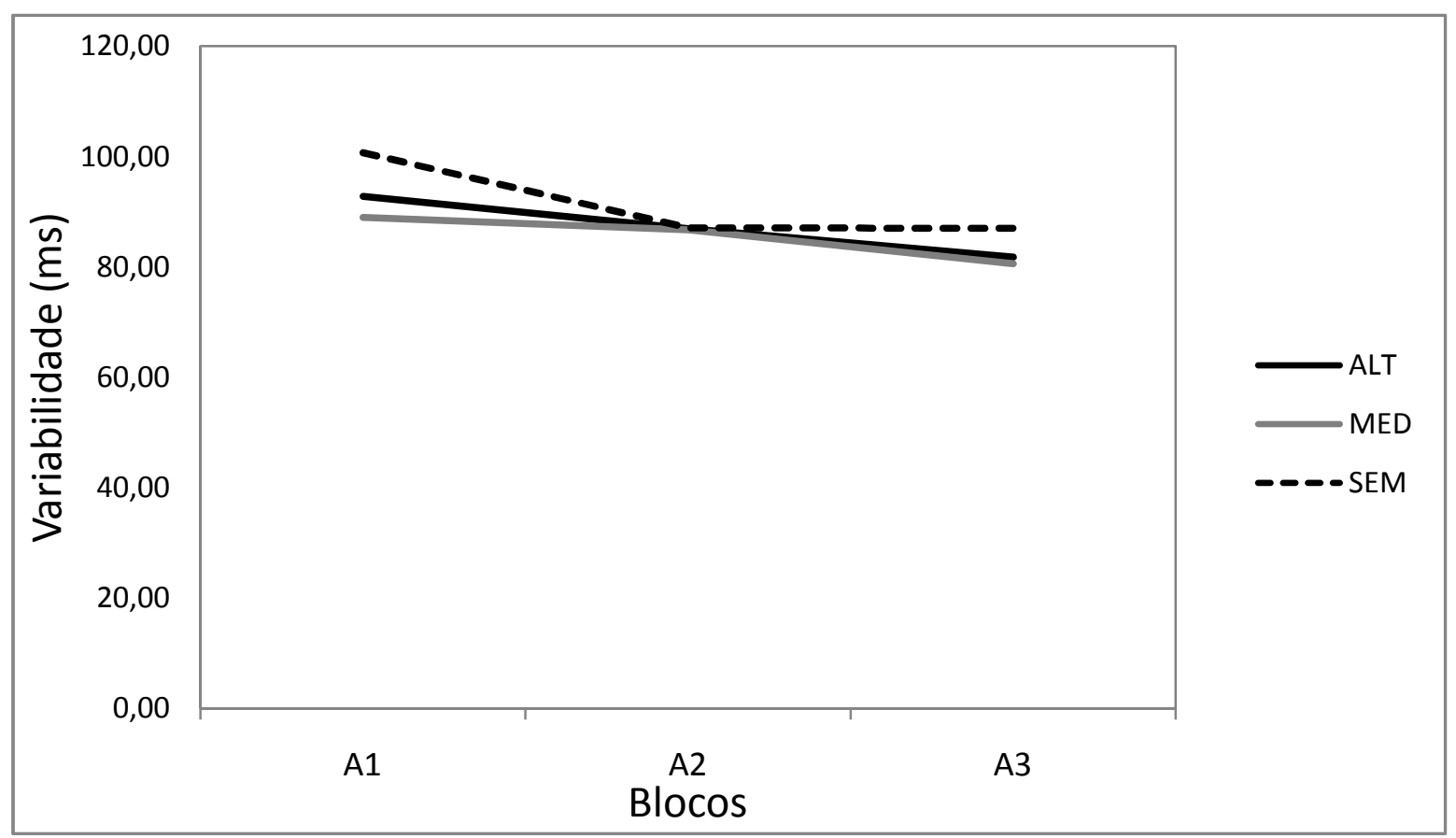

FIGURA 19 - Média da média do desvio padrão dos tempos de toques absolutos na fase de adaptação (A1, A2 e A3) por condição do início da fase de estabilização (ALT, MED e SEM) por blocos de dez tentativas.

A variabilidade da microestrutura em razão da condição do final da estabilização (FIGURA 20) também apresenta redução semelhante à variabilidade da macroestrutura nas mesmas condições, com diferenças entre condições menos nítidas. A ANOVA não apontou diferença na variabilidade em conseqüência da condição do final da estabilização [Fim: $F(2 ; 132)=2,33 ; p=0,10$; Fim $X$ Blocos: $F(3,50 ; 231,54)=1,67 ; p=0,15]$, apontando novamente apenas diferenças entre blocos $[F(1,75 ; 231,5)=13,28 ; p<0,001]$. As diferenças foram localizadas entre A1 e A2 $(p<0,01)$ e entre $A 1$ e A3 $(p<0,001)$. 


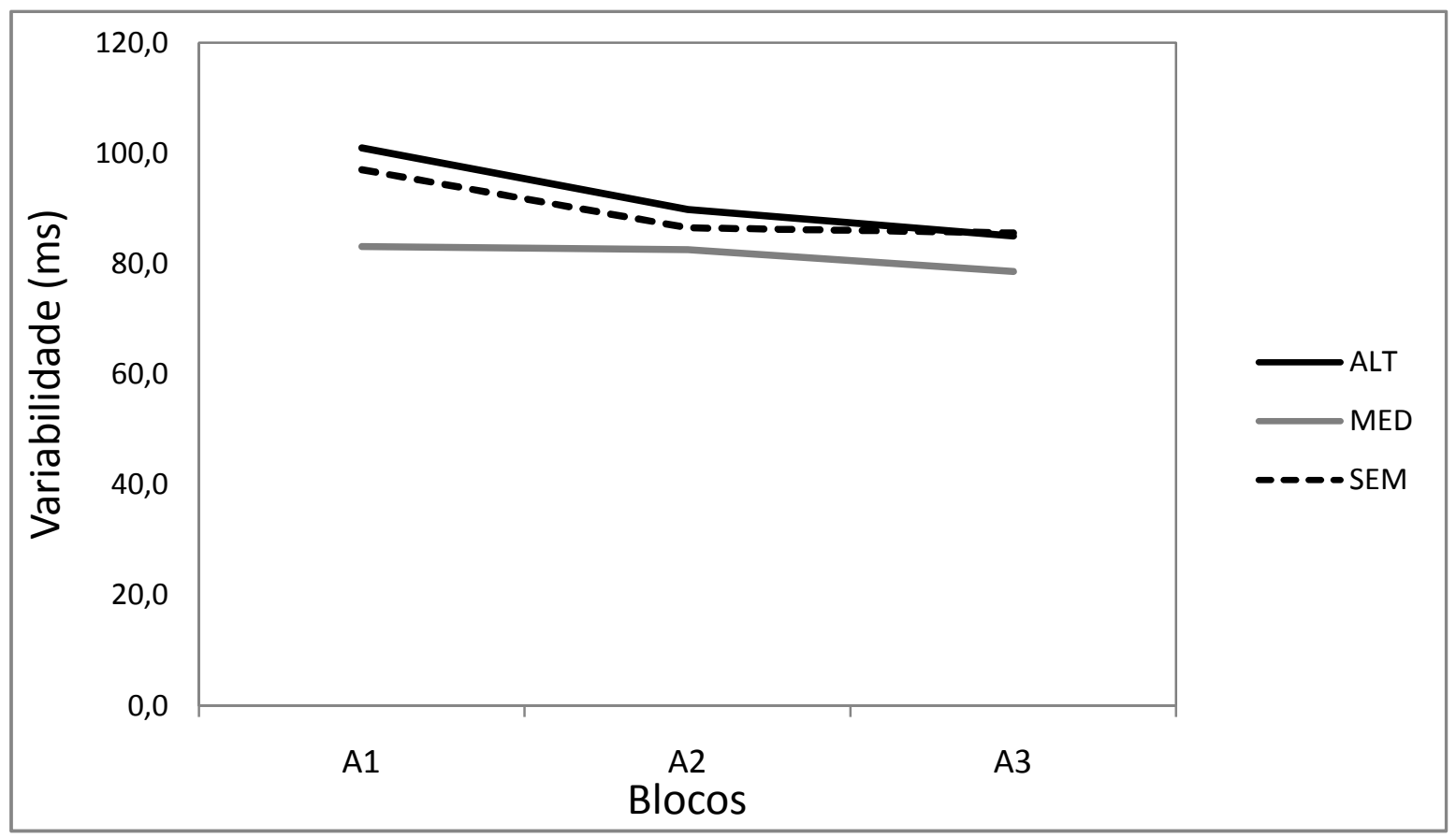

FIGURA 20 - Média da média do desvio padrão dos tempos de toques absolutos na fase de adaptação (A1, A2 e A3) por condição do final da fase de estabilização (ALT, MED e SEM) por blocos de dez tentativas.

O presente estudo teve como objetivo investigar o efeito da liberdade na escolha da resposta em diferentes momentos do processo de estabilização, no processo adaptativo em aprendizagem motora. Mais especificamente, (1) se há efeito da liberdade na escolha da resposta quando a prática vai além da estabilização inicial do desempenho e (2) se há efeito da liberdade na escolha da resposta nos diferentes momentos do processo de estabilização (antes e após a estabilização inicial do desempenho). A discussão será organizada tratando inicialmente dos resultados da fase de estabilização e, em seguida, dos resultados da fase de adaptação.

No que tange à fase de estabilização, a primeira preocupação é observar se a manipulação experimental teve como conseqüência diferenças entre grupos no que concerne à variabilidade do seqüenciamento, pois a partir da manipulação da variável independente (liberdade na escolha da resposta) os participantes do presente estudo poderiam ou não fazer uso da possibilidade de variar a ordem dos 
toques da seqüência praticada. Nesse sentido, ainda que os efeitos da variável independente pudessem manifestar-se mesmo na ausência de variações na ordem dos toques, foi possível observar diferenças nítidas entre as condições experimentais (SEM, MED e ALT) especialmente no primeiro e segundo blocos de prática. Portanto, é possível observar que os efeitos da condição experimental repercutiram na forma como os participantes realizaram a seqüência de toques na fase de estabilização.

Observando os efeitos da manipulação experimental nas medidas de erro na fase de estabilização é possível inferir que não houve efeitos negativos relacionados à introdução da possibilidade de escolha da resposta no erro absoluto, de execução, variável ou no número de tentativas para atingir o critério de desempenho. Todos os grupos foram capazes de reduzir o erro, em geral, do primeiro bloco para os demais. Ainda que os resultados da análise descritiva que apontam erros superiores no primeiro bloco para grupos na condição SEM não tenham sido confirmados pela análise inferencial, a possibilidade de variar os toques pode permitir ao aprendiz praticar inicialmente de acordo com as próprias preferências sem levar a uma degradação do desempenho. Os resultados também convergem para a ausência de diferenças na fase de prática entre condições autocontroladas e controladas pelo experimentador observada em estudos anteriores, com os efeitos do auto-controle de diferentes variáveis de prática se manifestando geralmente na fase de teste - retenção ou transferência (BUND; WIEMEYER, 2004; WULF, 2007).

No que se refere à fase de adaptação os efeitos da manipulação experimental em relação ao desempenho foram sutis. Em relação à primeira questão (efeito da liberdade na escolha da resposta na prática além da estabilização inicial do desempenho), pode-se inferir que não houve efeito da variável independente, pois não houve efeito detectável dos grupos nas medidas principais de desempenho (erro absoluto e erros de execução) e todos os grupos apresentaram redução dos erros após sua elevação inicial no início da adaptação, sugerindo adaptação bem sucedida. A divergência entre os resultados do presente estudo e o experimento 3 de Bastos (2007) vai além da ausência de grandes diferenças entre os grupos nas medidas de erro na fase de adaptação. O delineamento do experimento 3 de Bastos (2007) consistiu de prática realizada até o alcance do desempenho critério e a 
subseqüente passagem à fase de adaptação com modificação perceptivo-motora da tarefa idêntica à do presente estudo. No entanto, os efeitos da condição na prática até $\mathrm{o}$ alcance do critério de desempenho (análises do fator Início) no presente estudo, ou seja, a fase de prática similar ao experimento de Bastos (2007), não teve como resultado diferenças no desempenho na fase de adaptação.

Sem dúvida a quantidade de prática é um fator importante para explicar estes resultados. Estudos anteriores (FREUDENHEIM, 1999; UGRINOWITSCH, 2003) indicam que a partir do aumento do número de tentativas de prática os participantes tornam-se capazes de manter o desempenho frente a modificações na tarefa, o que não ocorre em participantes com menor quantidade de prática - os quais apresentam maior degradação do desempenho. $O$ desempenho semelhante dos grupos na fase de adaptação, ao contrário do experimento 3 de Bastos (2007), possivelmente se deve, em grande medida, à maior quantidade de prática.

As evidências de estudos anteriores investigando a liberdade na escolha da reposta (BASTOS, 2007; TANI, 1982; WALTER, 2007) sugerem que embora a possibilidade de escolher características da resposta motora possa favorecer a adaptação bem-sucedida, as condições com maiores graus de liberdade na escolha da resposta podem dificultar o alcance da estabilização funcional, sugerindo ainda a existência de graus ótimos de liberdade na escolha da resposta. Nesse sentido, uma das hipóteses do presente estudo foi que a partir da estabilização inicial do desempenho (aferida por meio do desempenho critério) a prática em condições com maiores graus de liberdade na escolha da resposta não traria tais efeitos deletérios ao desempenho.

Em geral, os resultados apontam ausência de diferenças entre o desempenho dos grupos, o que apóia a hipótese formulada. Entretanto, apesar da semelhança no desempenho dos grupos na fase de adaptação, há indícios que a condição de prática após o alcance do critério de desempenho pode ter um papel importante na adaptação bem-sucedida. Ainda que os resultados favoráveis aos grupos ALT-MED, MED-MED e SEM-MED, quais sejam, menor erro absoluto e menor variabilidade da macroestrutura, não tenham sido confirmados pela análise inferencial e portanto não sejam generalizáveis, a ausência de modificações nestes grupos no erro variável do último bloco da estabilização para os blocos da adaptação 
mostra que os participantes destes grupos foram capazes de enfrentar as modificações da tarefa mantendo a consistência do desempenho. Assim, o resultado indica que pode haver benefícios na prática com restrições intermediárias no que se refere à possibilidade de escolher a ordem dos toques. Frente aos resultados referentes ao erro variável, que aponta melhor desempenho para os grupos ALTMED, MED-MED, SEM-MED e SEM-SEM, ainda que para uma quantidade relativamente pequena de prática, é possível sugerir uma reconsideração dos efeitos das condições com maiores possibilidades de escolha, que podem não estar restritos apenas à estabilização inicial do desempenho. Esses resultados apontam na mesma direção que os estudos 3 e 4 de Tani (1982) onde o grupo em condição de liberdade intermediária na segunda metade da prática (seqüência determinada pelo experimentador e subelementos escolhidos pelos participantes) após uma condição de maior liberdade na primeira metade da prática (ordem dos elementos na seqüência e subelementos escolhidos pelo participante) alcançou melhor desempenho na adaptação quando comparado ao grupo em que ambos eram determinados pelo experimentador.

Que características da prática na fase de estabilização podem ter sido responsáveis pelo desempenho dos grupos na fase de adaptação? Uma medida que pode auxiliar nessa caracterização é a variabilidade de seqüenciamento. Os grupos que descritivamente apresentaram melhor desempenho (ALT-MED e MED-MED) foram aqueles que mantiveram variabilidade de seqüenciamento maior em relação aos demais grupos no primeiro bloco analisado, e reduziram consideravelmente a variabilidade nos demais. Por sua vez, os grupos que apresentaram menor variabilidade no bloco inicial (ALT-ALT, MED-ALT e MED-SEM) e maior variabilidade nos blocos após o alcance do critério (MED-ALT e SEM-MED) não apresentaram desempenho destacado na fase de adaptação. A estas observações se acrescentam os maiores valores de erro e variabilidade apresentados pelos grupos que praticaram na condição ALT no final da fase de estabilização em diversas medidas. O resultado, que deve ser interpretado com cautela em função da ausência de diferenças estatisticamente detectáveis, vai de encontro aos resultados dos experimentos de Bastos (2007) que aponta indicativos de maior erro absoluto na fase de adaptação no grupo que praticou a tarefa na condição SEM no experimento 2, e maior erro 
absoluto no grupo ALT no experimento 3, que empregou modificação na tarefa idêntica à introduzida no presente estudo. Os resultados do estudo de Walter (2007), onde condições de prática constante (com ou sem possibilidade de escolher a seqüência ou elementos da seqüência) eram seguidos, após o alcance do desempenho critério, pela mesma condição ou por condição com variação de seqüencias compulsória ou possibilidade de variar, fornecem evidências similares. Os grupos que alcançaram melhor desempenho, em relação ao erro absoluto, foram aqueles que praticaram após o critério de desempenho mantendo a ordem dos componentes da seqüência $[\mathrm{CO}(\mathrm{C})]$ ou a seqüência escolhida $[\mathrm{CO}(\mathrm{S})]$, e não aqueles em que foi introduzida a possibilidade de variar.

De forma geral, a ausência de diferenças entre os grupos no que se refere às medidas de desempenho sugere que não houve efeitos deletérios advindos da introdução da possibilidade de escolher a seqüência de toques. Os resultados convergem com os estudos anteriores realizados sob uma perspectiva de equilíbrio, que apontam desempenho superior ou similar das condições em que os participantes poderiam escolher quanto à variáveis da prática, instrução ou feedback aumentado quando contrastadas a condições em que estas variáveis eram controladas pelo experimentador (BUND; WIEMEYER, 2004; WULF, 2007). A realização de prática adicional após a estabilização inicial do desempenho minimizou o efeito da variável independente, permitindo a todos os grupos reduzirem os erros absoluto e de execução após a introdução da modificação perceptivo-motora na fase de adaptação. A partir dos resultados, pode-se considerar que, para a prática realizada após a estabilização inicial do desempenho, as condições com liberdade na escolha da resposta não foram prejudiciais ao desempenho na fase de adaptação. Entretanto, os resultados referentes ao erro variável sugerem que um grau intermediário de liberdade na escolha da resposta na prática após a estabilização inicial do desempenho pode favorecer a consistência do desempenho na adaptação, o que está em concordância com estudos anteriores realizados sob a perspectiva. 
Considerando o objetivo do presente estudo (investigar o efeito da liberdade na escolha da resposta em diferentes momentos do processo de estabilização, no processo adaptativo em aprendizagem motora) e com base nos resultados apresentados, pode-se concluir que:

- Os participantes utilizaram a possibilidade de variar a ordem dos toques de acordo com a condição experimental, especialmente no primeiro e segundo blocos da fase de estabilização. Mais especificamente, a variável indepentente provocou diferenças no que concerne à prática dos diferentes grupos.

- Não houve efeito das condições de liberdade na escolha da resposta do início da fase de estabilização no desempenho na fase de adaptação.

- Houve efeito da condição de liberdade na escolha da resposta do final da fase de estabilização no desempenho, em relação ao erro variável, na fase de adaptação. A condição de liberdade intermediária favoreceu a manutenção da consistência frente às modificações da tarefa quando comparada às demais condições. 


\section{REFERENNCIAS}

ADAMS, J. A. A closed-loop theory of motor learning. Journal of Motor Behavior, Washington, DC, v. 3, n. 2, p. 111-150, jun. 1971.

ARAUJO, U. O.; BASTOS, F. H.; FREUDENHEIM, A. M. Processo de estabilização em uma tarefa de timing coincidente seqüencial: um estudo exploratório. In: CONGRESSO BRASILEIRO DE COMPORTAMENTO MOTOR, 2., e SEMINÁRIO DE COMPORTAMENTO MOTOR, 4., 2004, Belo Horizonte. Anais... Belo Horizonte: Escola de Educação Física, Fisioterapia e Terapia Ocupacional, Universidade Federal de Minas Gerais, 2004. p. 119. 1 CD-ROM.

ARAUJO, U. O.; BASTOS, F. H.; FREUDENHEIM, A. M. Efeito da restrição do erro ao longo do processo de aquisição de habilidades motoras: um estudo exploratório. Revista Brasileira de Educação Física e Esporte, São Paulo, v. 20 (Suplemento n.5), p. 114, 2006.

BANDURA, A. Social foundations of thought and action: a social cognitive theory. Englewood Cliffs, NJ: Prentice-Hall, 1986.

BASTOS, F. H. Efeito do grau de liberdade na escolha da resposta no processo adaptativo em aprendizagem motora. 2006. xvi,127f. Dissertação (Mestrado) Escola de Educação Física e Esporte, Universidade de São Paulo, São Paulo, 2007.

BASTOS, F. H.; ARAUJO, U. O.; WALTER, C.; FREUDENHEIM, A. M. Liberdade de escolha do aprendiz no processo adaptativo em aprendizagem motora. Revista Brasileira de Educação Física e Esporte, São Paulo, v. 21, n. 3, p. 167-176, jul./set. 2008.

BERTALANFFY, L. (1968). Teoria geral dos sistemas. Petrópolis: Vozes, 1977

BOEKAERTS, M. Self-regulated learning: where are we today. International Journal of Educational Research, Oxford; New York, v. 31, n. 6, 1999.

BOYCE, B. A. Effects of assigned versus participant-set goals on skill acquisition and retention of a selected shooting task. Journal of Teaching in Physical Education, Champaign, IL, v. 11, n. 3, p. 220-234, apr. 1992.

BOYCE, B. A.; WAYDA, V. K.; JOHNSTON, T.; BUNKER, L. K.; ELIOT, J. The effects of three types of goal setting conditions on tennis performance: a field-based study. Journal of Teaching in Physical Education, Champaign, IL, v. 20, n. 2, p. 188-200, jan. 2001.

BUND, A.; WIEMEYER, J. Self-controlled learning of a complex motor skill: effects of the learner's preferences on performance and self-efficacy. Journal of Human Movement Studies, Edinburgh, UK, v. 47, n. 3, p. 215-236, mar. 2004. 
CHEN, D.D.; HENDRICK, J.L.; LIDOR, R. Enhancing self-controlled learning environments: The use of self-regulated feedback information. Journal of Human Movement Studies, Edinburgh, UK, v. 43, n. 1, p. 69-86, jan. 2002.

CHIVIACOWSKY, S. Efeito da freqüência de conhecimento de resultados controlada pelo experimentador e auto-controlada pelos sujeitos na aprendizagem de tarefas motoras com diferentes complexidades. 2000. xxvi, 335f. Dissertação (Doutorado), Faculdade de Motricidade Humana, Universidade Técnica de Lisboa, Lisboa, 2000.

CHIVIACOWSKY, S.; WULF, G. Self-controlled feedback: does it enhance learning because performers get feedback when they need it? Research Quarterly for Exercise and Sport, Washington, DC, v. 73, n. 4, p. 408-415, dec. 2002.

- Self-controlled feedback is effective if it is based on the learner's performance. Research Quarterly for Exercise and Sport, Washington, DC, v. 76, n. 1, p. 42-48, mar. 2005.

- Feedback after good trials enhances learning. Research Quarterly for Exercise and Sport, Washington, DC, v.78, n.1, p. 40-47, mar. 2007.

CHOSHI, K.; TANI, G. Stable system and adaptive system in motor learning. In: JAPANESE ASSOCIATION OF BIOMECHANICS (Ed.) The science of movement V. Tokyo: Kyorin, 1983. (em japonês).

COLLEY, A. M. Cognitive motor skills. In: HOLDING, D. (Ed.) Human skills. 2nd ed. Chichester: Wiley, 1989. Cap. 9, p. 229-248.

CONNOLLY, K.J. The nature of motor skill development. Journal of Human Movement Studies, Edinburgh, UK, v.3, p.128-143, 1977.

CORRÊA, U. C. Estrutura de prática e processo adaptativo na aquisição de habilidades motoras. 2001. 220f. Tese (Doutorado) - Escola de Educação Física e Esporte, Universidade de São Paulo, São Paulo, 2001.

CORREAA, U. C.; TANI, G. Aparelho de timing coincidente em tarefas complexas. $n^{\circ}$ PI 0.4.04.433-4, 03 agosto 2004. (Revista da Propriedade Industrial, n. 1763, p. 178, 19/10/2004).

FITTS, P. M.; POSNER, M. I. Human performance. Belmont: Brooks/Cole, 1967.

FREUDENHEIM, A. M. Estabilidade e variabilidade na aquisição de habilidades motoras. In: TANI, G. (Ed.). Comportamento motor: aprendizagem e desenvolvimento. Rio de Janeiro: Guanabara-Koogan, 2005. Cap. 9, p. 117-128. 
- Organização hierárquica de um programa de ação e a estabilização de habilidades motoras. 1999. xxi, 249f. Tese (Doutorado) - Escola de Educação Física e Esporte, Universidade de São Paulo, São Paulo, 1999.

. Um teste à formação de esquema: efeito da variabilidade e da quantidade de prática na produção de movimentos novos em adultos. Revista Paulista de Educação Física, São Paulo, v. 8, n. 1, p. 3-16, jan./jun. 1994.

FREUDENHEIM, A. M.; MANOEL, E. J. Organização hierárquica e a estabilização de um programa de ação: um estudo exploratório. Revista Paulista de Educação Física, São Paulo, v. 13, n. 2, p. 177-196, jul./dez. 1999.

GLENCROSS, D. J. Levels and strategies of response organization. In: STELMACH, G. E.; REQUIN, J. (Eds.) Tutorials in motor behavior. Amsterdam: North-Holland, 1980. Cap. 34, p. 551-566.

HAKEN, H. Synergetics: an introduction. Berlin: Springer-Verlag, 1977.

HARKINS, S. G.; LOWE, M. S. Effects of self-set goals on task performance. Journal of Applied Social Psychology, Washington, DC, v. 30, n. 1, p. 1-40, jan. 2000.

HEYLIGHEN, F.; JOSLYN, C. Cybernetics and second-order cybernetics. In: MEYERS, R. A. (Ed.). Encyclopedia of physical science and technology. 3rd ed. New York: Academic Press, 2001.

JANELLE, C. M.; BARBA, D. A.; FREHLICH, S. G.; TENNANT, S. K.; CAURAUGH, J. $\mathrm{H}$. Maximizing performance feedback effectiveness through videotape replay and a self-controlled learning environment. Research Quarterly for Exercise and Sport, Washington, DC, v. 68, n. 4, p. 269-279, dec. 1997.

JANELLE, C. M.; KIM, J.; SINGER, R. N. Subject-controlled performance feedback and learning of a closed motor skill. Perceptual and Motor Skills, Missoula, v. 81, n. 2, p. 627-634, oct. 1995.

KOESTLER, A. Beyond atomism and holism - the concept of holon. In: KOESTLER, A.; SMYTHIES, J. R. (Eds.) Beyond reductionism: new perspectives in life sciences. London: Hutchinson, 1969.

KUHN, T. S. (1970) A estrutura das revoluções científicas. $3^{a}$ ed. São Paulo: Perspectiva, 1995.

LOCKE, E. A. Toward a theory of task motivation and incentives. Organizational Behavior and Human Performance, San Diego, CA, v. 3, n. 2, p. 157-189, 1968.

LOCKE, E. A.; LATHAM, G. P. A theory of goal setting and task performance. Englewood Cliffs, NJ: Prentice Hall, 1990. 
. Building a practically useful theory of goal setting and task motivation: a 35year odyssey. American Psychologist, Washington, DC, v. 57, n. 4, p. 705-717, sep. 2002.

. New directions in goal-setting theory. Current Directions in Psychological Science, Rochester, v. 15, n. 5, p. 265-268, oct. 2006.

MANOEL, E. J. Desenvolvimento do comportamento motor humano: uma abordagem sistêmica. 1989. 312f. Dissertação (Mestrado) - Escola de Educação Física e Esporte, Universidade de São Paulo, São Paulo, 1989.

MANOEL, E. J.; CONNOLLY, K. J. Variability and the development of skilled actions. International Journal of Psychophysiology, Amsterdam, v. 19, n. 2, p. 129-147, mar. 1995.

. Variability and stability in the development of skilled actions. In: CONNOLLY, K. J.; FORSBERG, H. Neurophysiology and neuropsychology of motor development. London: Mac Keith / Cambridge: Cambridge University Press, 1997. Cap. 14, p. 286318.

MARTENIUK, R. G. Information processing in motor skills. New York: Holt, Rinehart and Winston, 1976.

MARUYAMA, M. Second cybernetics - deviation-amplifying mutual causal processes. American Scientist, New Haven, v. 51, p. 164-179, 1963

MEIRA JR., C. M. Conhecimento de resultados e processo adaptativo em aprendizagem motora. 2005. xv, 179 f. Tese (Doutorado em Educação Física) Escola de Educação Física e Esporte, Universidade de São Paulo, São Paulo, 2005.

MILLER, J. G. Living systems. New York: McGraw-Hill, 1978.

NEWELL, K. M.; CORCOS, D. M. Variability and motor control. Champaign, IL: Human Kinetics, 1993.

PAROLI, R. Efeito da estrutura de prática na aquisição de uma habilidade motora. 2004. xviii, 278f. Dissertação (Mestrado) - Escola de Educação Física e Esporte, Universidade de São Paulo, São Paulo, 2004.

PEAT, J.; BARTON, B. Medical statistics: a guide to data analysis and critical appraisal. Oxford: Blackwell, 2005.

PEW, R. W. Levels of analysis in motor control. Brain Research, Amsterdam, v. 71, n. 2-3, p. 764-771, may 1974.

PINKER, S. Como a mente funciona. $2^{\mathrm{a}}$ Ed. São Paulo: Companhia das Letras, 1998. 
PRIGOGINE, I. O fim das certezas: tempo, caos e as leis da natureza. São Paulo: Editora da Universidade Estadual Paulista, 1996.

SCHMIDT, R. A. A schema theory of discrete motor skill learning. Psychological Review, Washington, DC, v. 82, n. 4, p.225-260, jul. 1975.

. Motor schema theory after 27 years: reflections and implications for a new theory. Research Quarterly for Exercise and Sport, Washington, DC, v. 74, n. 4, p. 366-375, dec. 2003.

Toward a better understanding of the acquisition of skill: theoretical and practical contributions of the task approach. In: SKINNER, J. S.; CORBIN, C. B.; LANDERS, D. M.; MARTIN, P. E.; WELLS, C. L. Future directions in exercise and sport science research. Champaign, IL: Human Kinetics, 1989.

SCHMIDT, R. A.; LEE, T. D. Motor control and learning: a behavioral emphasis. 3rd ed. Champaign, IL: Human Kinetics, 1999.

SCHUNK, D. H.; ZIMMERMAN, B. J. Self-regulation in education: retrospect and prospect. In: SCHUNK, D. H.; ZIMMERMAN, B. J. (Eds.). Self-regulation of learning and performance: issues and educational applications. Hillsdale, NJ: Lawrence Erlbaum, 1994. Cap 13, p. 305-314.

SHANNON, C.; WEAVER, W. The mathematical theory of communication. Urbana: University of Illinois, 1949.

TANI, G. Adaptive process in perceptual-motor skill learning. Doctoral Dissertation. Faculty of Education, Hiroshima University, Hiroshima, 1982. (em japonês).

Criança e movimento: o conceito de prática na aquisição de habilidades motoras. In: KREBS, R. J.; COPETTI, F.; BELTRAME, T. S.; USTRA, M. (Orgs). Perspectivas para o desenvolvimento infantil. Santa Maria: Edições SIEC, 1999. p. $57-64$.

Hierarchical organisation of an action programme in the acquisition of a graphic skill. 1995. 169f. Relatório Final de Atividades (Pós-Doutorado) - Department of Psychology, University of Sheffield, 1995.

- Processo adaptativo: uma concepção de aprendizagem motora além da estabilização. In: _. (Ed.). Comportamento motor: aprendizagem e desenvolvimento. Rio de Janeiro: Guanabara-Koogan, 2005. Cap. 5, p. 60-70.

- Variabilidade de resposta e processo adaptativo em aprendizagem motora. 1989. 78f. Tese (Livre Docência) - Escola de Educação Física e Esporte, Universidade de São Paulo, São Paulo, 1989. 
. Variabilidade e programação motora. In: AMADIO, A. C.; BARBANTI, V. J. (Orgs.) A biodinâmica do movimento humano e suas relações interdisciplinares. São Paulo: Estação Liberdade, 2000. Cap. 14, p. 245-260.

TANI, G.; CORREAA, U. C.; BENDA, R. N.; MANOEL, E. de J. O paradigma sistêmico e o estudo do comportamento motor humano. In: TANI, G. (Ed). Comportamento motor: aprendizagem e desenvolvimento. Rio de Janeiro: Guanabara-Koogan, 2005. Cap. 4, p. 45-59.

TANI, G.; FREUDENHEIM, A. M.; MEIRA JR., C. M.; CORREAA, U. C. Aprendizagem motora: tendências, perspectivas e aplicações. Revista Paulista de Educação Física, São Paulo, v.18, n. especial, p. 55-72, ago. 2004 (número especial em comemoração aos 70 anos da Escola de Educação Física e Esporte da Universidade de São Paulo).

TITZER, R.; SHEA, J. B.; ROMACK, J. The effect of learner control on the acquisition and retention of a motor task. Journal of Sport and Exercise Psychology, Champaign, IL, v. 15 (Supplement), p. S84, jun. 1993.

THORESEN, C. E.; MAHONEY, M. J. Behavioral self-control. New York : Holt, Rinehart and Winston, 1974.

TURVEY, M. T. Preliminaries to a theory of action with reference to vision. In: SHAW, R.; BRANSFORD, J. Perceiving, acting and knowing: toward an ecological psychology. Hillsdale: Erlbaum, 1977. Cap. 9, p. 211-263.

UGRINOWITSCH, H. Efeito do nível de estabilização do desempenho e do tipo de perturbação no processo adaptativo em aprendizagem motora. 2003. xxxii, 365f. Tese (Doutorado) - Escola de Educação Física e Esporte, Universidade de São Paulo, São Paulo, 2003.

VASCONCELOS, M. J. E. Pensamento sistêmico: o novo paradigma da ciência. $3^{a}$ ed. Campinas: Papirus, 2002.

VINCENT, W. J. Statistics in kinesiology. 2nd Ed. Champaign, IL: Human Kinetics, 1999.

WALTER, C. Estrutura de prática e liberdade de escolha no processo adaptativo em aprendizagem motora. 2007. Dissertação (Mestrado) - Escola de Educação Física e Esporte, Universidade de São Paulo, São Paulo, 2007.

WALTER, C.; BASTOS, F. H.; ARAUJO, U. O.; SILVA, J. A. O.; CORREAA, U. C. Estrutura de prática e liberdade de escolha na aprendizagem de habilidades motoras. Revista Portuguesa de Ciências do Desporto, Porto, v. 8, n. 3, p 337-346, set./dez. 2008.

WIENER, N. (1948). Cibernética. São Paulo: Pioneira, 1970. 
. (1954). Cibernética e sociedade: o uso humano de seres humanos. São Paulo: Cultrix, 1984.

WRISBERG, C. A.; PEIN, R. L. Note on learners' control of the frequency of model presentation during skill acquisition. Perceptual and Motor Skills, Missoula, v. 94, n. 3 (Part 1), p.792-794, jun 2002.

WU, W. F. W.; MAGILL, R. A. To dictate or not: the exploration of a self-regulated practice schedule. Journal of Sport and Exercise Psychology, Champaign, IL, v. 26 (Supplement), p. S202, jun. 2004

WU, W. F. W.; MAGILL, R. A.; FOTO J. G. Journal of Sport and Exercise Psychology, Champaign, IL, v. 27 (Supplement), p. S161, jun. 2005.

WULF, G. Self-controlled practice enhaces motor learning: implications for physiotherapy. Physiotherapy, London, v. 93, n. 2, p. 96-101, jun. 2007

WULF, G.; CLAUSS, A.; SHEA, C. H.; WHITACRE, C. Benefits of self-control in dyad practice. Research Quarterly for Exercise and Sport, Washington, DC, v. 72, n. 3, p. 299-303, sep. 2001.

WULF, G.; RAUPACH, M.; PFEIFFER, F. Self-controlled observational practice enhances learning. Research Quarterly for Exercise and Sport, Washington, DC, v. 76, n. 1, p. 107-111, mar. 2005.

WULF, G.; TOOLE, T. Physical assistance devices in complex motor skill learning: Benefits of a self-controlled practice schedule. Research Quarterly for Exercise and Sport, Washington, DC, v. 70, n. 3, p. 265-272, sep. 1999.

YATES, E. F. (Ed.) Self-organizing systems: the emergence of order. New York: Plenum Press, 1987

ZIMMERMAN, B. J. Dimensions of academic self-regulation: a conceptual framework for education. In: SCHUNK, D. H.; ZIMMERMAN, B. J. (Eds.). Self-regulation of learning and performance: issues and educational applications. Hillsdale, $\mathrm{NJ}$ : Lawrence Erlbaum, 1994. Cap. 1, p. 3-21.

- Models of self-regulated learning and academic achievement. In: ZIMMERMAN, B. J.; SCHUNK, D. H. (Eds.). Self-regulated learning and academic achievement: theory, research and practice. New York: Springer Verlag, 1989. Cap. 1, p. 1-25. 
ANEXO I - Termo de consentimento livre e esclarecido

ESCOLA DE EDUCAÇÃo FísICA E ESPORTE DA UNIVERSIDADE DE SÃO PAULO
Comitê de Ética em Pesquisa

TERMO DE CONSENTIMENTO LIVRE E ESCLARECIDO

(Instruções para preenchimento ao final)

\section{I - DADOS DE IDENTIFICAÇÃO DO SUJEITO DA PESQUISA OU RESPONSÁVEL LEGAL}

1. NOME DO INDIVÍDUO:

Documento de identidade $\mathrm{N}^{\circ}$ :

Data de nascimento:

Endereço:

Bairro:

Cidade:

Sexo: $\square \mathrm{M} \square \mathrm{F}$

Telefone:

$\mathrm{N}^{\circ}$

CEP:

APTO

2. RESPONSÁVEL LEGAL:

Natureza (grau de parentesco, tutor, curador, etc.)

Documento de identidade $\mathrm{N}^{\circ}$ :

Sexo: $\square \mathrm{M} \square \mathrm{F}$

Data de nascimento:

Endereço:

Bairro:

Cidade:

$\mathrm{N}^{\circ}$

Telefone:

CEP:

APTO

\section{II - DADOS SOBRE A PESQUISA CIENTÍFICA}

1. Título do Projeto de Pesquisa

Liberdade na escolha da resposta e momento da estabilização no processo adaptativo em aprendizagem motora

2. Pesquisador Responsável

Profa. Dra. Andrea Michele Freudenheim

3. Cargo/Função

Professor Assistente Doutor

4. Avaliação do risco da pesquisa:

RISCO MÍNIMO $\square \quad$ RISCO BAIXO $\square \quad$ RISCO MÉDIO $\square \quad$ RISCO MAIOR

(probabilidade de que o indivíduo sofra algum dano como conseqüência imediata ou tardia do estudo)

5. Duração da Pesquisa

Fevereiro de 2008 a Julho de 2008 
ANEXO I - Termo de consentimento livre e esclarecido (cont.)

\section{III - EXPLICAÇÕES DO PESQUISADOR AO INDIVÍDUO OU SEU REPRESENTANTE LEGAL SOBRE A PESQUISA, DE FORMA CLARA E SIMPLES, CONSIGNANDO:}

1. Esse estudo está sendo desenvolvido pelo Laboratório de Comportamento Motor da Escola de Educação Física e Esporte da USP com o objetivo de investigar os efeitos da liberdade de escolha e do momento da estabilização na adaptação a uma modificação da tarefa.

2. Você será instruído a praticar uma tarefa de laboratório, que constitui-se de uma seqüência de toques em sensores dispostos sobre uma mesa em uma das condições do experimento, para que possa ser realizada a comparação do desempenho entre os grupos nas diferentes condições.

3. Não há desconfortos e riscos esperados;

4. Você poderá manter parte do desempenho obtido na tarefa do estudo em tarefas similares.

\section{IV - ESCLARECIMENTOS DADOS PELO PESQUISADOR SOBRE GARANTIAS DO SUJEITO DA} PESQUISA:

1. acesso, a qualquer tempo, às informações sobre procedimentos, riscos e benefícios relacionados à pesquisa, inclusive para dirimir eventuais dúvidas;

2. liberdade de retirar seu consentimento a qualquer momento e de deixar de participar do estudo, sem que isto traga prejuízo à continuidade da assistência;

3. salvaguarda da confidencialidade, sigilo e privacidade; e

4. disponibilidade de assistência no HU ou HCFMUSP, por eventuais danos à saúde, decorrentes da pesquisa.

\section{V - INFORMAÇÕES DE NOMES, ENDEREÇOS E TELEFONES DOS RESPONSÁVEIS PELO ACOMPANHAMENTO DA PESQUISA, PARA CONTATO EM CASO DE INTERCORRÊNCIAS CLÍNICAS E REAÇÕES ADVERSAS.}

Para questões associadas com este experimento, por favor, entre em contato com Profa. Dra. Andrea Michele Freudenheim -, pesquisadora responsável pelo estudo pelo telefone (11) 30913135.

O Laboratório de Comportamento Motor fica na escola de Educação Física e Esporte, Universidade de São Paulo (USP), na avenida Prof. Dr. Mello Moraes, 65 - Butantã, São Paulo, SP. CEP 05508-030, fone (11) 3091-2147.

\section{VI. - OBSERVAÇÕES COMPLEMENTARES \\ Não há.}

\section{VII - CONSENTIMENTO PÓS-ESCLARECIDO}

Declaro que, após convenientemente esclarecido pelo pesquisador e ter entendido o que me foi explicado, consinto em participar do presente Projeto de Pesquisa.

São Paulo, de de 20 
ANEXO II - Dados individuais médios do erro absoluto nos grupos ALT-ALT, ALTMED, ALT-SEM, MED-ALT, MED-MED, MED-SEM, SEM-ALT, SEMMED e SEM-SEM na fase de estabilização (E1, E2 e E3) e na fase de adaptação (A1, A2 e A3)

\begin{tabular}{|c|c|c|c|c|c|c|c|}
\hline Grupo & Sujeito & E1 & E2 & E3 & A1 & A2 & A3 \\
\hline ALT-ALT & 1 & 208 & 45 & 34,8 & 81 & 152 & 65,8 \\
\hline ALT-ALT & 2 & 105,75 & 88,66667 & 55,88889 & 426 & 439 & 507,1429 \\
\hline ALT-ALT & 3 & 1009,714 & 34,2 & 14,125 & 1178,25 & 395,5556 & 169,5714 \\
\hline ALT-ALT & 4 & 396,625 & 37,22222 & 35,4 & 110,5 & 113,2 & 62,33333 \\
\hline ALT-ALT & 5 & 61,5 & 55,66667 & 23,33333 & 52,25 & 50,4 & 46,11111 \\
\hline ALT-ALT & 6 & 175,625 & 83,25 & 100,5 & 116,6667 & 194,3333 & 93,375 \\
\hline ALT-ALT & 7 & 119,9 & 30,7 & 47 & 29,875 & 45,125 & 85,125 \\
\hline ALT-ALT & 8 & 122,6667 & 50,2 & 46,375 & 234 & 221,25 & 208 \\
\hline ALT-ALT & 9 & 97,77778 & 45 & 32,1 & 147,875 & 157,875 & 54,6 \\
\hline ALT-ALT & 10 & 107,6667 & 23,375 & 46,625 & 186,2 & 158,125 & 81 \\
\hline ALT-ALT & 11 & 162,1429 & 89,9 & 44,22222 & 327 & 106 & 70,57143 \\
\hline ALT-ALT & 12 & 127,125 & 28,7 & 21,2 & 77,5 & 58 & 49,83333 \\
\hline ALT-ALT & 13 & 71,42857 & 26,55556 & 46,25 & 51,14286 & 67,85714 & 91,8 \\
\hline ALT-ALT & 14 & 91,5 & 52,7 & 35 & 872,1667 & 121,5 & 99,6 \\
\hline ALT-ALT & 15 & 103 & 47 & 48,7 & 120 & 67,57143 & 49,57143 \\
\hline ALT-MED & 1 & 691,5 & 76,33333 & 48,375 & 264,125 & 291,875 & 46,375 \\
\hline ALT-MED & 2 & 305,2222 & 31,25 & 23,14286 & 92,66667 & 190 & 118 \\
\hline ALT-MED & 3 & 181,4 & 43,88889 & 99,3 & 44,5 & 52,71429 & 38,5 \\
\hline ALT-MED & 4 & 118,5 & 51,8 & 26,6 & 106,4444 & 178,6667 & 64,3 \\
\hline ALT-MED & 5 & 122,875 & 47,6 & 33,77778 & 164,3333 & 148,375 & 152,1111 \\
\hline ALT-MED & 6 & 77,1 & 55,55556 & 52,88889 & 56,1 & 87 & 118,2222 \\
\hline ALT-MED & 7 & 148,5 & 97,25 & 42,2 & 71,7 & 114,875 & 64 \\
\hline ALT-MED & 8 & 73 & 86,3 & 64,8 & 153,1429 & 121,8889 & 59,33333 \\
\hline ALT-MED & 9 & 118,5 & 42 & 28,44444 & 149,2857 & 70,88889 & 74,5 \\
\hline ALT-MED & 10 & 69,28571 & 104,2 & 60,3 & 107,625 & 104,8571 & 158,25 \\
\hline ALT-MED & 11 & 159,3333 & 91,77778 & 64,33333 & 116,3 & 48,8 & 45,77778 \\
\hline ALT-MED & 12 & 63,625 & 27,3 & 40,7 & 91 & 41,375 & 84,33333 \\
\hline ALT-MED & 13 & 33,4 & 22,6 & 54,4 & 58,125 & 51,88889 & 42,5 \\
\hline ALT-MED & 14 & 76,1 & 22,33333 & 27,6 & 34,28571 & 43 & 60,9 \\
\hline ALT-MED & 15 & 57,625 & 38,2 & 29,77778 & 39,875 & 19,44444 & 31,88889 \\
\hline ALT-SEM & 1 & 92,5 & 55,375 & 53,25 & 206 & 78,8 & 219,875 \\
\hline ALT-SEM & 2 & 336,375 & 26,4 & 51,3 & 51,5 & 111,1111 & 45,6 \\
\hline ALT-SEM & 3 & 67,6 & 125,5 & 82 & 721,6667 & 86,66667 & 48,28571 \\
\hline ALT- & 4 & 139 & 40,44 & 57,7 & 45,5 & 47,3 & 40,57143 \\
\hline ALT- & 5 & & 47,66 & 18 & 47,14 & 61,88889 & 68,6 \\
\hline ALT-SEM & 6 & 139,5 & 56,77778 & 34,75 & 803,25 & 296 & 128,2857 \\
\hline ALT-SEM & 7 & 84,6 & 165,1 & 66,2 & 240,2 & 197,4286 & 169,5714 \\
\hline ALT-SEM & 8 & 199,1429 & 25,5 & 41,4 & 46,28571 & 46,16667 & 96,75 \\
\hline ALT-SEM & 9 & 151,8 & 145 & 111,5 & 347,5 & 64,28571 & 50,57143 \\
\hline ALT-SEM & 10 & 218,7143 & 50,77778 & 42,88889 & 604,7143 & 141,7778 & 194,8 \\
\hline ALT-SEM & 11 & 175,8 & 47 & 32,85714 & 17 & 127,4444 & 64,77778 \\
\hline ALT-SEM & 12 & 108,5 & 90,44444 & 47,8 & 87 & 48,375 & 73,5 \\
\hline ALT-SEM & 13 & 46 & 34,1 & 52,5 & 33,6 & 43,7 & 52,11111 \\
\hline ALT-SEM & 14 & 145,8889 & 44,75 & 66,33333 & 72,33333 & 99,66667 & 58,5 \\
\hline ALT-SEM & 15 & 49,88889 & 69,5 & 33,1 & 67,16667 & 49,25 & 46,77778 \\
\hline
\end{tabular}


ANEXO II - Dados individuais médios do erro absoluto nos grupos ALT-ALT, ALTMED, ALT-SEM, MED-ALT, MED-MED, MED-SEM, SEM-ALT, SEMMED e SEM-SEM na fase de estabilização (E1, E2 e E3) e na fase de adaptação (A1, A2 e A3) (cont.)

\begin{tabular}{|c|c|c|c|c|c|c|c|}
\hline Grupo & Sujeito & E1 & E2 & E3 & $\mathrm{A} 1$ & $\mathrm{~A} 2$ & A3 \\
\hline MED-ALT & 1 & 386 & 135,625 & 112,75 & 386,5 & 452 & 350,5 \\
\hline MED-ALT & 2 & 76,42857 & 46,1 & 24,33333 & 66,71429 & 24,75 & 54,33333 \\
\hline MED-ALT & 3 & 105,7143 & 41,33333 & 40,44444 & 636 & 426 & 61,33333 \\
\hline MED-ALT & 4 & 365,8 & 142 & 155,25 & 309 & 172,3333 & 142,6667 \\
\hline MED-ALT & 5 & 38 & 40,88889 & 48 & 33,33333 & 64,33333 & 30,42857 \\
\hline MED-ALT & 6 & 210,1 & 41,25 & 31,75 & 76,66667 & 98,57143 & 29,77778 \\
\hline MED-ALT & 7 & 69,7 & 40 & 32,3 & 124,375 & 86,55556 & 38,4 \\
\hline MED-ALT & 8 & 240,5556 & 96,4 & 45,8 & 269,5 & 304,4 & 121,7778 \\
\hline MED-ALT & 9 & 75,83333 & 109,2857 & 45,66667 & 81,5 & 256,4 & 333 \\
\hline MED-ALT & 10 & 151,125 & 31,5 & 87 & 676 & 358,7143 & 310,7778 \\
\hline MED-ALT & 11 & 163,1429 & 35,1 & 37,7 & 65,6 & 84 & 89,7 \\
\hline MED-ALT & 12 & 101,4444 & 49,3 & 68 & 465,6667 & 356,8 & 146,4286 \\
\hline MED-ALT & 13 & 63,55556 & 41,3 & 47,9 & 29 & 58,11111 & 33,75 \\
\hline MED-ALT & 14 & 96,28571 & 114,1111 & 67 & 89 & 35,14286 & 30,28571 \\
\hline MED-ALT & 15 & 72,55556 & 54,4 & 22,9 & 54 & 23,11111 & 32 \\
\hline MED-MED & 1 & 75 & 35,83333 & 22 & 106,5 & 54 & 48 \\
\hline MED-MED & 2 & 72,125 & 38,33333 & 86,22222 & 165,4 & 197 & 65,625 \\
\hline MED-MED & 3 & 341,4444 & 46,55556 & 57,9 & 329,3333 & 110,5556 & 74,75 \\
\hline MED-MED & 4 & 108,4444 & 47,22222 & 39,5 & 42 & 40,44444 & 60,125 \\
\hline MED-MED & 5 & 86,77778 & 43,2 & 47,85714 & 156,8 & 105,3333 & 83 \\
\hline MED-MED & 6 & 101,125 & 46,3 & 45 & 64,9 & 21,6 & 53,11111 \\
\hline MED-MED & 7 & 98,33333 & 28,1 & 43,4 & 129,3333 & 114,3 & 80,77778 \\
\hline MED-MED & 8 & 238,7143 & 41,5 & 59,22222 & 273 & 238 & 71,22222 \\
\hline MED-MED & 9 & 183,3333 & 75,44444 & 22,44444 & 99,7 & 65 & 88,55556 \\
\hline MED-MED & 10 & 314,4286 & 86,3 & 59 & 156,5 & 37,5 & 54,3 \\
\hline MED-MED & 11 & 67,11111 & 54,1 & 65,2 & 45,875 & 50,44444 & 85,14286 \\
\hline MED-MED & 12 & 236,4 & 61,88889 & 58,4 & 185,5 & 84,88889 & 73,77778 \\
\hline MED-MED & 13 & 90,88889 & 24,77778 & 27,2 & 58 & 83,85714 & 73,66667 \\
\hline MED-MED & 14 & 78,75 & 49 & 36,8 & 66,5 & 47,33333 & 55,25 \\
\hline MED-MED & 15 & 56,375 & 28,42857 & 35 & 54,66667 & 134,6667 & 77,42857 \\
\hline MED-SEM & 1 & 85,22222 & 32,5 & 71,85714 & 141,4286 & 103,3333 & 113,75 \\
\hline MED-SEM & 2 & 42,5 & 26,77778 & 15,71429 & 43,77778 & 45,5 & 81,85714 \\
\hline MED-SEM & 3 & 153,4 & 67,8 & 46,375 & 85,25 & 140,4286 & 97,75 \\
\hline MED-SEM & 4 & 69,6 & 65,625 & 93,42857 & 264,5 & 86,16667 & 244,75 \\
\hline MED-SEM & 5 & 328,4 & 37,285 & 42 & 349,1 & 286,7143 & 159,8333 \\
\hline MED-SEM & 6 & 123,9 & 36,55556 & 38,11111 & 149,8889 & 135,75 & 129 \\
\hline MED-SEM & 7 & 78,6 & 116,4444 & 43,6 & 41,33333 & 116,2 & 50,4 \\
\hline MED-SEM & 8 & 182,1 & 77 & 66,7 & 346,5714 & 172,5 & 71,5 \\
\hline MED-SEM & 9 & 204,4286 & 103 & 48,71429 & 195,75 & 162,8571 & 338,4286 \\
\hline MED-SEM & 10 & 45,88889 & 41,5 & 66,33333 & 148,7143 & 65,875 & 72,875 \\
\hline MED-SEM & 11 & 99,33333 & 18,2 & 54,375 & 162 & 79,375 & 63 \\
\hline MED-SEM & 12 & 145,3 & 37,5 & 37,9 & 90,7 & 74,33333 & 118,9 \\
\hline MED-SEM & 13 & 64,75 & 85,2 & 48,9 & 217,375 & 314,2857 & 240,375 \\
\hline MED-SEM & 14 & 62,71429 & 46,8 & 53,2 & 168,7778 & 174 & 94,55556 \\
\hline MED-SEM & 15 & 86 & 74,85714 & 61,75 & 209,6667 & 269,4 & 212,7778 \\
\hline
\end{tabular}


ANEXO II - Dados individuais médios do erro absoluto nos grupos ALT-ALT, ALTMED, ALT-SEM, MED-ALT, MED-MED, MED-SEM, SEM-ALT, SEMMED e SEM-SEM na fase de estabilização (E1, E2 e E3) e na fase de adaptação (A1, A2 e A3) (cont.)

\begin{tabular}{|c|c|c|c|c|c|c|c|}
\hline Grupo & Sujeito & E1 & E2 & E3 & A1 & A2 & A3 \\
\hline SEM-ALT & 1 & 893 & 164,625 & 86,5 & 597,8571 & 60 & 65,25 \\
\hline SEM-ALT & 2 & 210,5556 & 47,77778 & 45,66667 & 86,71429 & 62,125 & 472,25 \\
\hline SEM-ALT & 3 & 91,125 & 53,8 & 25,125 & 50,57143 & 57,66667 & 68,22222 \\
\hline SEM-ALT & 4 & 419,6667 & 58,2 & 36,6 & 73,66667 & 148,4444 & 138,6 \\
\hline SEM-ALT & 5 & 47,5 & 53,44444 & 58,88889 & 108,1111 & 203 & 354,7778 \\
\hline SEM-ALT & 6 & 339,4286 & 78,71429 & 29,75 & 76,33333 & 48,55556 & 69,28571 \\
\hline SEM-ALT & 7 & 82,5 & 39 & 43,66667 & 144,3333 & 94,625 & 62,33333 \\
\hline SEM-ALT & 8 & 59,77778 & 39,88889 & 37,1 & 464,3333 & 75,14286 & 89,44444 \\
\hline SEM-ALT & 9 & 154,3333 & 34,8 & 26,7 & 886,6667 & 291,1429 & 74,9 \\
\hline SEM-ALT & 10 & 87,11111 & 75,1 & 74,7 & 124,3 & 66,3 & 73,125 \\
\hline SEM-ALT & 11 & 240 & 79,66667 & 50,1 & 449,6 & 516,5 & 489,3333 \\
\hline SEM-ALT & 12 & 307,6667 & 56,44444 & 98,625 & 107,9 & 77,9 & 89,625 \\
\hline SEM-ALT & 13 & 122 & 53,55556 & 69,6 & 47,5 & 44 & 64,125 \\
\hline SEM-ALT & 14 & 44,875 & 42,125 & 47 & 49 & 22,44444 & 79,375 \\
\hline SEM-ALT & 15 & 31,5 & 62,875 & 71,28571 & 38,625 & 63,55556 & 92,7 \\
\hline SEM-MED & 1 & 70,375 & 18,22222 & 36,42857 & 222,375 & 240,2 & 136,1429 \\
\hline SEM-MED & 2 & 632 & 40,9 & 46,44444 & 752,6667 & 111,8889 & 161 \\
\hline SEM-MED & 3 & 68,3 & 66,55556 & 60,625 & 199 & 136,7143 & 101,1667 \\
\hline SEM-MED & 4 & 446,6667 & 64,5 & 52 & 154 & 174,6667 & 211,75 \\
\hline SEM-MED & 5 & 107,7778 & 59 & 96,25 & 549,7778 & 127,8571 & 81,5 \\
\hline SEM-MED & 6 & 70 & 50,7 & 76,1 & 91 & 67,88889 & 120,3 \\
\hline SEM-MED & 7 & 159,625 & 59,3 & 58 & & 897 & 598 \\
\hline SEM-MED & 8 & 63,28571 & 30,6 & 71,55556 & 97,5 & 133,75 & 71,875 \\
\hline SEM-MED & 9 & 38 & 52,625 & 47,1 & 90,85714 & 56,71429 & 63,125 \\
\hline SEM-MED & 10 & 104,8333 & 261 & 202,8571 & 406,5 & 244 & 267,2857 \\
\hline SEM-MED & 11 & 204,7 & 31,2 & 65,3 & 83,44444 & 84,9 & 106,2 \\
\hline SEM-MED & 12 & 121,25 & 56,5 & 53,2 & 247,25 & 174,2 & 114,5556 \\
\hline SEM-MED & 13 & 132,8 & 75,5 & 70,4 & 261,3333 & 53,71429 & 69,28571 \\
\hline SEM-MED & 14 & 240,9 & 64,7 & 44 & 44,85714 & 104,4 & 104,6 \\
\hline SEM-MED & 15 & 67,25 & 42,8 & 77,14286 & 37,25 & 77,1 & 51,125 \\
\hline SEM-SEM & 1 & 671 & 89,5 & 92,1 & 603,4 & 271,375 & 214,25 \\
\hline SEM-SEM & 2 & 1264,2 & 43,28571 & 151,25 & 727,8 & 375,6667 & 225,2857 \\
\hline SEM-SEM & 3 & 59,66667 & 53,28571 & 37,66667 & 57,33333 & 97,5 & 63,125 \\
\hline SEM-SEM & 4 & 395,5 & 83,3 & 44,77778 & 864,5 & 192,7143 & 104,6667 \\
\hline SEM-SEM & 5 & 64,28571 & 47,33333 & 27,33333 & 82,4 & 63,2 & 61,4 \\
\hline SEM-SEM & 6 & 57,11111 & 79,2 & 162,9 & 271 & 94,77778 & 90,9 \\
\hline SEM-SEM & 7 & 63,11111 & 31,55556 & 30,3 & 246 & 81 & 43,88889 \\
\hline SEM-SEM & 8 & 113,75 & 34,33333 & 21,75 & 90,88889 & 36,77778 & 40,71429 \\
\hline SEM-SEM & 9 & 214,625 & 60,11111 & 58,22222 & 55,5 & 24,7 & 44,77778 \\
\hline SEM-SEM & 10 & 363,3333 & 37,25 & 41,25 & 88,11111 & 82,83333 & 119,1667 \\
\hline SEM-SEM & 11 & 145,8889 & 27,4 & 32,1 & 36,88889 & 23,4 & 53,2 \\
\hline SEM-SEM & 12 & 57 & 36,3 & 41,375 & 60,2 & 50 & 36,9 \\
\hline SEM-SEM & 13 & 464,8889 & 61,5 & 84,25 & 181,2857 & 108,8333 & 53,1 \\
\hline SEM-SEM & 14 & 71,625 & 46,77778 & 31,625 & 90,9 & 69,22222 & 77,66667 \\
\hline SEM-SEM & 15 & 111,2222 & 39,22222 & 29,66667 & 70,5 & 39,5 & 85,16667 \\
\hline
\end{tabular}




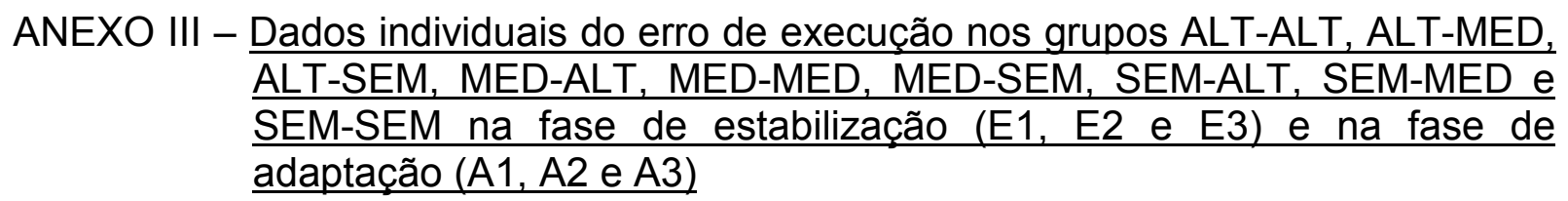

\begin{tabular}{cccccccc}
\hline Grupo & Sujeito & E1 & E2 & E3 & A1 & A2 & A3 \\
\hline ALT-ALT & 1 & 2 & 1 & 0 & 2 & 2 & 0 \\
ALT-ALT & 2 & 2 & 4 & 1 & 7 & 5 & 3 \\
ALT-ALT & 3 & 3 & 0 & 2 & 2 & 1 & 3 \\
ALT-ALT & 4 & 2 & 1 & 5 & 2 & 0 & 1 \\
ALT-ALT & 5 & 4 & 1 & 1 & 2 & 5 & 1 \\
ALT-ALT & 6 & 2 & 2 & 0 & 1 & 1 & 2 \\
ALT-ALT & 7 & 0 & 0 & 1 & 2 & 2 & 2 \\
ALT-ALT & 8 & 1 & 0 & 2 & 5 & 6 & 8 \\
ALT-ALT & 9 & 1 & 1 & 0 & 2 & 2 & 0 \\
ALT-ALT & 10 & 4 & 2 & 2 & 5 & 2 & 0 \\
ALT-ALT & 11 & 3 & 0 & 1 & 7 & 5 & 3 \\
ALT-ALT & 12 & 2 & 0 & 0 & 2 & 2 & 4 \\
ALT-ALT & 13 & 3 & 1 & 6 & 3 & 3 & 0 \\
ALT-ALT & 14 & 2 & 0 & 0 & 4 & 2 & 5 \\
ALT-ALT & 15 & 1 & 1 & 0 & 1 & 3 & 3 \\
ALT-MED & 1 & 4 & 4 & 2 & 2 & 2 & 2 \\
ALT-MED & 2 & 1 & 6 & 3 & 4 & 4 & 3 \\
ALT-MED & 3 & 0 & 1 & 0 & 0 & 3 & 2 \\
ALT-MED & 4 & 0 & 0 & 0 & 1 & 1 & 0 \\
ALT-MED & 5 & 2 & 0 & 1 & 7 & 2 & 1 \\
ALT-MED & 6 & 0 & 1 & 1 & 0 & 2 & 1 \\
ALT-MED & 7 & 0 & 2 & 0 & 0 & 2 & 2 \\
ALT-MED & 8 & 3 & 0 & 0 & 3 & 1 & 1 \\
ALT-MED & 9 & 2 & 0 & 1 & 3 & 1 & 2 \\
ALT-MED & 10 & 3 & 0 & 0 & 2 & 3 & 2 \\
ALT-MED & 11 & 1 & 1 & 1 & 0 & 0 & 1 \\
ALT-MED & 12 & 2 & 0 & 0 & 3 & 2 & 1 \\
ALT-MED & 13 & 0 & 0 & 0 & 2 & 1 & 0 \\
ALT-MED & 14 & 0 & 1 & 0 & 3 & 3 & 0 \\
ALT-MED & 15 & 2 & 0 & 1 & 2 & 1 & 1 \\
ALT-SEM & 1 & 6 & 2 & 2 & 2 & 5 & 2 \\
ALT-SEM & 2 & 2 & 0 & 0 & 0 & 1 & 0 \\
ALT-SEM & 3 & 2 & 4 & 3 & 7 & 4 & 3 \\
ALT-SEM & 4 & 2 & 1 & 0 & 0 & 2 & 3 \\
ALT-SEM & 5 & 0 & 1 & 1 & 3 & 1 & 0 \\
ALT-SEM & 6 & 2 & 1 & 2 & 6 & 3 & 3 \\
ALT-SEM & 7 & 0 & 0 & 0 & 0 & 3 & 3 \\
ALT-SEM & 8 & 3 & 0 & 0 & 3 & 4 & 2 \\
ALT-SEM & 9 & 0 & 1 & 2 & 8 & 3 & 3 \\
ALT-SEM & 10 & 3 & 1 & 1 & 3 & 1 & 0 \\
ALT-SEM & 11 & 0 & 1 & 3 & 3 & 1 & 1 \\
ALT-SEM & 12 & 2 & 1 & 0 & 3 & 2 & 2 \\
ALT-SEM & 13 & 2 & 0 & 2 & 0 & 0 & 1 \\
ALT-SEM & 14 & 1 & 2 & 1 & 1 & 1 & 0 \\
ALT-SEM & 15 & 1 & 4 & 0 & 4 & 2 & 1 \\
\hline
\end{tabular}




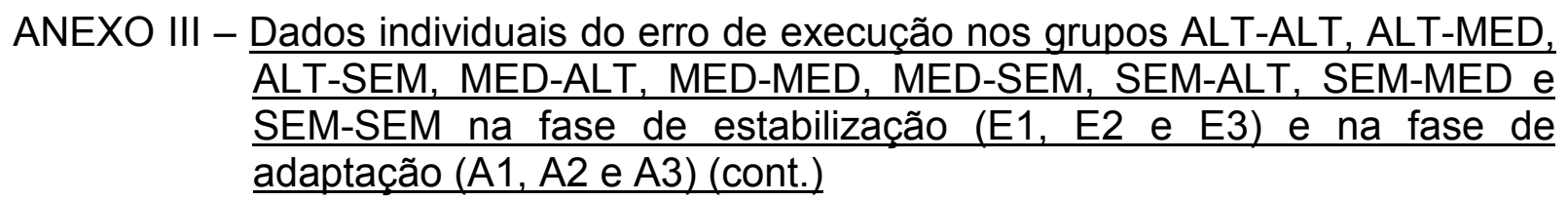

\begin{tabular}{cccccccc}
\hline Grupo & Sujeito & E1 & E2 & E3 & A1 & A2 & A3 \\
\hline MED-ALT & 1 & 6 & 2 & 2 & 8 & 9 & 8 \\
MED-ALT & 2 & 3 & 0 & 1 & 3 & 2 & 1 \\
MED-ALT & 3 & 3 & 1 & 1 & 8 & 7 & 7 \\
MED-ALT & 4 & 0 & 1 & 2 & 2 & 1 & 1 \\
MED-ALT & 5 & 3 & 1 & 3 & 1 & 4 & 3 \\
MED-ALT & 6 & 0 & 2 & 2 & 1 & 3 & 1 \\
MED-ALT & 7 & 0 & 0 & 0 & 2 & 1 & 0 \\
MED-ALT & 8 & 1 & 0 & 0 & 8 & 5 & 1 \\
MED-ALT & 9 & 4 & 3 & 1 & 6 & 5 & 4 \\
MED-ALT & 10 & 2 & 2 & 0 & 5 & 3 & 1 \\
MED-ALT & 11 & 3 & 0 & 0 & 0 & 0 & 0 \\
MED-ALT & 12 & 1 & 0 & 0 & 4 & 5 & 3 \\
MED-ALT & 13 & 1 & 0 & 0 & 5 & 1 & 2 \\
MED-ALT & 14 & 3 & 1 & 4 & 5 & 3 & 3 \\
MED-ALT & 15 & 1 & 0 & 0 & 2 & 1 & 2 \\
MED-MED & 1 & 8 & 4 & 3 & 4 & 1 & 2 \\
MED-MED & 2 & 2 & 4 & 1 & 5 & 4 & 2 \\
MED-MED & 3 & 1 & 1 & 0 & 4 & 1 & 2 \\
MED-MED & 4 & 1 & 1 & 0 & 1 & 1 & 2 \\
MED-MED & 5 & 1 & 0 & 3 & 0 & 1 & 2 \\
MED-MED & 6 & 2 & 0 & 2 & 0 & 0 & 1 \\
MED-MED & 7 & 1 & 0 & 0 & 1 & 0 & 1 \\
MED-MED & 8 & 3 & 2 & 1 & 8 & 5 & 1 \\
MED-MED & 9 & 1 & 1 & 1 & 0 & 1 & 1 \\
MED-MED & 10 & 3 & 0 & 1 & 4 & 0 & 0 \\
MED-MED & 11 & 1 & 0 & 0 & 2 & 1 & 3 \\
MED-MED & 12 & 5 & 1 & 0 & 6 & 1 & 1 \\
MED-MED & 13 & 1 & 1 & 0 & 8 & 3 & 1 \\
MED-MED & 14 & 2 & 0 & 0 & 4 & 1 & 2 \\
MED-MED & 15 & 2 & 3 & 0 & 4 & 1 & 3 \\
MED-SEM & 1 & 1 & 2 & 3 & 3 & 1 & 2 \\
MED-SEM & 2 & 4 & 1 & 3 & 1 & 4 & 3 \\
MED-SEM & 3 & 0 & 0 & 2 & 2 & 3 & 2 \\
MED-SEM & 4 & 2 & 2 & 3 & 8 & 4 & 6 \\
MED-SEM & 5 & 3 & 3 & 3 & 0 & 3 & 4 \\
MED-SEM & 6 & 0 & 1 & 1 & 1 & 2 & 3 \\
MED-SEM & 7 & 0 & 1 & 0 & 1 & 5 & 0 \\
MED-SEM & 8 & 0 & 2 & 0 & 3 & 2 & 2 \\
MED-SEM & 9 & 3 & 1 & 3 & 6 & 3 & 3 \\
MED-SEM & 10 & 1 & 0 & 4 & 3 & 2 & 2 \\
MED-SEM & 11 & 1 & 0 & 2 & 5 & 2 & 1 \\
MED-SEM & 12 & 0 & 0 & 0 & 0 & 1 & 0 \\
MED-SEM & 13 & 2 & 0 & 0 & 2 & 3 & 2 \\
MED-SEM & 14 & 3 & 0 & 0 & 1 & 3 & 1 \\
\hline & 15 & 4 & 3 & 2 & 4 & 5 & 1 \\
\hline
\end{tabular}




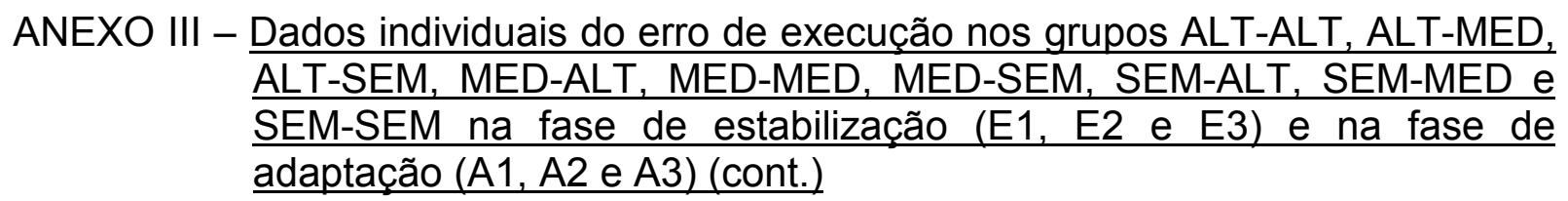

\begin{tabular}{|c|c|c|c|c|c|c|c|}
\hline Grupo & Sujeito & E1 & E2 & E3 & A1 & A2 & $\mathrm{A} 3$ \\
\hline SEM-ALT & 1 & 8 & 2 & 8 & 3 & 2 & 2 \\
\hline SEM-ALT & 2 & 1 & 1 & 1 & 3 & 2 & 2 \\
\hline SEM-ALT & 3 & 2 & 5 & 2 & 3 & 1 & 1 \\
\hline SEM-ALT & 4 & 1 & 0 & 0 & 4 & 1 & 0 \\
\hline SEM-ALT & 5 & 0 & 1 & 1 & 1 & 0 & 1 \\
\hline SEM-ALT & 6 & 3 & 3 & 2 & 4 & 1 & 3 \\
\hline SEM-ALT & 7 & 2 & 3 & 4 & 4 & 2 & 1 \\
\hline SEM-ALT & 8 & 1 & 1 & 0 & 7 & 3 & 1 \\
\hline SEM-ALT & 9 & 1 & 0 & 0 & 7 & 3 & 0 \\
\hline SEM-ALT & 10 & 1 & 0 & 0 & 0 & 0 & 2 \\
\hline SEM-ALT & 11 & 1 & 1 & 0 & 5 & 2 & 1 \\
\hline SEM-ALT & 12 & 4 & 1 & 2 & 0 & 0 & 2 \\
\hline SEM-ALT & 13 & 5 & 1 & 0 & 4 & 3 & 2 \\
\hline SEM-ALT & 14 & 2 & 2 & 2 & 2 & 1 & 2 \\
\hline SEM-ALT & 15 & 4 & 2 & 3 & 2 & 1 & 0 \\
\hline SEM-MED & 1 & 2 & 1 & 3 & 2 & 5 & 3 \\
\hline SEM-MED & 2 & 8 & 0 & 1 & 4 & 1 & 1 \\
\hline SEM-MED & 3 & 0 & 1 & 2 & 5 & 3 & 4 \\
\hline SEM-MED & 4 & 7 & 2 & 1 & 3 & 7 & 6 \\
\hline SEM-MED & 5 & 1 & 2 & 2 & 1 & 3 & 6 \\
\hline SEM-MED & 6 & 1 & 0 & 0 & 0 & 1 & 0 \\
\hline SEM-MED & 7 & 2 & 0 & 1 & 10 & 8 & 1 \\
\hline SEM-MED & 8 & 3 & 0 & 1 & 4 & 6 & 2 \\
\hline SEM-MED & 9 & 6 & 2 & 0 & 3 & 3 & 2 \\
\hline SEM-MED & 10 & 4 & 2 & 3 & 4 & 2 & 3 \\
\hline SEM-MED & 11 & 0 & 0 & 0 & 1 & 0 & 0 \\
\hline SEM-MED & 12 & 6 & 2 & 0 & 2 & 0 & 1 \\
\hline SEM-MED & 13 & 5 & 2 & 5 & 4 & 3 & 3 \\
\hline SEM-MED & 14 & 0 & 0 & 1 & 3 & 0 & 0 \\
\hline SEM-MED & 15 & 2 & 0 & 3 & 2 & 0 & 2 \\
\hline SEM-SEM & 1 & 9 & 0 & 0 & 5 & 2 & 2 \\
\hline SEM-SEM & 2 & 5 & 3 & 2 & 5 & 4 & 3 \\
\hline SEM-SEM & 3 & 4 & 3 & 4 & 7 & 4 & 2 \\
\hline SEM-SEM & 4 & 8 & 0 & 1 & 8 & 3 & 4 \\
\hline SEM-SEM & 5 & 3 & 1 & 1 & 0 & 0 & 0 \\
\hline SEM-SEM & 6 & 1 & 0 & 0 & 1 & 1 & 0 \\
\hline SEM-SEM & 7 & 1 & 1 & 0 & 2 & 2 & 1 \\
\hline SEM-SEM & 8 & 2 & 1 & 2 & 1 & 1 & 3 \\
\hline SEM-SEM & 9 & 2 & 1 & 1 & 0 & 0 & 1 \\
\hline SEM-SEM & 10 & 7 & 2 & 2 & 1 & 4 & 4 \\
\hline SEM-SEM & 11 & 1 & 0 & 0 & 1 & 0 & 0 \\
\hline SEM-SEM & 12 & 0 & 0 & 2 & 0 & 1 & 0 \\
\hline SEM-SEM & 13 & 1 & 0 & 2 & 3 & 4 & 0 \\
\hline SEM-SEM & 14 & 2 & 1 & 2 & 0 & 1 & 1 \\
\hline SEM-SEM & 15 & 1 & 1 & 1 & 6 & 6 & 4 \\
\hline
\end{tabular}


ANEXO IV - Dados individuais médios do erro variável nos grupos ALT-ALT, ALTMED, ALT-SEM, MED-ALT, MED-MED, MED-SEM, SEM-ALT, SEMMED e SEM-SEM na fase de estabilização (E1, E2 e E3) e na fase de adaptação (A1, A2 e A3)

\begin{tabular}{|c|c|c|c|c|c|c|c|}
\hline Grupo & Sujeito & E1 & E2 & E3 & A1 & A2 & A3 \\
\hline ALT-ALT & 1 & 241,4107 & 50,40861 & 66,81151 & 115,8247 & 77,47995 & 81,2133 \\
\hline ALT-ALT & 2 & 192,7424 & 97,48641 & 71,45278 & 200,8905 & 172,7527 & 269,9441 \\
\hline ALT-ALT & 3 & 853,7099 & 42,24321 & 16,32209 & 637,6579 & 299,4587 & 91,71488 \\
\hline ALT-ALT & 4 & 417,6764 & 49,01049 & 41,99643 & 207,3933 & 156,3478 & 86,44652 \\
\hline ALT-ALT & 5 & 46,24464 & 42,45521 & 23,95714 & 63,17493 & 19,19114 & 62,46488 \\
\hline ALT-ALT & 6 & 265,2177 & 75,40746 & 35,72503 & 80,03454 & 107,9352 & 54,78774 \\
\hline ALT-ALT & 7 & 223,4975 & 50,36985 & 63,2741 & 40,53019 & 52,02317 & 62,1391 \\
\hline ALT-ALT & 8 & 190,7442 & 65,04392 & 52,22872 & 227,5939 & 178,4272 & 195,1615 \\
\hline ALT-ALT & 9 & 118,6442 & 59,34012 & 40,74323 & 88,88586 & 229,6033 & 53,95018 \\
\hline ALT-ALT & 10 & 128,6214 & 26,88036 & 41,31737 & 221,8299 & 210,6998 & 61,50736 \\
\hline ALT-ALT & 11 & 216,3653 & 101,6071 & 53,41582 & 353,344 & 76,77565 & 64,39166 \\
\hline ALT-ALT & 12 & 212,5622 & 33,683 & 26,70747 & 104,2154 & 81,18233 & 72,08259 \\
\hline ALT-ALT & 13 & 76,90997 & 16,66917 & 43,69115 & 58,45755 & 22,67472 & 25,20494 \\
\hline ALT-ALT & 14 & 113,2153 & 61,51685 & 26,69665 & 665,5636 & 157,1623 & 140,0132 \\
\hline ALT-ALT & 15 & 107,4501 & 80,26795 & 57,74513 & 180,3661 & 41,4344 & 55,67593 \\
\hline ALT-MED & 1 & 1058,58 & 86,31493 & 63,98312 & 566,7843 & 720,0801 & 61,69843 \\
\hline ALT-MED & 2 & 476,355 & 46,73596 & 35,6404 & 114,9377 & 330,5872 & 135,3452 \\
\hline ALT-MED & 3 & 380,2815 & 53,32448 & 106,8805 & 54,86762 & 56,49189 & 49,27184 \\
\hline ALT-MED & 4 & 161,8621 & 60,87839 & 31,6586 & 133,9888 & 373,6443 & 69,66116 \\
\hline ALT-MED & 5 & 179,9158 & 67,76266 & 30,25723 & 24,02776 & 145,6806 & 107,8917 \\
\hline ALT-MED & 6 & 88,69204 & 64,56392 & 55,36922 & 76,62064 & 126,8801 & 132,0945 \\
\hline ALT-MED & 7 & 127,1949 & 128,75 & 55,25255 & 70,96548 & 148,439 & 77,79598 \\
\hline ALT-MED & 8 & 61,75219 & 74,58217 & 56,61409 & 88,23723 & 145,6615 & 47,74964 \\
\hline ALT-MED & 9 & 177,5798 & 51,1312 & 33,632 & 241,0496 & 92,8459 & 65,80925 \\
\hline ALT-MED & 10 & 38,12198 & 148,0219 & 51,30096 & 100,3827 & 37,87888 & 166,7265 \\
\hline ALT-MED & 11 & 113,2817 & 149,9056 & 104,7569 & 117,1402 & 41,5 & 41,17375 \\
\hline ALT-MED & 12 & 72,40055 & 28,18766 & 54,45 & $106, \varepsilon$ & 43,15235 & 99,35179 \\
\hline ALT-MED & 13 & 45,76801 & 34,47769 & 62,16287 & 55,31065 & 44,90669 & 27,2896 \\
\hline ALT-MED & 14 & 91,34069 & 30,16206 & 35,32327 & 44,09622 & 47,55498 & 84,57613 \\
\hline ALT-MED & 15 & & 42,82834 & 45,90207 & 58,44152 & 131 & 39,85738 \\
\hline ALT-SEM & 1 & 85,92245 & 71,20381 & 78,86471 & 401,3588 & 110,6151 & 143,9806 \\
\hline ALT-SEM & 2 & 700,7464 & 33,58902 & 60,01379 & 66,59705 & 64,67504 & 36,93 \\
\hline ALT-SEM & 3 & & 169,0145 & 103,4785 & 839,3952 & 100,74 & \\
\hline ALT- & 4 & & & 50,1 & 55,66657 & 67,3 & 50,50224 \\
\hline ALT. & 5 & & 47,4 & 22,7 & 62,67224 & 79,4 & 77,86998 \\
\hline ALT-S & 6 & 137,5749 & 80,80859 & 42,57 & 511,9 & 252, & 133,0 \\
\hline ALT-S & 7 & 74,07954 & 51,70311 & 92,29638 & 159,8804 & 104,6452 & 68,6048 \\
\hline EM & 8 & 318,0596 & 44,26549 & 35,50837 & 68,27884 & 52,08231 & 61,57864 \\
\hline ALT-SEM & 9 & 113,9842 & 100,075 & 132,2606 & 289,2067 & 124,5298 & 63,8458 \\
\hline ALT-SEM & 10 & 233,9229 & 63,67452 & 50,35375 & 548,931 & 158,4304 & 203,4796 \\
\hline ALT-SEM & 11 & 398,1206 & 56,99293 & 30,31423 & 16,12304 & 171,9882 & 41,65967 \\
\hline ALT-SEM & 12 & 71,07541 & 80,95369 & 55,62214 & 139,7959 & 53,89656 & 66,96908 \\
\hline ALT-SEM & 13 & 60,30636 & 41,45265 & 73,65363 & 49,40265 & 50,55261 & 46,99734 \\
\hline ALT-SEM & 14 & 276,3457 & 52,723 & 62,81476 & 93,64264 & 113,9945 & 82,54729 \\
\hline ALT-SEM & 15 & 64,87681 & 74,43498 & 54,22474 & 38,94312 & 64,26897 & 53,42856 \\
\hline
\end{tabular}


ANEXO IV - Dados individuais médios do erro variável nos grupos ALT-ALT, ALTMED, ALT-SEM, MED-ALT, MED-MED, MED-SEM, SEM-ALT, SEMMED e SEM-SEM na fase de estabilização (E1, E2 e E3) e na fase de adaptação (A1, A2 e A3) (cont.)

\begin{tabular}{|c|c|c|c|c|c|c|c|}
\hline Grupo & Sujeito & E1 & E2 & E3 & A1 & A2 & A3 \\
\hline MED-ALT & 1 & 553,2335 & 77,15094 & 78,05447 & 0,707107 & & 55,86144 \\
\hline MED-ALT & 2 & 79,50442 & 47,48345 & 23,85605 & 80,48484 & 32,0758 & 52,40256 \\
\hline MED-ALT & 3 & 144,2907 & 47,06497 & 56,73868 & 202,2325 & 409,1601 & 41,30779 \\
\hline MED-ALT & 4 & 655,9157 & 134,9127 & 84,58934 & 168,2125 & 166,1558 & 196,2503 \\
\hline MED-ALT & 5 & 63,41398 & 45,89965 & 51,38742 & 39,68557 & 83,73928 & 42,81522 \\
\hline MED-ALT & 6 & 492,2385 & 40,36264 & 39,17269 & 113,67 & 135,8231 & 24,57641 \\
\hline MED-ALT & 7 & 87,3222 & 37,04652 & 41,07189 & 95,60848 & 101,7044 & 45,58752 \\
\hline MED-ALT & 8 & 425,1852 & 155,0583 & 42,9801 & 153,4422 & 453,3902 & 152,9485 \\
\hline MED-ALT & 9 & 104,2889 & 143,1744 & 54,20101 & 111,1321 & 217,9261 & 264,2938 \\
\hline MED-ALT & 10 & 254,0885 & 29,03077 & 95,48263 & 412,6385 & 527,457 & 310,6582 \\
\hline MED-ALT & 11 & 281,9603 & 30,46327 & 45,22401 & 78,27189 & 128,7523 & 105,9434 \\
\hline MED-ALT & 12 & 142,3758 & 61,70044 & 80,87301 & 208,8566 & 307,2087 & 115,2597 \\
\hline MED-ALT & 13 & 67,87304 & 44,9104 & 54,50882 & 37,74917 & 86,1628 & 32,38165 \\
\hline MED-ALT & 14 & 114,1355 & 130,4458 & 35,40621 & 122,2444 & 41,24087 & 37,11244 \\
\hline MED-ALT & 15 & 70,0125 & 57,1979 & 26,96108 & 53,44156 & 30,30447 & 35,323 \\
\hline MED-MED & 1 & 56,56854 & 44,85867 & 18,3017 & 125,1885 & 76,9298 & 64,15773 \\
\hline MED-MED & 2 & 74,12044 & 46,94536 & 78,96043 & 173,0644 & 113,8596 & 37,62194 \\
\hline MED-MED & 3 & 712,1917 & 52,49471 & 54,05769 & 360,6298 & 86,90816 & 77,66043 \\
\hline MED-MED & 4 & 126,6249 & 33,43941 & 47,51245 & 68,14833 & 56,35034 & 72,55134 \\
\hline MED-MED & 5 & 144,2245 & 43,87305 & 69,0645 & 152,9276 & 135,9057 & 102,4974 \\
\hline MED-MED & 6 & 185,174 & 45,01963 & 54,4505 & 58,24136 & 31,1334 & 51,84834 \\
\hline MED-MED & 7 & 153,9081 & 35,09748 & 63,22447 & 195,5165 & 169,9621 & 109,4555 \\
\hline MED-MED & 8 & 395,2518 & 46,83329 & 85,14465 & 145,664 & 309,5602 & 91,8483 \\
\hline MED-MED & 9 & 331,8091 & 90,00478 & 28,02677 & 154,556 & 25,26856 & 63,93834 \\
\hline MED-MED & 10 & 133,1101 & 110,4657 & 70,84451 & 175,2318 & 44 & 73,12736 \\
\hline MED-MED & 11 & 80,05467 & 23,59 & 73,63725 & 61,41181 & & 39,49442 \\
\hline MED-MED & 12 & 417,8598 & 59,47222 & 47,93468 & 223,127 & 42,6 & 86,77717 \\
\hline MED-MED & 13 & 99,13627 & 33,39328 & 38,0228 & 26,87006 & 92,67 & 94,63233 \\
\hline MED-MED & 14 & 101,012 & 57,57932 & 44,7462 & 48,1944 & 49,48737 & 71,64396 \\
\hline MED-MED & 15 & 62,23214 & 33,02524 & 47,35446 & 3434 & & 101,9 \\
\hline MED-SEM & 1 & 104,2854 & 39,83896 & 86,7849 & 88,48675 & & 156,5072 \\
\hline MED-SEM & 2 & 71,68752 & 24,5204 & 19,39686 & 60,28889 & & 62,77852 \\
\hline MED-SEM & 3 & 236,2851 & 58,54343 & 52,32027 & & & 55,823 \\
\hline MED-SEM & 4 & 101,72 & & & & & 359,8373 \\
\hline MED-SEM & 5 & 594,51 & & & & & 138,7017 \\
\hline MED-SEM & 6 & 257,8122 & 44,3255 & 014 & 368 & 211 & 215,949 \\
\hline MED-SEM & 7 & 102,9744 & 216,6154 & 53,99136 & 48,54379 & 133 & 81,55816 \\
\hline MED-SEM & 8 & 306,0786 & 78,86652 & 83,08 & 3416 & 172,0722 & 103,1185 \\
\hline MED-SEM & 9 & 333,9249 & 135,7378 & 24,69625 & 50,67133 & 44,96454 & 92,43711 \\
\hline MED-SEM & 10 & 58,19961 & 43,08661 & 38,70228 & 150,1074 & 72,17328 & 85,13508 \\
\hline MED-SEM & 11 & 52,32112 & 22,5428 & 62,43153 & 268,8745 & 103,7696 & 97,87804 \\
\hline MED-SEM & 12 & 210,461 & 43,09176 & 43,05565 & 114,632 & 95,1566 & 68,30203 \\
\hline MED-SEM & 13 & 64,12878 & 97,9628 & 61,42032 & 220,4472 & 327,9683 & 298,9476 \\
\hline MED-SEM & 14 & 63,45302 & 62,0129 & 68,97665 & 293,7116 & 188,6813 & 80,90598 \\
\hline MED-SEM & 15 & 77,73459 & 70,33728 & 72,31429 & 145,3419 & 220,012 & 153,6691 \\
\hline
\end{tabular}


ANEXO IV - Dados individuais médios do erro variável nos grupos ALT-ALT, ALTMED, ALT-SEM, MED-ALT, MED-MED, MED-SEM, SEM-ALT, SEMMED e SEM-SEM na fase de estabilização (E1, E2 e E3) e na fase de adaptação (A1, A2 e A3) (cont.)

\begin{tabular}{|c|c|c|c|c|c|c|c|}
\hline Grupo & Sujeito & E1 & E2 & E3 & A1 & A2 & A3 \\
\hline SEM-ALT & 1 & 1125,714 & 357,0914 & 122,3295 & 825,9493 & 101,2321 & 53,81118 \\
\hline SEM-ALT & 2 & 293,4357 & 57,88134 & 41,57256 & 120,2093 & 69,74738 & 490,9777 \\
\hline SEM-ALT & 3 & 129,1189 & 60,35064 & 32,03096 & 61,25007 & 76,31841 & 97,3884 \\
\hline SEM-ALT & 4 & 758,3392 & 71,73532 & 37,25229 & 98,79069 & 85,43532 & 71,61967 \\
\hline SEM-ALT & 5 & 41,2134 & 51,00681 & 45,08326 & 151,6796 & 334,8896 & 802,3849 \\
\hline SEM-ALT & 6 & 588,9844 & 106,2291 & 31,30951 & 108,1326 & 60,73462 & 104,7903 \\
\hline SEM-ALT & 7 & 113,4873 & 34,08533 & 29,31666 & 129,2718 & 110,3189 & 65,38178 \\
\hline SEM-ALT & 8 & 76,99838 & 53,60037 & 37,30192 & 717,2206 & 95,18553 & 154,5121 \\
\hline SEM-ALT & 9 & 261,0776 & 36,42588 & 33,24806 & 436,0967 & 228,969 & 99,35352 \\
\hline SEM-ALT & 10 & 90,60874 & 95,814 & 84,17106 & 184,2452 & 58,54808 & 84,50602 \\
\hline SEM-ALT & 11 & 409,47 & 132,5189 & 52,31114 & 172,403 & 165,3334 & 109,942 \\
\hline SEM-ALT & 12 & 588,546 & 56,5349 & 228,4228 & 190,7628 & 87,64252 & 62,483 \\
\hline SEM-ALT & 13 & 164,2294 & 63,21876 & 74,62678 & 68,92145 & 67,49744 & 80,28865 \\
\hline SEM-ALT & 14 & 50,51997 & 34,03543 & 40,5216 & 62,91661 & 18,54125 & 111,9604 \\
\hline SEM-ALT & 15 & 47,56224 & 58,16587 & 75,34777 & 47,5062 & 70,38722 & 105,5073 \\
\hline SEM-MED & 1 & 78,40451 & 26,03257 & 42,25208 & 160,2952 & 98,77601 & 84,54979 \\
\hline SEM-MED & 2 & 195,1615 & 45,55205 & 47,36765 & 431,0033 & 77,44747 & 115,9752 \\
\hline SEM-MED & 3 & 96,8243 & 77,21579 & 66,77668 & 254,9092 & 250,5352 & 136,7637 \\
\hline SEM-MED & 4 & 379,6964 & 102,6673 & 61,281 & 86,76405 & 185,9543 & 295,2404 \\
\hline SEM-MED & 5 & 106,3043 & 62,57795 & 131,3327 & 313,5613 & 120,2606 & 89,44645 \\
\hline SEM-MED & 6 & 86,97238 & 61,21411 & 76,38361 & & 88,76623 & 78,73592 \\
\hline SEM-MED & 7 & 222,7028 & 77,15648 & 56,45573 & & 49,49747 & 179,9389 \\
\hline SEM-MED & 8 & 77,15291 & 40,4442 & 78,46726 & 96,9297 & 126,2573 & 87,08 \\
\hline SEM-MED & 9 & 58,54058 & 64,80506 & 47,20652 & 68,11125 & 34,4176 & 69,23549 \\
\hline SEM-MED & 10 & 128,6288 & 259,7697 & 218,8031 & 226,7058 & 96,08924 & 248,4698 \\
\hline SEM-MED & 11 & 243,5836 & 42,16634 & 61,82996 & 93,54544 & 93,54791 & 117,0 \\
\hline SEM-MED & 12 & & 79,55546 & 66,69633 & 237,2106 & 166,8897 & \\
\hline SEM-MED & 13 & & 77,24497 & 83,60801 & 125,8422 & 56,95278 & \\
\hline SEM-MED & 14 & 409,7298 & 82,60354 & 57,29311 & 58,72657 & 104,9002 & \\
\hline SEM-MED & 15 & 74,05211 & & 65,952 & 54,98506 & & \\
\hline SEM-SEM & 1 & & 109,0804 & 101,6432 & 127,7959 & 198, & \\
\hline SEM-SEM & 2 & & 71,49 & 131,9978 & & & 169,2904 \\
\hline SEM-S & 3 & & 13,1 & 60,9 & & & 55,26802 \\
\hline SEM-S & 4 & 34 & 101,8162 & 40,86563 & 321,7336 & 225, & 138,3296 \\
\hline SEM-S & 5 & 60,96564 & 48,56296 & 30,50592 & 102,2037 & 94,24 & 76,20615 \\
\hline SEM-SEM & 6 & 59,24947 & 35,64891 & 223,7961 & 419,8101 & 154,8322 & 102,3763 \\
\hline SEM-SEM & 7 & 72,73582 & 25,53429 & 33,54748 & 245,3342 & 114,4761 & 33,93417 \\
\hline SEM-SEM & 8 & 223,3183 & 49,33559 & 16,47292 & 182,1177 & 59,68249 & 48,98542 \\
\hline SEM-SEM & 9 & 441,7263 & 92,16034 & 83,79307 & 92,70029 & 28,89156 & 55,97718 \\
\hline SEM-SEM & 10 & 98,33785 & 45,71652 & 44,30334 & 72,52547 & 38,29056 & 131,3292 \\
\hline SEM-SEM & 11 & 119,4461 & 32,79634 & 40,50912 & 40,80441 & 30,02517 & 64,02604 \\
\hline SEM-SEM & 12 & 70,03301 & 29,50499 & 41,59305 & 47,88458 & 43,29389 & 37,78433 \\
\hline SEM-SEM & 13 & 740,1513 & 77,63597 & 79,72229 & 181,6074 & 136,977 & 67,96282 \\
\hline SEM-SEM & 14 & 77,24624 & 54,65599 & 48,81726 & 131,8461 & 109,9065 & 45,36518 \\
\hline SEM-SEM & 15 & 211,4218 & 39,75585 & 43,16956 & 27,3313 & 46,6869 & 88,42718 \\
\hline
\end{tabular}


ANEXO $V$ - Número de tentativas utilizadas pelos participantes nos grupos ALT-ALT, ALT-MED, ALT-SEM, MED-ALT, MED-MED, MED-SEM, SEM-ALT, SEM-MED e SEM-SEM para alcançar o critério de desempenho

\begin{tabular}{ccc}
\hline Grupo & Sujeito & Tentativas \\
\hline ALT-ALT & 1 & 22 \\
ALT-ALT & 2 & 18 \\
ALT-ALT & 3 & 38 \\
ALT-ALT & 4 & 35 \\
ALT-ALT & 5 & 19 \\
ALT-ALT & 6 & 32 \\
ALT-ALT & 7 & 20 \\
ALT-ALT & 8 & 59 \\
ALT-ALT & 9 & 28 \\
ALT-ALT & 10 & 20 \\
ALT-ALT & 11 & 23 \\
ALT-ALT & 12 & 10 \\
ALT-ALT & 13 & 83 \\
ALT-ALT & 14 & 12 \\
ALT-ALT & 15 & 14 \\
ALT-MED & 1 & 10 \\
ALT-MED & 2 & 24 \\
ALT-MED & 3 & 24 \\
ALT-MED & 4 & 30 \\
ALT-MED & 5 & 27 \\
ALT-MED & 6 & 56 \\
ALT-MED & 7 & 67 \\
ALT-MED & 8 & 18 \\
ALT-MED & 9 & 35 \\
ALT-MED & 10 & 70 \\
ALT-MED & 11 & 52 \\
ALT-MED & 12 & 37 \\
ALT-MED & 13 & 15 \\
ALT-MED & 14 & 39 \\
ALT-MED & 15 & 14 \\
ALT-SEM & 1 & 24 \\
ALT-SEM & 2 & 18 \\
ALT-SEM & 3 & 23 \\
ALT-SEM & 4 & 26 \\
ALT-SEM & 5 & 32 \\
ALT-SEM & 6 & 19 \\
ALT-SEM & 7 & 65 \\
ALT-SEM & 8 & 49 \\
ALT-SEM & 9 & 28 \\
ALT-SEM & 10 & 19 \\
ALT-SEM & 11 & 21 \\
ALT-SEM & 12 & 53 \\
ALT-SEM & 13 & 21 \\
ALT-SEM & 14 & 18 \\
ALT-SEM & 15 & 78 \\
\hline & & \\
\end{tabular}


ANEXO $V$ - Número de tentativas utilizadas pelos participantes nos grupos ALT-ALT, ALT-MED, ALT-SEM, MED-ALT, MED-MED, MED-SEM, SEM-ALT, SEM-MED e SEM-SEM para alcançar o critério de desempenho (cont.)

\begin{tabular}{ccc}
\hline Grupo & Sujeito & Tentativas \\
\hline MED-ALT & 1 & 19 \\
MED-ALT & 2 & 23 \\
MED-ALT & 3 & 55 \\
MED-ALT & 4 & 21 \\
MED-ALT & 5 & 18 \\
MED-ALT & 6 & 23 \\
MED-ALT & 7 & 19 \\
MED-ALT & 8 & 31 \\
MED-ALT & 9 & 84 \\
MED-ALT & 10 & 23 \\
MED-ALT & 11 & 26 \\
MED-ALT & 12 & 11 \\
MED-ALT & 13 & 25 \\
MED-ALT & 14 & 50 \\
MED-ALT & 15 & 47 \\
MED-MED & 1 & 27 \\
MED-MED & 2 & 11 \\
MED-MED & 3 & 36 \\
MED-MED & 4 & 17 \\
MED-MED & 5 & 10 \\
MED-MED & 6 & 47 \\
MED-MED & 7 & 10 \\
MED-MED & 8 & 32 \\
MED-MED & 9 & 17 \\
MED-MED & 10 & 31 \\
MED-MED & 11 & 52 \\
MED-MED & 12 & 13 \\
MED-MED & 13 & 62 \\
MED-MED & 14 & 24 \\
MED-MED & 15 & 11 \\
MED-SEM & 1 & 79 \\
MED-SEM & 2 & 34 \\
MED-SEM & 3 & 76 \\
MED-SEM & 4 & 10 \\
MED-SEM & 5 & 29 \\
MED-SEM & 6 & 48 \\
MED-SEM & 7 & 33 \\
MED-SEM & 8 & 24 \\
MED-SEM & 9 & 47 \\
MED-SEM & 10 & 71 \\
MED-SEM & 11 & 24 \\
MED-SEM & 12 & 13 \\
MED-SEM & 13 & 10 \\
MED-SEM & 14 & 42 \\
MED-SEM & 15 & 16 \\
\hline
\end{tabular}


ANEXO $V$ - Número de tentativas utilizadas pelos participantes nos grupos ALT-ALT, ALT-MED, ALT-SEM, MED-ALT, MED-MED, MED-SEM, SEM-ALT, SEM-MED e SEM-SEM para alcançar o critério de desempenho (cont.)

\begin{tabular}{|c|c|c|}
\hline Grupo & Sujeito & Tentativas \\
\hline SEM-ALT & 1 & 19 \\
\hline SEM-ALT & 2 & 28 \\
\hline SEM-ALT & 3 & 25 \\
\hline SEM-ALT & 4 & 53 \\
\hline SEM-ALT & 5 & 17 \\
\hline SEM-ALT & 6 & 42 \\
\hline SEM-ALT & 7 & 26 \\
\hline SEM-ALT & 8 & 30 \\
\hline SEM-ALT & 9 & 51 \\
\hline SEM-ALT & 10 & 12 \\
\hline SEM-ALT & 11 & 32 \\
\hline SEM-ALT & 12 & 16 \\
\hline SEM-ALT & 13 & 70 \\
\hline SEM-ALT & 14 & 36 \\
\hline SEM-ALT & 15 & 10 \\
\hline SEM-MED & 1 & 35 \\
\hline SEM-MED & 2 & 43 \\
\hline SEM-MED & 3 & 10 \\
\hline SEM-MED & 4 & 73 \\
\hline SEM-MED & 5 & 51 \\
\hline SEM-MED & 6 & 11 \\
\hline SEM-MED & 7 & 44 \\
\hline SEM-MED & 8 & 38 \\
\hline SEM-MED & 9 & 15 \\
\hline SEM-MED & 10 & 65 \\
\hline SEM-MED & 11 & 68 \\
\hline SEM-MED & 12 & 16 \\
\hline SEM-MED & 13 & 90 \\
\hline SEM-MED & 14 & 13 \\
\hline SEM-MED & 15 & 95 \\
\hline SEM-SEM & 1 & 61 \\
\hline SEM-SEM & 2 & 51 \\
\hline SEM-SEM & 3 & 33 \\
\hline SEM-SEM & 4 & 73 \\
\hline SEM-SEM & 5 & 27 \\
\hline SEM-SEM & 6 & 10 \\
\hline SEM-SEM & 7 & 60 \\
\hline SEM-SEM & 8 & 35 \\
\hline SEM-SEM & 9 & 33 \\
\hline SEM-SEM & 10 & 35 \\
\hline SEM-SEM & 11 & 12 \\
\hline SEM-SEM & 12 & 22 \\
\hline SEM-SEM & 13 & 13 \\
\hline SEM-SEM & 14 & 17 \\
\hline SEM-SEM & 15 & 24 \\
\hline
\end{tabular}


ANEXO VI - Dados individuais da proporção de variações do seqüenciamento nos grupos ALT-ALT, ALT-MED, ALT-SEM, MED-ALT, MED-MED, MEDSEM, SEM-ALT, SEM-MED e SEM-SEM na fase de estabilização (E1, $\underline{E 2 \text { e E3) }}$

\begin{tabular}{ccccc}
\hline Grupo & Sujeito & E1 & E2 & E3 \\
\hline ALT-ALT & 1 & 5,714286 & 5 & 4,444444 \\
ALT-ALT & 2 & 0 & 0 & 0 \\
ALT-ALT & 3 & 0 & 0 & 0 \\
ALT-ALT & 4 & 85,71429 & 0 & 0 \\
ALT-ALT & 5 & 0 & 0 & 0 \\
ALT-ALT & 6 & 7,5 & 0 & 0 \\
ALT-ALT & 7 & 4,444444 & 8,888889 & 0 \\
ALT-ALT & 8 & 15 & 0 & 0 \\
ALT-ALT & 9 & 7,5 & 15 & 0 \\
ALT-ALT & 10 & 0 & 0 & 0 \\
ALT-ALT & 11 & 0 & 8,888889 & 0 \\
ALT-ALT & 12 & 5,714286 & 0 & 0 \\
ALT-ALT & 13 & 0 & 50 & 0 \\
ALT-ALT & 14 & 0 & 0 & 0 \\
ALT-ALT & 15 & 0 & 0 & 0 \\
ALT-MED & 1 & 0 & 8 & 0 \\
ALT-MED & 2 & 0 & 0 & 0 \\
ALT-MED & 3 & 4,444444 & 15 & 2,222222 \\
ALT-MED & 4 & 17,77778 & 4,444444 & 0 \\
ALT-MED & 5 & 28,57143 & 13,33333 & 0 \\
ALT-MED & 6 & 0 & 0 & 5 \\
ALT-MED & 7 & 66,66667 & 5 & 15,55556 \\
ALT-MED & 8 & 13,33333 & 0 & 0 \\
ALT-MED & 9 & 31,42857 & 4,444444 & 0 \\
ALT-MED & 10 & 0 & 0 & 0 \\
ALT-MED & 11 & 20 & 15 & 15 \\
ALT-MED & 12 & 0 & 0 & 0 \\
ALT-MED & 13 & 0 & 0 & 0 \\
ALT-MED & 14 & 11,11111 & 0 & 0 \\
ALT-MED & 15 & 12,5 & 0 & 0 \\
ALT-SEM & 1 & 40 & 0 & 0 \\
ALT-SEM & 2 & 0 & 0 & 0 \\
ALT-SEM & 3 & 11,42857 & 0 & 0 \\
ALT-SEM & 4 & 15 & 0 & 0 \\
ALT-SEM & 5 & 0 & 0 & 0 \\
ALT-SEM & 6 & 22,85714 & 0 & 0 \\
ALT-SEM & 7 & 4,444444 & 0 & 0 \\
ALT-SEM & 8 & 0 & 0 & 0 \\
ALT-SEM & 9 & 20 & 0 & 0 \\
ALT-SEM & 10 & 40 & 0 & 0 \\
ALT-SEM & 11 & 0 & 0 & 0 \\
ALT-SEM & 12 & 0 & 0 & 0 \\
ALT-SEM & 13 & 8,571429 & 0 & 0 \\
ALT-SEM & 14 & 0 & 0 & 0 \\
ALT-SEM & 15 & 10 & 0 & 0 \\
\hline & & & & \\
\hline
\end{tabular}


ANEXO VI - Dados individuais da proporção de variações do seqüenciamento nos grupos ALT-ALT, ALT-MED, ALT-SEM, MED-ALT, MED-MED, MEDSEM, SEM-ALT, SEM-MED e SEM-SEM na fase de estabilização (E1, E2 e E3) (cont.)

\begin{tabular}{ccccc}
\hline Grupo & Sujeito & E1 & E2 & E3 \\
\hline MED-ALT & 1 & 10 & 50 & 0 \\
MED-ALT & 2 & 0 & 0 & 10 \\
MED-ALT & 3 & 11,42857 & 17,5 & 0 \\
MED-ALT & 4 & 0 & 15 & 5,714286 \\
MED-ALT & 5 & 0 & 22,5 & 0 \\
MED-ALT & 6 & 4,444444 & 28,57143 & 15 \\
MED-ALT & 7 & 0 & 8,888889 & 0 \\
MED-ALT & 8 & 17,5 & 53,33333 & 6,666667 \\
MED-ALT & 9 & 0 & 46,66667 & 0 \\
MED-ALT & 10 & 0 & 0 & 0 \\
MED-ALT & 11 & 0 & 11,11111 & 8,888889 \\
MED-ALT & 12 & 22,5 & 13,33333 & 0 \\
MED-ALT & 13 & 5 & 26,66667 & 31,11111 \\
MED-ALT & 14 & 0 & 46,66667 & 0 \\
MED-ALT & 15 & 0 & 17,77778 & 0 \\
MED-MED & 1 & 20 & 16 & 10 \\
MED-MED & 2 & 0 & 0 & 0 \\
MED-MED & 3 & 15 & 31,11111 & 13,33333 \\
MED-MED & 4 & 0 & 0 & 0 \\
MED-MED & 5 & 0 & 0 & 0 \\
MED-MED & 6 & 0 & 0 & 0 \\
MED-MED & 7 & 5 & 0 & 0 \\
MED-MED & 8 & 0 & 0 & 0 \\
MED-MED & 9 & 0 & 5 & 0 \\
MED-MED & 10 & 13,33333 & 8,888889 & 0 \\
MED-MED & 11 & 5 & 4,444444 & 0 \\
MED-MED & 12 & 15 & 0 & 17,77778 \\
MED-MED & 13 & 15 & 0 & 0 \\
MED-MED & 14 & 5,714286 & 0 & 0 \\
MED-MED & 15 & 0 & 0 & 0 \\
MED-SEM & 1 & 5 & 0 & 0 \\
MED-SEM & 2 & 10 & 0 & 0 \\
MED-SEM & 3 & 13,33333 & 0 & 0 \\
MED-SEM & 4 & 0 & 0 & 0 \\
MED-SEM & 5 & 0 & 0 & 0 \\
MED-SEM & 6 & 4,444444 & 0 & 0 \\
MED-SEM & 7 & 13,33333 & 0 & 0 \\
MED-SEM & 8 & 22,22222 & 0 & 0 \\
MED-SEM & 9 & 0 & 0 & 0 \\
MED-SEM & 10 & 0 & 0 & 0 \\
MED-SEM & 11 & 0 & 0 & 0 \\
MED-SEM & 12 & 0 & 0 & 0 \\
MED-SEM & 13 & 11,42857 & 0 & 0 \\
MED-SEM & 14 & 0 & 0 & 0 \\
MED-SEM & 15 & 0 & 0 & 0 \\
\hline
\end{tabular}


ANEXO VI - Dados individuais da proporção de variações do seqüenciamento nos grupos ALT-ALT, ALT-MED, ALT-SEM, MED-ALT, MED-MED, MEDSEM, SEM-ALT, SEM-MED e SEM-SEM na fase de estabilização (E1, E2 e E3) (cont.)

\begin{tabular}{|c|c|c|c|c|}
\hline Grupo & Sujeito & E1 & E2 & E3 \\
\hline SEM-ALT & 1 & 0 & 25 & 0 \\
\hline SEM-ALT & 2 & 0 & 27,5 & 12,5 \\
\hline SEM-ALT & 3 & 0 & 45 & 40 \\
\hline SEM-ALT & 4 & 0 & 28,88889 & 0 \\
\hline SEM-ALT & 5 & 0 & 55 & 80 \\
\hline SEM-ALT & 6 & 0 & 80 & 42,5 \\
\hline SEM-ALT & 7 & 0 & 0 & 0 \\
\hline SEM-ALT & 8 & 0 & 0 & 0 \\
\hline SEM-ALT & 9 & 0 & 0 & 0 \\
\hline SEM-ALT & 10 & 0 & 8,888889 & 57,77778 \\
\hline SEM-ALT & 11 & 0 & 0 & 0 \\
\hline SEM-ALT & 12 & 0 & 0 & 0 \\
\hline SEM-ALT & 13 & 0 & 5 & 0 \\
\hline SEM-ALT & 14 & 0 & 0 & 0 \\
\hline SEM-ALT & 15 & 0 & 0 & 0 \\
\hline SEM-MED & 1 & 0 & 0 & 0 \\
\hline SEM-MED & 2 & 0 & 4,444444 & 0 \\
\hline SEM-MED & 3 & 0 & 10 & 25,71429 \\
\hline SEM-MED & 4 & 0 & 5 & 0 \\
\hline SEM-MED & 5 & 0 & 11,42857 & 34,28571 \\
\hline SEM-MED & 6 & 0 & 22,22222 & 22,22222 \\
\hline SEM-MED & 7 & 0 & 8,888889 & 0 \\
\hline SEM-MED & 8 & 0 & 17,77778 & 0 \\
\hline SEM-MED & 9 & 0 & 11,42857 & 0 \\
\hline SEM-MED & 10 & 0 & 37,14286 & 13,33333 \\
\hline SEM-MED & 11 & 0 & 0 & 0 \\
\hline SEM-MED & 12 & 0 & 0 & 0 \\
\hline SEM-MED & 13 & 0 & 30 & 10 \\
\hline SEM-MED & 14 & 0 & 26,66667 & 42,22222 \\
\hline SEM-MED & 15 & 0 & 8,888889 & 0 \\
\hline SEM-SEM & 1 & 0 & 0 & 0 \\
\hline SEM-SEM & 2 & 0 & 0 & 0 \\
\hline SEM-SEM & 3 & 0 & 0 & 4 \\
\hline SEM-SEM & 4 & 0 & 0 & 0 \\
\hline SEM-SEM & 5 & 0 & 0 & 0 \\
\hline SEM-SEM & 6 & 0 & 0 & 0 \\
\hline SEM-SEM & 7 & 0 & 0 & 0 \\
\hline SEM-SEM & 8 & 0 & 0 & 0 \\
\hline SEM-SEM & 9 & 0 & 0 & 0 \\
\hline SEM-SEM & 10 & 0 & 0 & 0 \\
\hline SEM-SEM & 11 & 0 & 0 & 0 \\
\hline SEM-SEM & 12 & 0 & 0 & 0 \\
\hline SEM-SEM & 13 & 0 & 0 & 0 \\
\hline SEM-SEM & 14 & 0 & 0 & 0 \\
\hline SEM-SEM & 15 & 0 & 0 & 0 \\
\hline
\end{tabular}


ANEXO VII - Dados individuais médios do desvio padrão dos tempos de movimento relativos nos grupos ALT-ALT, ALT-MED, ALT-SEM, MED-ALT, MEDMED, MED-SEM, SEM-ALT, SEM-MED e SEM-SEM nas fases de estabilização (E1, E2 e E3) e adaptação (A1, A2 e A3)

\begin{tabular}{|c|c|c|c|c|c|c|c|}
\hline Grupo & Sujeito & $\mathrm{E} 1$ & E2 & E3 & A1 & $\mathrm{A} 2$ & A3 \\
\hline ALT-ALT & 1 & 7,618706 & 6,047135 & 6,017517 & 5,359501 & 4,8944 & 5,144419 \\
\hline ALT-ALT & 2 & 6,078682 & 6,803389 & 6,583194 & 6,137082 & 5,736822 & 5,333628 \\
\hline ALT-ALT & 3 & 13,76808 & 3,674593 & 3,01186 & 8,640495 & 4,399998 & 3,240548 \\
\hline ALT-ALT & 4 & 6,516528 & 5,804269 & 6,335138 & 5,661792 & 5,663228 & 5,521439 \\
\hline ALT-ALT & 5 & 4,580432 & 3,908313 & 4,587091 & 4,599372 & 3,399064 & 4,261377 \\
\hline ALT-ALT & 6 & 5,725068 & 4,405051 & 4,149545 & 4,303014 & 4,830506 & 4,677504 \\
\hline ALT-ALT & 7 & 6,466499 & 5,781135 & 6,346944 & 4,632186 & 4,720624 & 4,458117 \\
\hline ALT-ALT & 8 & 4,074826 & 5,224184 & 5,571871 & 7,535057 & 7,657765 & 8,072252 \\
\hline ALT-ALT & 9 & 4,784305 & 5,193308 & 4,919066 & 4,131383 & 5,84124 & 4,755593 \\
\hline ALT-ALT & 10 & 4,625235 & 3,466844 & 3,30305 & 4,569171 & 5,147982 & 3,927695 \\
\hline ALT-ALT & 11 & 4,173342 & 4,776854 & 2,798553 & 5,041812 & 3,949219 & 3,719253 \\
\hline ALT-ALT & 12 & 5,159453 & 4,785767 & 4,747936 & 5,032153 & 4,296349 & 4,919628 \\
\hline ALT-ALT & 13 & 7,421543 & 3,376785 & 4,414594 & 4,008865 & 4,223062 & 3,985296 \\
\hline ALT-ALT & 14 & 6,267014 & 5,492273 & 5,33291 & 6,795508 & 5,513282 & 5,343701 \\
\hline ALT-ALT & 15 & 5,534738 & 4,132848 & 4,718179 & 5,529684 & 4,946746 & 4,153787 \\
\hline ALT-MED & 1 & 10,66529 & 5,491296 & 4,690375 & 6,176482 & 6,622771 & 4,845775 \\
\hline ALT-MED & 2 & 5,980295 & 4,756829 & 3,862761 & 4,418902 & 6,231567 & 4,633817 \\
\hline ALT-MED & 3 & 5,996947 & 5,089921 & 5,744887 & 3,879747 & 4,018339 & 4,315722 \\
\hline ALT-MED & 4 & 5,728137 & 5,031332 & 4,619721 & 5,369982 & 5,869199 & 4,525552 \\
\hline ALT-MED & 5 & 6,885818 & 6,033943 & 6,330631 & 5,071139 & 5,89202 & 5,869981 \\
\hline ALT-MED & 6 & 3,9171 & 5,212991 & 4,284499 & 4,3735 & 5,050844 & 5,35513 \\
\hline ALT-MED & 7 & 3,530745 & 5,454935 & 4,926315 & 5,364322 & 5,783558 & 6,042326 \\
\hline ALT-MED & 8 & 5,112694 & 4,747624 & 5,036765 & 3,021437 & 4,16335 & 3,360922 \\
\hline ALT-MED & 9 & 5,069602 & 4,414811 & 4,238879 & 5,025506 & 4,13 & 4,350594 \\
\hline ALT-MED & 10 & 3,445072 & 6,1328 & 6,460387 & 4,21303 & 5424 & 4,095019 \\
\hline ALT-MED & 11 & 3,958947 & 4,273703 & 4,877526 & 4,084466 & 3,81 & \\
\hline ALT-MED & 12 & 3,375073 & 2,913018 & 2,984609 & & & \\
\hline ALT-MED & 13 & 3,981795 & 4,942467 & 5,737464 & 3,397595 & 3,825582 & 5,260652 \\
\hline ALT-MED & 14 & 5,098282 & 3,271762 & 3,493907 & 3,726437 & 4,132985 & \\
\hline ALT-MED & 15 & & & & & & \\
\hline ALT- & 1 & & 4,443 & 4,914367 & & & \\
\hline ALT- & 2 & 7,13 & & 4,47 & & & \\
\hline ALT. & 3 & & & 6,97 & & & \\
\hline ALT- & 4 & & 3,8561 & 3,325 & 4,45 & & 6228 \\
\hline ALT-S & 5 & 4,832327 & 6,441703 & 6,131822 & 5,622079 & 5,447641 & 5,8 \\
\hline ALT-S & 6 & 4,611828 & 3,820073 & 4,121479 & 6,623367 & 5,091123 & 4,654685 \\
\hline ALT-S & 7 & 5,996489 & 3,486541 & 4,887396 & 5,906098 & 5,261897 & 5,934 \\
\hline ALT-SEM & 8 & 6,370621 & 4,497165 & 5,08105 & 4,0663 & 3,901544 & 4,365582 \\
\hline ALT-SEM & 9 & 5,939943 & 4,623887 & 5,433683 & 5,183094 & 4,627118 & 4,50483 \\
\hline ALT-SEM & 10 & 4,882117 & 4,59764 & 4,441535 & 7,583117 & 4,539894 & 4,996813 \\
\hline ALT-SEM & 11 & 5,13797 & 3,831693 & 3,866938 & 2,906719 & 3,495769 & 3,122447 \\
\hline ALT-SEM & 12 & 4,669514 & 4,421339 & 4,491939 & 4,733006 & 4,062597 & 4,281062 \\
\hline ALT-SEM & 13 & 3,663629 & 4,060286 & 4,318579 & 4,117989 & 4,088523 & 4,220095 \\
\hline ALT-SEM & 14 & 3,349369 & 2,699511 & 2,937554 & 3,04854 & 2,873318 & 2,354658 \\
\hline ALT-SEM & 15 & 3,872392 & 5,197551 & 5,592979 & 4,025832 & 4,591545 & 4,463452 \\
\hline
\end{tabular}


ANEXO VII - Dados individuais médios do desvio padrão dos tempos de movimento relativos nos grupos ALT-ALT, ALT-MED, ALT-SEM, MED-ALT, MEDMED, MED-SEM, SEM-ALT, SEM-MED e SEM-SEM nas fases de estabilização (E1, E2 e E3) e adaptação (A1, A2 e A3) (cont.)

\begin{tabular}{|c|c|c|c|c|c|c|c|}
\hline Grupo & Sujeito & E1 & E2 & E3 & A1 & A2 & A3 \\
\hline MED-ALT & 1 & 8,254572 & 5,491128 & 5,193686 & 5,847837 & 5,165177 & 3,734021 \\
\hline MED-ALT & 2 & 6,699812 & 3,9441 & 3,75498 & 5,257485 & 5,147859 & 5,084069 \\
\hline MED-ALT & 3 & 5,814475 & 4,633309 & 4,993234 & 6,170978 & 5,926 & 5,458477 \\
\hline MED-ALT & 4 & 5,47527 & 3,693365 & 3,818542 & 4,723472 & 4,30518 & 4,136256 \\
\hline MED-ALT & 5 & 3,468487 & 3,683927 & 2,941504 & 2,836314 & 2,571586 & 2,010241 \\
\hline MED-ALT & 6 & 6,343536 & 4,405591 & 4,062795 & 4,411191 & 3,711182 & 3,977822 \\
\hline MED-ALT & 7 & 4,47395 & 4,533417 & 4,237299 & 4,590937 & 4,326372 & 4,579226 \\
\hline MED-ALT & 8 & 6,119016 & 4,073735 & 3,492609 & 4,407853 & 4,663015 & 4,474285 \\
\hline MED-ALT & 9 & 7,189916 & 6,514824 & 5,037771 & 5,561435 & 6,837021 & 5,084182 \\
\hline MED-ALT & 10 & 4,070718 & 3,624695 & 4,173732 & 8,011267 & 6,077765 & 6,312203 \\
\hline MED-ALT & 11 & 5,363322 & 4,966023 & 3,519092 & 3,861666 & 4,805959 & 4,567197 \\
\hline MED-ALT & 12 & 4,538552 & 4,089134 & 4,023889 & 4,16892 & 3,242606 & 3,131264 \\
\hline MED-ALT & 13 & 5,983067 & 4,165281 & 5,495585 & 3,695611 & 3,928507 & 3,950318 \\
\hline MED-ALT & 14 & 5,824902 & 5,557876 & 5,18971 & 4,013507 & 4,151033 & 4,094262 \\
\hline MED-ALT & 15 & 5,794617 & 5,377859 & 5,360864 & 4,007082 & 4,175912 & 4,570548 \\
\hline MED-MED & 1 & 6,558007 & 5,831518 & 5,890193 & 7,548885 & 5,900342 & 6,070071 \\
\hline MED-MED & 2 & 5,967651 & 5,791162 & 5,747818 & 4,624855 & 4,868247 & 4,448795 \\
\hline MED-MED & 3 & 7,525796 & 8,084507 & 8,09204 & 9,048142 & 5,546458 & 4,634597 \\
\hline MED-MED & 4 & 5,117016 & 5,020359 & 5,230389 & 4,99329 & 5,200863 & 5,011216 \\
\hline MED-MED & 5 & 4,736906 & 4,300925 & 5,113128 & 4,93082 & 5,050093 & 4,701801 \\
\hline MED-MED & 6 & 4,869295 & 3,794516 & 3,878927 & 2,929991 & 3,201473 & 3,800877 \\
\hline MED-MED & 7 & 4,578783 & 5,420174 & 4,051429 & 4,822612 & 4,874 & 3,640768 \\
\hline MED-MED & 8 & 6,275728 & 4,090277 & 4,181043 & 5,076732 & 4,963106 & 3,641175 \\
\hline MED-MED & 9 & 3,935 & 4,015324 & 3,420484 & 3691 & 3,55 & 3,740812 \\
\hline MED-MED & 10 & 4,626771 & 4,33004 & 4,677712 & 3,963021 & 3,282951 & 3,255174 \\
\hline MED-MED & 11 & 4,089047 & 4,36 & 4,047834 & 3,782487 & 4,057 & 3,46 \\
\hline MED-MED & 12 & 4,075719 & 4,26 & 4,003 & 3,727163 & 3,142994 & 3,249402 \\
\hline MED-MED & 13 & 4,784589 & 4,584162 & 4,430771 & 5,026365 & 4,847013 & 5,062181 \\
\hline MED-MED & 14 & 5,058001 & 3,117201 & 3,261564 & 328 & 2,625471 & 3,132115 \\
\hline MED-MED & 15 & & 4,931 & 5,705889 & 339 & 4,857722 & 4,774 \\
\hline MED-SEM & 1 & 5,357435 & 6,475 & 6,52877 & 5,427 & 5,936848 & 6,41 \\
\hline MED-SEM & 2 & 6,246396 & 5,590 & 5,831591 & 4,84 & 4,390868 & 5,034575 \\
\hline MED-SEM & 3 & 5,671078 & 5,063 & 4,38 & & 375 & 4,870542 \\
\hline MED-SEM & 4 & 4,146 & 3,73 & 3,64 & & 586 & 6,870098 \\
\hline MED-SEM & 5 & 6,251 & 5,10 & 4,85 & & 3179 & 3,93 \\
\hline MED-SEM & 6 & 6,539 & 5,055 & 5,588203 & 5,36 & 5,864736 & 5,9745 \\
\hline MED-SEM & 7 & 4,462976 & 4,330999 & 3,702754 & 4,258405 & 4,285758 & 4,1045 \\
\hline MED-SEM & 8 & 6,522573 & 5,215 & 5,168 & 7,43 & 5,506647 & 4,704 \\
\hline MED-SEM & 9 & 5,172873 & 5,913689 & 6,266967 & 4,264705 & 4,374871 & 4,590663 \\
\hline MED-SEM & 10 & 3,384079 & 3,481153 & 3,97471 & 3,912984 & 4,011828 & 3,389829 \\
\hline MED-SEM & 11 & 4,567036 & 3,476517 & 4,644373 & 4,730958 & 3,741624 & 4,381083 \\
\hline MED-SEM & 12 & 3,651686 & 3,549652 & 3,246076 & 4,230931 & 4,380486 & 3,571893 \\
\hline MED-SEM & 13 & 5,326354 & 5,343466 & 5,179096 & 5,217684 & 5,931568 & 5,654454 \\
\hline MED-SEM & 14 & 6,643301 & 5,47486 & 5,199871 & 6,358621 & 5,520608 & 5,490566 \\
\hline MED-SEM & 15 & 5,55946 & 4,652328 & 4,089351 & 5,146973 & 6,857002 & 6,042688 \\
\hline
\end{tabular}


ANEXO VII - Dados individuais médios do desvio padrão dos tempos de movimento relativos nos grupos ALT-ALT, ALT-MED, ALT-SEM, MED-ALT, MEDMED, MED-SEM, SEM-ALT, SEM-MED e SEM-SEM nas fases de estabilização (E1, E2 e E3) e adaptação (A1, A2 e A3) (cont.)

\begin{tabular}{|c|c|c|c|c|c|c|c|}
\hline Grupo & Sujeito & E1 & E2 & E3 & A1 & A2 & A3 \\
\hline SEM-ALT & 1 & 5,460574 & 6,557494 & 6,06125 & 8,136036 & 5,814332 & 5,419727 \\
\hline SEM-ALT & 2 & 5,215027 & 4,593391 & 3,426434 & 5,497588 & 4,685809 & 8,211784 \\
\hline SEM-ALT & 3 & 4,707646 & 3,635237 & 3,748295 & 3,904314 & 4,771295 & 5,609455 \\
\hline SEM-ALT & 4 & 7,052494 & 4,296326 & 4,117487 & 4,806212 & 4,156735 & 4,373001 \\
\hline SEM-ALT & 5 & 5,136442 & 3,991513 & 4,792837 & 6,084254 & 6,659171 & 7,927855 \\
\hline SEM-ALT & 6 & 7,777103 & 5,595728 & 5,386123 & 5,460196 & 4,657989 & 5,949143 \\
\hline SEM-ALT & 7 & 4,227763 & 3,461468 & 3,046222 & 4,391774 & 3,694281 & 4,08366 \\
\hline SEM-ALT & 8 & 3,625356 & 4,967328 & 5,439871 & 7,405765 & 4,677806 & 4,500212 \\
\hline SEM-ALT & 9 & 4,843344 & 4,646024 & 4,230508 & 7,951437 & 6,839425 & 4,70767 \\
\hline SEM-ALT & 10 & 5,972108 & 5,736358 & 6,134113 & 6,429751 & 5,485992 & 5,377771 \\
\hline SEM-ALT & 11 & 6,728867 & 5,431227 & 4,338633 & 5,503891 & 5,429255 & 6,272112 \\
\hline SEM-ALT & 12 & 6,306024 & 4,399195 & 4,113041 & 4,626541 & 3,542357 & 3,741014 \\
\hline SEM-ALT & 13 & 5,116284 & 4,397595 & 4,465807 & 4,314387 & 3,734253 & 3,959948 \\
\hline SEM-ALT & 14 & 5,042605 & 5,848113 & 6,052264 & 4,939306 & 4,437536 & 4,823889 \\
\hline SEM-ALT & 15 & 4,171634 & 3,845489 & 4,974938 & 3,59942 & 3,331048 & 3,763209 \\
\hline SEM-MED & 1 & 4,664484 & 4,09377 & 4,696856 & 4,747476 & 4,82868 & 4,733196 \\
\hline SEM-MED & 2 & 9,253402 & 5,234794 & 5,268477 & 9,582432 & 5,706838 & 5,583326 \\
\hline SEM-MED & 3 & 4,724156 & 4,590858 & 4,387538 & 5,453231 & 4,275095 & 4,471874 \\
\hline SEM-MED & 4 & 5,829802 & 4,609417 & 3,89711 & 5,48417 & 5,909444 & 5,311095 \\
\hline SEM-MED & 5 & 5,343075 & 5,583055 & 5,58798 & 5,605966 & 3,751655 & 4,384242 \\
\hline SEM-MED & 6 & 2,231414 & 2,470003 & 3,788633 & & 4,026679 & 3,538357 \\
\hline SEM-MED & 7 & 4,228621 & 3,914278 & 4,677944 & & 4,768665 & 6,10752 \\
\hline SEM-MED & 8 & 5,839698 & 5,339166 & 5,504023 & 4,777998 & 4,767235 & 4,721239 \\
\hline SEM-MED & 9 & 4,166627 & 4,130022 & 3,614745 & 4,02154 & 2,996988 & 2,966731 \\
\hline SEM-MED & 10 & 5,219911 & 7,87701 & 5,462507 & 5,134487 & 5,049255 & 5,621124 \\
\hline SEM-MED & 11 & 4,24253 & 5,0321 & 5,285682 & 1573 & 3,777347 & \\
\hline SEM-MED & 12 & 4,306 & 5,389561 & 6,188483 & 6,670794 & 6,624929 & \\
\hline SEM-MED & 13 & 5,895605 & 5,062118 & 4,273597 & 4,741594 & 3,72818 & \\
\hline SEM-MED & 14 & 5,268653 & 5,215623 & 5,849152 & 5146 & 4,426518 & \\
\hline SEM-MED & 15 & 4,917116 & 3,995761 & 4,569594 & & 4,528709 & \\
\hline SEM-SEM & 1 & & 4,948 & 5,683476 & & 5,8 & \\
\hline SEM-SEM & 2 & 14,22062 & 6,093663 & 5,399091 & & 904 & 526 \\
\hline SEM-SEM & 3 & $5,75 \varepsilon$ & 3,747707 & 3,807239 & & 606 & \\
\hline SEM-S & 4 & 3,79 & 4,057188 & 4,845856 & 7,407636 & 5,036076 & 4,1 \\
\hline SEM-S & 5 & 5,456827 & 4,054575 & 4,268633 & 4,713918 & 4,673615 & 5,167822 \\
\hline SEM-SEM & 6 & 6,185 & 5,34826 & 6,573609 & 5,350218 & 5,307828 & 4,889313 \\
\hline SEM-SEM & 7 & 5,858 & 5,804822 & 5,697112 & 5,463381 & 5,516063 & 5,375529 \\
\hline SEM-SEM & 8 & 5,0 & 5,517291 & 4,715084 & 5,176662 & 5,529706 & 3,998597 \\
\hline SEM-SEM & 9 & 8,060778 & 7,646126 & 7,48197 & 5,82461 & 5,209275 & 5,318183 \\
\hline SEM-SEM & 10 & 4,707491 & 4,394849 & 4,750248 & 4,728044 & 4,887576 & 4,86326 \\
\hline SEM-SEM & 11 & 5,61338 & 5,695903 & 5,690056 & 5,25623 & 4,957093 & 5,018413 \\
\hline SEM-SEM & 12 & 5,184262 & 4,548006 & 4,765279 & 4,981339 & 4,651266 & 4,713483 \\
\hline SEM-SEM & 13 & 8,089032 & 3,838954 & 3,88982 & 4,411018 & 4,320178 & 3,611945 \\
\hline SEM-SEM & 14 & 5,118699 & 4,954693 & 4,722324 & 5,49296 & 4,337936 & 4,901164 \\
\hline SEM-SEM & 15 & 3,409775 & 3,123543 & 3,469784 & 3,156998 & 3,162566 & 3,124326 \\
\hline
\end{tabular}


ANEXO VIII - Dados individuais médios do desvio padrão dos tempos de movimento absolutos nos grupos ALT-ALT, ALT-MED, ALT-SEM, MED-ALT, MEDMED, MED-SEM, SEM-ALT, SEM-MED e SEM-SEM nas fases de estabilização (E1, E2 e E3) e adaptação (A1, A2 e A3)

\begin{tabular}{|c|c|c|c|c|c|c|c|}
\hline Grupo & Sujeito & E1 & E2 & E3 & A1 & A2 & A3 \\
\hline ALT-ALT & 1 & 135,7226 & 93,70052 & 94,23236 & 95,56608 & 92,03971 & 90,80831 \\
\hline ALT-ALT & 2 & 100,4291 & 107,8763 & 103,3173 & 131,3423 & 123,9119 & 119,8901 \\
\hline ALT-ALT & 3 & 398,882 & 56,53993 & 46,41651 & 270,8684 & 97,37171 & 61,5116 \\
\hline ALT-ALT & 4 & 134,5998 & 89,49587 & 98,81788 & 105,9302 & 102,4959 & 95,87476 \\
\hline ALT-ALT & 5 & 67,85962 & 58,18291 & 69,73302 & 80,94768 & 56,99759 & 73,65727 \\
\hline ALT-ALT & 6 & 98,46245 & 71,52033 & 67,84832 & 79,05107 & 94,02787 & 85,28345 \\
\hline ALT-ALT & 7 & 104,6154 & 88,6513 & 98,22633 & 81,00051 & 82,61668 & 74,32913 \\
\hline ALT-ALT & 8 & 65,50886 & 82,25097 & 87,14093 & 149,0038 & 149,9094 & 158,3573 \\
\hline ALT-ALT & 9 & 75,8992 & 79,13323 & 75,16962 & 77,47501 & 112,1652 & 80,15337 \\
\hline ALT-ALT & 10 & 67,21977 & 53,10431 & 49,4849 & 86,09169 & 91,54115 & 64,9367 \\
\hline ALT-ALT & 11 & 75,95987 & 76,80089 & 42,80194 & 108,8148 & 64,5467 & 61,95434 \\
\hline ALT-ALT & 12 & 87,93548 & 72,39125 & 73,09773 & 87,6655 & 74,0471 & 85,32231 \\
\hline ALT-ALT & 13 & 111,6014 & 51,06761 & 65,99244 & 68,71744 & 70,17377 & 65,25079 \\
\hline ALT-ALT & 14 & 97,41384 & 81,93128 & 80,04544 & 185,7556 & 99,43581 & 94,42934 \\
\hline ALT-ALT & 15 & 81,33932 & 62,32745 & 70,97321 & 98,82549 & 82,26829 & 71,08947 \\
\hline ALT-MED & 1 & 308,4613 & 87,64748 & 72,48014 & 143,6511 & 163,6646 & 84,94624 \\
\hline ALT-MED & 2 & 124,6355 & 73,39991 & 59,46775 & 80,16776 & 122,9037 & 79,73303 \\
\hline ALT-MED & 3 & 108,9299 & 79,91405 & 93,66729 & 68,13077 & 70,69928 & 75,0061 \\
\hline ALT-MED & 4 & 94,38923 & 77,56489 & 70,67353 & 94,617 & 114,2534 & 76,40629 \\
\hline ALT-MED & 5 & 109,894 & 93,34787 & 95,38227 & 96,17627 & 112,48 & 110,6584 \\
\hline ALT-MED & 6 & 58,57111 & 83,08247 & 67,36871 & 77,41227 & 90,79359 & 98,68478 \\
\hline ALT-MED & 7 & 58,6996 & 83,65688 & 75,24913 & 89,51657 & 100,2962 & 104,6239 \\
\hline ALT-MED & 8 & 75,95332 & 70,29358 & 74,84236 & 47,55794 & 72,83955 & 56,53481 \\
\hline ALT-MED & 9 & 80,22587 & 69,40838 & 65,3816 & 92,11974 & 70,10831 & 73,22271 \\
\hline ALT-MED & 10 & 50,60106 & 94,01192 & 96,42965 & 71,1 & 60,25 & 71,25336 \\
\hline ALT-MED & 11 & 67,27576 & 70,35772 & 76,8795 & 75,05794 & $67,7 \mathrm{C}$ & 72,0 \\
\hline ALT-MED & 12 & 50,28438 & 44,2096 & 45,90159 & 65,50156 & $62,1 \varepsilon$ & 61,5677 \\
\hline ALT-MED & 13 & 61,15288 & 76,50 & 86,8707 & 57,19374 & 64,43 & 88,68591 \\
\hline ALT-MED & 14 & 79,8733 & 50,30746 & 53,64262 & 64,39678 & 72,99325 & 65,07434 \\
\hline ALT-MED & 15 & 65,78923 & 70,15182 & 67,87991 & 72,88942 & 72,99498 & 68,96046 \\
\hline ALT-SEM & 1 & 59,66451 & 70,010 & 77,26405 & 116,8135 & 88,60842 & 118,6265 \\
\hline ALT-SEM & 2 & 169,161 & 61,01295 & 67,73455 & 64,48873 & 60,95957 & 62,21286 \\
\hline ALT-SEM & 3 & 90,52027 & & & 272,1126 & 105,6945 & \\
\hline ALT- & 4 & 67,2585 & & & 77,41727 & 72,0844 & 56,63002 \\
\hline ALT. & 5 & 81,22 & & & 96,1 & 90,8 & \\
\hline ALT-S & 6 & 76,84 & 58,80644 & 62,65817 & 174,5862 & 106,6342 & 86,3298 \\
\hline ALT-S & 7 & 97,09933 & 59,29899 & 76,74898 & 117,8727 & 101,6924 & 112,8732 \\
\hline EM & 8 & 115,9635 & 69,57333 & 76,31142 & 71,00408 & 68,81239 & 80,0556 \\
\hline ALT-SEM & 9 & 100,6212 & 77,99299 & 88,42766 & 107,9041 & 82,49888 & 77,27669 \\
\hline ALT-SEM & 10 & 89,27719 & 72,15339 & 67,88545 & 198,9908 & 85,86054 & 98,29614 \\
\hline ALT-SEM & 11 & 98,10775 & 59,46097 & 58,63366 & 49,86233 & 62,86052 & 51,92607 \\
\hline ALT-SEM & 12 & 75,91019 & 71,17094 & 68,25833 & 84,23098 & 71,24886 & 76,5275 \\
\hline ALT-SEM & 13 & 56,9421 & 61,92786 & 66,50737 & 71,75107 & 70,17927 & 71,11483 \\
\hline ALT-SEM & 14 & 58,91389 & 41,75612 & 43,36766 & 52,82858 & 51,54939 & 41,08753 \\
\hline ALT-SEM & 15 & 58,74401 & 78,19741 & 85,1819 & 72,28049 & 79,25032 & 76,09332 \\
\hline
\end{tabular}


ANEXO VIII - Dados individuais médios do desvio padrão dos tempos de movimento absolutos nos grupos ALT-ALT, ALT-MED, ALT-SEM, MED-ALT, MEDMED, MED-SEM, SEM-ALT, SEM-MED e SEM-SEM nas fases de estabilização (E1, E2 e E3) e adaptação (A1, A2 e A3) (cont.)

\begin{tabular}{|c|c|c|c|c|c|c|c|}
\hline Grupo & Sujeito & E1 & E2 & E3 & A1 & A2 & A3 \\
\hline MED-ALT & 1 & 168,7732 & 92,25192 & 85,6497 & 123,6471 & 112,6009 & 77,66755 \\
\hline MED-ALT & 2 & 97,53115 & 59,01967 & 56,91189 & 90,66516 & 88,8524 & 86,21316 \\
\hline MED-ALT & 3 & 92,64622 & 70,49289 & 77,84713 & 146,0529 & 130,6212 & 97,68497 \\
\hline MED-ALT & 4 & 123,9089 & 62,70962 & 64,53569 & 97,24654 & 82,97138 & 77,40733 \\
\hline MED-ALT & 5 & 53,34976 & 55,63111 & 46,00982 & 49,79264 & 45,93679 & 35,24992 \\
\hline MED-ALT & 6 & 124,0765 & 66,50474 & 61,37929 & 79,10457 & 65,3891 & 67,68175 \\
\hline MED-ALT & 7 & 69,11875 & 70,9455 & 65,3033 & 84,91018 & 78,90019 & 79,64087 \\
\hline MED-ALT & 8 & 117,8966 & 65,0425 & 54,81649 & 88,26204 & 99,03883 & 77,91236 \\
\hline MED-ALT & 9 & 107,1319 & 110,6475 & 78,66947 & 97,4424 & 138,463 & 106,5965 \\
\hline MED-ALT & 10 & 69,88747 & 56,90122 & 65,92833 & 198,2073 & 132,7045 & 131,4723 \\
\hline MED-ALT & 11 & 92,91711 & 77,72965 & 54,3857 & 66,132 & 83,93897 & 77,59396 \\
\hline MED-ALT & 12 & 71,88738 & 62,66962 & 65,40715 & 92,79622 & 71,94582 & 58,6311 \\
\hline MED-ALT & 13 & 93,7654 & 63,35619 & 85,02043 & 64,1766 & 66,83254 & 67,37379 \\
\hline MED-ALT & 14 & 88,66063 & 86,74143 & 76,06753 & 72,19775 & 71,35491 & 70,22873 \\
\hline MED-ALT & 15 & 85,61289 & 80,76989 & 81,51402 & 67,78432 & 71,71441 & 78,1226 \\
\hline MED-MED & 1 & 106,0286 & 89,8256 & 91,52327 & 133,6144 & 101,9263 & 104,0573 \\
\hline MED-MED & 2 & 95,1843 & 88,24133 & 92,09352 & 87,50803 & 93,84797 & 79,76793 \\
\hline MED-MED & 3 & 161,62 & 125,0555 & 120,3315 & 195,9511 & 91,00482 & 77,80179 \\
\hline MED-MED & 4 & 75,79343 & 74,69494 & 78,37198 & 87,49868 & 89,22374 & 86,57543 \\
\hline MED-MED & 5 & 76,44709 & 64,72835 & 79,81775 & 92,21156 & 93,04879 & 83,52413 \\
\hline MED-MED & 6 & 81,91669 & 57,28146 & 60,13365 & 52,24623 & 55,42121 & 66,92092 \\
\hline MED-MED & 7 & 75,04165 & 82,85985 & 62,52321 & 89,12332 & 90,52564 & 62,62508 \\
\hline MED-MED & 8 & 114,6822 & 63,67081 & 67,06263 & $102, C$ & 101,0422 & 65,11204 \\
\hline MED-MED & 9 & 70,61048 & 61,68615 & 52,15 & 71,32932 & 59,12881 & 61,95658 \\
\hline MED-MED & 10 & 85,6825 & 65,67301 & 70,70 & 75,50893 & 56,98229 & 56,05243 \\
\hline MED-MED & 11 & 62,12639 & 64,79298 & 60,94 & 64,6 & 69,20882 & 56,92711 \\
\hline MED-MED & 12 & 80,39766 & 67,42379 & 63,82 & 472 & 56,98479 & 57,42317 \\
\hline MED-MED & 13 & 75,77762 & 70,83628 & 68,33232 & 89,89453 & 82,44332 & 86,60288 \\
\hline MED-MED & 14 & 78,44475 & 46,5357 & 49,55052 & 46,7461 & 46,00149 & 54,96256 \\
\hline MED-MED & 15 & 78,38984 & 74,80745 & 87,41476 & 68,38524 & 87,5 & 82,76497 \\
\hline MED-SEM & 1 & 3,72622 & 99,715 & 102,0 & 101,3734 & 106,8 & 117,1826 \\
\hline MED-SEM & 2 & 3,88894 & 84,5 & 89,52179 & 5172 & 77,91903 & 91,22001 \\
\hline MED-SEM & 3 & 97,07 & 75,64442 & 65,96 & 74,76332 & 86,65798 & 89,105 \\
\hline MED-SEM & 4 & 63,56 & 57,52554 & 53,80625 & 136 , & 84,51041 & 145,3855 \\
\hline MED-SEM & 5 & 140,4 & 80,1 & 73,04 & 105,088 & 94,1 & 73,23829 \\
\hline MED-SEM & 6 & 105,0 & 76,11 & 85,1 & 89,89283 & 107,6496 & 112,4024 \\
\hline MED-SEM & 7 & 69,14 & 73,81003 & 57,20 & 73,02088 & 74,02532 & 70,585 \\
\hline MED-SEM & 8 & ,8004 & 78,260 & 78,71 & 157,6729 & 91,91 & $79,06 c$ \\
\hline MED-SEM & 9 & 93,32606 & 97,20399 & 99,23419 & 82,11625 & 82,85503 & 95,35524 \\
\hline MED-SEM & 10 & 52,51556 & 54,42288 & 63,5959 & 72,79876 & 71,85787 & 60,02898 \\
\hline MED-SEM & 11 & 74,75169 & 53,36455 & 72,30411 & 88,54445 & 64,11891 & 78,72468 \\
\hline MED-SEM & 12 & 59,81906 & 53,63797 & 49,11836 & 73,65695 & 75,98117 & 57,92374 \\
\hline MED-SEM & 13 & 85,18459 & 85,70093 & 81,22705 & 101,8156 & 125,5624 & 113,3149 \\
\hline MED-SEM & 14 & 97,73752 & 84,74381 & 81,39314 & 122,9102 & 104,2807 & 100,5811 \\
\hline MED-SEM & 15 & 82,67019 & 75,0428 & 62,7148 & 99,97544 & 138,7208 & 118,6471 \\
\hline
\end{tabular}


ANEXO VIII - Dados individuais médios do desvio padrão dos tempos de movimento absolutos nos grupos ALT-ALT, ALT-MED, ALT-SEM, MED-ALT, MEDMED, MED-SEM, SEM-ALT, SEM-MED e SEM-SEM nas fases de estabilização (E1, E2 e E3) e adaptação (A1, A2 e A3) (cont.)

\begin{tabular}{|c|c|c|c|c|c|c|c|}
\hline Grupo & Sujeito & E1 & E2 & E3 & A1 & A2 & A3 \\
\hline SEM-ALT & 1 & 156,099 & 115,0227 & 90,60496 & 217,4577 & 102,9486 & 96,65075 \\
\hline SEM-ALT & 2 & 83,43051 & 71,08469 & 53,86777 & 100,8055 & 80,33244 & 195,9691 \\
\hline SEM-ALT & 3 & 74,83728 & 54,84828 & 57,34461 & 67,59478 & 82,75131 & 100,2656 \\
\hline SEM-ALT & 4 & 181,6885 & 65,50031 & 62,26512 & 84,50611 & 66,14363 & 69,37453 \\
\hline SEM-ALT & 5 & 76,60724 & 59,64586 & 71,2163 & 107,2702 & 129,7049 & 198,5786 \\
\hline SEM-ALT & 6 & 158,9633 & 84,26228 & 84,27604 & 96,13006 & 80,40731 & 103,6462 \\
\hline SEM-ALT & 7 & 65,25823 & 52,08282 & 45,45214 & 83,38082 & 66,19979 & 73,15512 \\
\hline SEM-ALT & 8 & 56,23268 & 75,809 & 81,9465 & 181,2958 & 83,35781 & 82,68288 \\
\hline SEM-ALT & 9 & 81,91703 & 72,28 & 65,08183 & 213,2752 & 141,8906 & 84,77303 \\
\hline SEM-ALT & 10 & 95,80343 & 88,17979 & 91,46173 & 117,1757 & 91,82296 & 91,83939 \\
\hline SEM-ALT & 11 & 122,5909 & 88,62938 & 68,36949 & 121,4573 & 122,8097 & 140,7895 \\
\hline SEM-ALT & 12 & 138,2967 & 65,98529 & 70,55016 & 86,22217 & 60,19639 & 61,85064 \\
\hline SEM-ALT & 13 & 80,27644 & 68,18014 & 70,84689 & 75,41049 & 65,78718 & 70,23725 \\
\hline SEM-ALT & 14 & 77,25631 & 87,77315 & 90,9094 & 84,77929 & 75,88787 & 83,02718 \\
\hline SEM-ALT & 15 & 63,42947 & 56,97634 & 79,13308 & 61,74701 & 55,92975 & 63,91375 \\
\hline SEM-MED & 1 & 73,14463 & 62,85648 & 72,30665 & 93,48973 & 95,18958 & 88,10332 \\
\hline SEM-MED & 2 & 199,6977 & 81,67179 & 82,85638 & 246,1365 & 105,2398 & 106,0411 \\
\hline SEM-MED & 3 & 72,23174 & 68,52018 & 65,91992 & 107,7847 & 79,81635 & 73,60741 \\
\hline SEM-MED & 4 & 122,5617 & 72,57818 & 60,91546 & 104,0636 & 114,0617 & 108,0704 \\
\hline SEM-MED & 5 & 87,86652 & 87,95081 & 87,03225 & 129,8993 & 67,73498 & 79,14885 \\
\hline SEM-MED & 6 & 35,80472 & 37,58541 & 56,57955 & & 70,07688 & 57,75081 \\
\hline SEM-MED & 7 & 75,55938 & 59,40101 & 70,01629 & & 125,8016 & 141,9574 \\
\hline SEM-MED & 8 & 87,45302 & 81,97029 & 86,99571 & 86,52638 & 86,36 & 79,56648 \\
\hline SEM-MED & 9 & 63,59229 & 63,42776 & 54,2512 & 66,66 & 50,13 & 49,85678 \\
\hline SEM-MED & 10 & 83,93912 & 143,4208 & 95,13776 & 109,9 & 99,9 & 115,5669 \\
\hline SEM-MED & 11 & 74,76237 & 77,53 & 78,53461 & $74,5 \varepsilon$ & 63,23 & 68,20759 \\
\hline SEM-MED & 12 & 68,75699 & 83,64989 & 95,13473 & 99 & 125,2896 & 99,2 \\
\hline SEM-MED & 13 & 99,72617 & 81,56638 & 65,99188 & 94,82124 & 66,00 & 69,1 \\
\hline SEM-MED & 14 & 103,5313 & 82,17267 & 90,44987 & 71,08772 & 74,45998 & 65,03351 \\
\hline SEM-MED & 15 & 73,26321 & 63,12 & 73,20768 & 72,3529 & 81,27323 & 71,72138 \\
\hline SEM-SEM & 1 & 189,8936 & 78,54189 & 92,0486 & 144,957 & 118,4 & 124,5489 \\
\hline SEM-SEM & 2 & 409,2621 & 95,35358 & 89,50899 & 158,6808 & 93,85151 & 111,2838 \\
\hline SEM-SEM & 3 & 85,83676 & 55,59545 & 57,88036 & 63,1939 & 70,18145 & 47,9965 \\
\hline SEM-SEM & 4 & 73,40 & 62,58613 & 72,68114 & 193,3614 & 100,4 & 73,08032 \\
\hline SEM-SEM & 5 & 81,95 & 60,87014 & 64,87251 & 82,91679 & 81,19 & 87,66487 \\
\hline SEM-SEM & 6 & 98,11212 & 77,82801 & 111,1287 & 103,7132 & 95,87406 & 87,37178 \\
\hline SEM-S & 7 & 90,94903 & 87,36298 & 86,72619 & 107,8982 & 96,12794 & 90,98 \\
\hline SEM-SEM & 8 & 83,51 & 85,046 & 71,37491 & 92,1 & 96,7838 & 69,321 \\
\hline SEM-SEM & 9 & 147,4211 & 119,3605 & 119,7417 & 104,4402 & 90,81486 & 91,17626 \\
\hline SEM-SEM & 10 & 89,96498 & 67,81508 & 71,66929 & 85,69498 & 88,62661 & 90,71051 \\
\hline SEM-SEM & 11 & 94,01415 & 86,41367 & 88,9745 & 90,08816 & 85,90491 & 85,72093 \\
\hline SEM-SEM & 12 & 78,67606 & 68,41689 & 71,78266 & 83,75169 & 78,41072 & 79,88205 \\
\hline SEM-SEM & 13 & 187,0664 & 57,9974 & 62,80869 & 85,31081 & 79,92695 & 63,63366 \\
\hline SEM-SEM & 14 & 81,76113 & 77,61056 & 72,46285 & 98,0857 & 76,02517 & 80,93822 \\
\hline SEM-SEM & 15 & 52,88263 & 48,92209 & 53,71794 & 56,83056 & 55,06593 & 56,8384 \\
\hline
\end{tabular}




\begin{abstract}
ANEXO IX - Dados ausentes (missing values) substituídos pela média dos participantes nas variáveis erro absoluto (EA), erro variável (EV), erros de execução (EE), variabilidade do seqüenciamento (SEQ), variabilidade do tempo relativo (VTR) e variabilidade do tempo absoluto (VTA) por bloco das fases de estabilização (E1, E2 e E3) e adaptação (A1, A2 e A3)
\end{abstract}

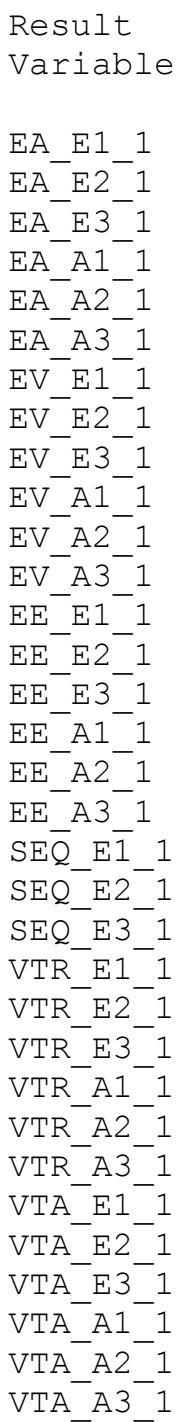

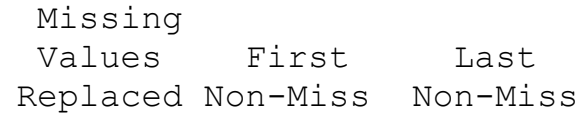




\begin{abstract}
ANEXO X - Outliers extremos substituídos pela média dos participantes nas variáveis erro absoluto (EA), erro variável (EV), erros de execução (EE), variabilidade do seqüenciamento (SEQ), variabilidade do tempo relativo (VTR) e variabilidade do tempo absoluto (VTA) por bloco das fases de estabilização (E1, E2 e E3) e adaptação (A1, A2 e A3)
\end{abstract}

Missing

Values

First

Replaced Non-Miss

Last

Non-Miss

135

135

135

135

135

135

135

135

135

135

135

135

135

135

135

135

135

135

135

135

135

135

135

135

135

135

135

135

135

135

135

135

135 $\begin{array}{ll}\text { Valid } & \text { Creating } \\ \text { Cases } & \text { Function }\end{array}$

135 SMEAN (EA_E1)

135 SMEAN (EA E2)

135 SMEAN (EA_E3)

135 SMEAN (EA_A1)

135 SMEAN (EA $\left.{ }^{-} \mathrm{A} 2\right)$

$135 \operatorname{SMEAN}\left(\mathrm{EA}^{-} \mathrm{A} 3\right)$

135 SMEAN (EV_E1)

135 SMEAN (EV_E2)

135 SMEAN (EV_E3)

135 SMEAN (EV_A1)

135 SMEAN (EV_A2)

135 SMEAN (EV_A3)

135 SMEAN (EE E1)

135 SMEAN (EE E2)

135 SMEAN (EE E3)

$135 \operatorname{SMEAN}\left(\mathrm{EE}^{-} \mathrm{A} 1\right)$

$135 \operatorname{SMEAN}\left(\mathrm{EE}^{-} \mathrm{A} 2\right)$

135 SMEAN (EE A3)

$135 \operatorname{SMEAN}\left(\mathrm{SE} \bar{Q} \_\mathrm{E} 1\right)$

$135 \operatorname{SMEAN}(\mathrm{SEQ} E 2)$

135 SMEAN (SEQ_E3)

135 SMEAN (VTR_E1)

135 SMEAN (VTR E2)

135 SMEAN (VTR E3)

135 SMEAN (VTR_A1)

135 SMEAN (VTR_A2)

135 SMEAN (VTR A3)

135 SMEAN (VTA_E1)

135 SMEAN (VTA_E2)

135 SMEAN (VTA_E3)

$135 \operatorname{SMEAN}\left(\mathrm{VTA}^{-} \mathrm{A} 1\right)$

135 SMEAN (VTA A2)

135 SMEAN (VTA_A3) 